\title{
Posicionamento sobre Diagnóstico e Tratamento da Amiloidose Cardíaca - 2021
}

\section{Position Statement on Diagnosis and Treatment of Cardiac Amyloidosis - 2021}

Realização: Departamento de Insuficiência Cardíaca (DEIC) e Grupo de Estudos em Miocardiopatias (GEMIC) da Sociedade Brasileira de Cardiologia (SBC)

Conselho de Normatizações e Diretrizes (2020-2021): Antonio Carlos Sobral Sousa, Aurora Felice de Castro Issa, Bruno Ramos Nascimento, Harry Corrêa Filho, Marcelo Luiz Campos Vieira

Coordenador de Normatizações e Diretrizes (2020-2021): Brivaldo Markman Filho

Autores da Diretriz: Marcus V. Simões, ${ }^{1 \oplus}$ Fabio Fernandes, ${ }^{2}{ }^{\oplus}$ Fabiana G. Marcondes-Braga, ${ }^{2} \oplus$ Philip Scheinberg, ${ }^{3}$ Edileide de Barros Correia, ${ }^{4 \oplus}$ Luis Eduardo P. Rohde, ${ }^{5,6,7}$ Fernando Bacal, ${ }^{2}{ }^{\circledR}$ Silvia Marinho Martins Alves, ${ }^{8,9}$ Sandrigo Mangini, ${ }^{2}$ Andréia Biolo, ${ }^{5}$ Luis Beck-da-Silva, ${ }^{5,7}$ Roberta Shcolnik Szor, ${ }^{10,11}$ Wilson Marques Junior, 1 Acary Souza Bulle Oliveira, ${ }^{12} @$ Márcia Waddington Cruz, ${ }^{13}$ Bruno Vaz Kerges Bueno, ${ }^{14}$ Ludhmila Abrahão Hajjar, ${ }^{2,11}$ Aurora Felice Castro Issa, ${ }^{15}$ Celix José Alvarez Ramires, ${ }^{2,16}$ @ Otavio Rizzi Coelho Filho, ${ }^{17 \odot}$ André Schmidt, ${ }^{1 \oplus ~ I b r a i m ~ M a s c i a r e l l i ~ F r a n c i s c o ~ P i n t o, ~}{ }^{18}$ Carlos Eduardo Rochitte, ${ }^{2,19,20 \odot ~ F l a ́ v i o ~ H e n r i q u e ~}$ Valicelli, ${ }^{1}$ Marcelo Luiz Campos Vieira, ${ }^{2,16}$ Cláudio Tinoco Mesquita, ${ }^{21}$ Celso Dario Ramos, ${ }^{17}$ José Soares-Junior, ${ }^{2}$ Minna Moreira Dias Romano, ${ }^{10}$ Wilson Mathias Junior, ${ }^{10}$ Marcelo lório Garcia, ${ }^{13}$ Marcelo Westerlund Montera, ${ }^{20}$ Marcelo Dantas Tavares de Melo, ${ }^{22}$ Sandra Marques e Silva, ${ }^{23}$ Pedro Manoel Marques Garibaldi, ${ }^{1}$ Aristóteles Comte de Alencar Neto, ${ }^{2}$ Renato Delascio Lopes, ${ }^{24}$ Diane Xavier de Ávila, ${ }^{20,25,26,27}$ Denizar Viana, ${ }^{28}$ José Francisco Kerr Saraiva, ${ }^{29}$ Manoel Fernandes Canesin, ${ }^{30}$ Glaucia Maria Moraes de Oliveira, ${ }^{31 \odot}$ Evandro Tinoco Mesquita ${ }^{21,32 @ ~}$

Faculdade de Medicina de Ribeirão Preto da Universidade de São Paulo, ${ }^{1}$ Ribeirão Preto - Brasil

Instituto do Coração (InCor) do Hospital das Clínicas da Faculdade de Medicina da Universidade de São Paulo (HCFMUSP), ${ }^{2}$ São Paulo, SP - Brasil Hospital da Beneficência Portuguesa de São Paulo, ${ }^{3}$ São Paulo, SP - Brasil

Instituto Dante Pazzanese de Cardiologia, ${ }^{4}$ São Paulo, SP - Brasil

Hospital de Clínicas de Porto Alegre, ${ }^{5}$ Porto Alegre, $R S$ - Brasil

Hospital Moinhos de Vento, ${ }^{6}$ Porto Alegre, RS - Brasil

Universidade Federal do Rio Grande do Sul (UFRGS), ${ }^{7}$ Porto Alegre, RS - Brasil

Pronto Socorro Cardiológico de Pernambuco (PROCAPE), ${ }^{8}$ Recife, PE - Brasil

Universidade de Pernambuco (UPE), ${ }^{9}$ Recife, $P E-$ Brasil

Fundação Faculdade de Medicina, ${ }^{10}$ São Paulo, SP - Brasil

Instituto do Câncer do Estado de São Paulo da Faculdade de Medicina da Universidade de São Paulo, ${ }^{11}$ São Paulo, SP - Brasil

Universidade Federal de São Paulo, ${ }^{12}$ São Paulo, SP - Brasil

Hospital Universitário Clementino Fraga Filho (HUCFF) da Universidade Federal do Rio de Janeiro (UFRJ), ${ }^{13}$ Rio de Janeiro, RJ - Brasil

Faculdade de Ciências Médicas da Santa Casa de São Paulo, ${ }^{14}$ São Paulo, SP - Brasil

Instituto Nacional de Cardiologia, ${ }^{15}$ Rio de Janeiro, RJ - Brasil

Hospital Israelita Albert Einstein, ${ }^{16}$ São Paulo, SP - Brasil

Faculdade de Ciências Médicas da Universidade Estadual de Campinas (UNICAMP), ${ }^{17}$ Campinas, SP - Brasil

Grupo Fleury, ${ }^{18}$ São Paulo, SP - Brasil

Hospital do Coração (HCor), ${ }^{19}$ São Paulo, SP - Brasil

Hospital Pró-Cardíaco, ${ }^{20}$ Rio de Janeiro, RJ - Brasil

Universidade Federal Fluminense (UFF), ${ }^{21}$ Rio de Janeiro, RJ - Brasil

Universidade Federal da Paraíba (UFPB), ${ }^{22}$ João Pessoa, PB - Brasil

Hospital de Base do DF, ${ }^{23}$ Brasília, DF - Brasil

Duke University, ${ }^{24}$ Durham - EUA

Complexo Hospitalar de Niterói, ${ }^{25}$ Rio de Janeiro, RJ - Brasil

Hospital e Maternidade Christóvão da Gama, ${ }^{26}$ Santo André, SP - Brasil

Hospital Universitário Antônio Pedro (Huap), ${ }^{27}$ Rio de Janeiro, RJ - Brasil

Universidade do Estado do Rio de Janeiro, ${ }^{28}$ Rio de Janeiro, RJ - Brasil

Sociedade Campineira de Educação e Instrução, ${ }^{29}$ Campinas, SP - Brasil 
Hospital Universitário da Universidade Estadual de Londrina, ${ }^{30}$ Londrina, PR - Brasil

Universidade Federal do Rio de Janeiro (UFRJ), ${ }^{31}$ Rio de Janeiro, RJ - Brasil

Centro de Ensino e Treinamento Edson de Godoy Bueno / UHG, ${ }^{32}$ Rio de Janeiro, RJ-Brasil

Este posicionamento deverá ser citado como: Simões MV, et al. Posicionamento sobre Diagnóstico e Tratamento da Amiloidose Cardíaca - 2021. Arq Bras Cardiol. 2021; 117(3):561-598

Nota: Estes posicionamentos se prestam a informar e não a substituir o julgamento clínico do médico que, em última análise, deve determinar o tratamento apropriado para seus pacientes.

Correspondência: Sociedade Brasileira de Cardiologia - Av. Marechal Câmara, 360/330 - Centro - Rio de Janeiro CEP: 20020-907. E-mail: diretrizes@cardiol.br 


\begin{tabular}{|c|c|}
\hline & Posicionamento sobre Diagnóstico e Tratamento da Amiloidose Cardíaca - 2021 \\
\hline \multicolumn{2}{|c|}{$\begin{array}{l}0 \text { relatório abaixo lista as declarações de interesse conforme relatadas à SBC pelos especialistas durante } \\
\text { o período de desenvolvimento deste posicionamento, } 2020 / 2021 \text {. }\end{array}$} \\
\hline Especialista & Tipo de relacionamento com a indústria \\
\hline Acary Souza Bulle Oliveira & Nada a ser declarado \\
\hline André Schmidt & $\begin{array}{l}\text { Declaração financeira } \\
\text { A - Pagamento de qualquer espécie e desde que economicamente apreciáveis, feitos a (i) você, (ii) ao seu cônjuge/ } \\
\text { companheiro ou a qualquer outro membro que resida com você, (iii) a qualquer pessoa jurídica em que qualquer } \\
\text { destes seja controlador, sócio, acionista ou participante, de forma direta ou indireta, recebimento por palestras, } \\
\text { aulas, atuação como proctor de treinamentos, remunerações, honorários pagos por participações em conselhos } \\
\text { consultivos, de investigadores, ou outros comitês, etc. Provenientes da indústria farmacêutica, de órteses, próteses, } \\
\text { equipamentos e implantes, brasileiras ou estrangeiras: } \\
\text { - Bayer: Anticoagulantes. } \\
\text { Outros relacionamentos } \\
\text { Financiamento de atividades de educação médica continuada, incluindo viagens, hospedagens e inscrições para } \\
\text { congressos e cursos, provenientes da indústria farmacêutica, de órteses, próteses, equipamentos e implantes, } \\
\text { brasileiras ou estrangeiras: } \\
\text { - Sanofi: Anticoagulantes. }\end{array}$ \\
\hline Andréia Biolo & Nada a ser declarado \\
\hline Aristóteles Comte de Alencar Neto & Nada a ser declarado \\
\hline Aurora Felice Castro Issa & Nada a ser declarado \\
\hline Bruno Vaz Kerges Bueno & $\begin{array}{l}\text { Declaração financeira } \\
\text { A - Pagamento de qualquer espécie e desde que economicamente apreciáveis, feitos a (i) você, (ii) ao seu cônjuge/ } \\
\text { companheiro ou a qualquer outro membro que resida com você, (iii) a qualquer pessoa jurídica em que qualquer } \\
\text { destes seja controlador, sócio, acionista ou participante, de forma direta ou indireta, recebimento por palestras, } \\
\text { aulas, atuação como proctor de treinamentos, remunerações, honorários pagos por participações em conselhos } \\
\text { consultivos, de investigadores, ou outros comitês, etc. Provenientes da indústria farmacêutica, de órteses, próteses, } \\
\text { equipamentos e implantes, brasileiras ou estrangeiras: } \\
\text { - Pfiser: Eliquis; Alnylam: Patisiran. }\end{array}$ \\
\hline Carlos Eduardo Rochitte & Nada a ser declarado \\
\hline Celso Dario Ramos & Nada a ser declarado \\
\hline Cláudio Tinoco Mesquita & $\begin{array}{l}\text { Declaração financeira } \\
\text { A - Pagamento de qualquer espécie e desde que economicamente apreciáveis, feitos a (i) você, (ii) ao seu cônjuge/ } \\
\text { companheiro ou a qualquer outro membro que resida com você, (iii) a qualquer pessoa jurídica em que qualquer } \\
\text { destes seja controlador, sócio, acionista ou participante, de forma direta ou indireta, recebimento por palestras, } \\
\text { aulas, atuação como proctor de treinamentos, remunerações, honorários pagos por participações em conselhos } \\
\text { consultivos, de investigadores, ou outros comitês, etc. Provenientes da indústria farmacêutica, de órteses, próteses, } \\
\text { equipamentos e implantes, brasileiras ou estrangeiras: } \\
\text { - Pfizer: Participação em advisory board de amiloidose. } \\
\text { B - Financiamento de pesquisas sob sua responsabilidade direta/pessoal (direcionado ao departamento ou } \\
\text { instituição) provenientes da indústria farmacêutica, de órteses, próteses, equipamentos e implantes, brasileiras } \\
\text { ou estrangeiras: } \\
\text { - Alnylam: Investigador Principal do estudo Apollo B com Patisiran. } \\
\text { Outros relacionamentos } \\
\text { Financiamento de atividades de educação médica continuada, incluindo viagens, hospedagens e inscrições para } \\
\text { congressos e cursos, provenientes da indústria farmacêutica, de órteses, próteses, equipamentos e implantes, } \\
\text { brasileiras ou estrangeiras: } \\
\text { - Pfizer: Amiloidose. }\end{array}$ \\
\hline Denizar Viana & Nada a ser declarado \\
\hline Diane Xavier de Ávila & $\begin{array}{l}\text { Declaração financeira } \\
\text { A - Pagamento de qualquer espécie e desde que economicamente apreciáveis, feitos a (i) você, (ii) ao seu cônjuge/ } \\
\text { companheiro ou a qualquer outro membro que resida com você, (iii) a qualquer pessoa jurídica em que qualquer } \\
\text { destes seja controlador, sócio, acionista ou participante, de forma direta ou indireta, recebimento por palestras, } \\
\text { aulas, atuação como proctor de treinamentos, remunerações, honorários pagos por participações em conselhos } \\
\text { consultivos, de investigadores, ou outros comitês, etc. Provenientes da indústria farmacêutica, de órteses, próteses, } \\
\text { equipamentos e implantes, brasileiras ou estrangeiras: } \\
\text { - Alnylam: Patisiran. } \\
\text { Outros relacionamentos } \\
\text { Financiamento de atividades de educação médica continuada, incluindo viagens, hospedagens e inscrições para } \\
\text { congressos e cursos, provenientes da indústria farmacêutica, de órteses, próteses, equipamentos e implantes, } \\
\text { brasileiras ou estrangeiras: } \\
\text { - Alnylam: Patisiran. }\end{array}$ \\
\hline
\end{tabular}


Edileide de Barros Correia

Evandro Tinoco Mesquita

Fabio Fernandes

Declaração financeira

A - Pagamento de qualquer espécie e desde que economicamente apreciáveis, feitos a (i) você, (ii) ao seu cônjuge/ companheiro ou a qualquer outro membro que resida com você, (iii) a qualquer pessoa jurídica em que qualquer destes seja controlador, sócio, acionista ou participante, de forma direta ou indireta, recebimento por palestras, aulas, atuação como proctor de treinamentos, remunerações, honorários pagos por participações em conselhos consultivos, de investigadores, ou outros comitês, etc. Provenientes da indústria farmacêutica, de órteses, próteses, equipamentos e implantes, brasileiras ou estrangeiras: - Pfizer: Tafamidis (Vyndaqel); Alnylam: Patsiram (Onpatro); Takeda: Replagal.

Vínculo empregatício com a indústria farmacêutica, de órteses, próteses, Equipamentos e implantes, brasileiras ou estrangeiras, assim como se tem Relação vínculo empregatício com operadoras de planos de saúde ou em Auditorias médicas (incluindo meio período) durante o ano para o qual você está declarando: - UnitedHealth Group.

Declaração financeira

A - Pagamento de qualquer espécie e desde que economicamente apreciáveis, feitos a (i) você, (ii) ao seu cônjuge/ companheiro ou a qualquer outro membro que resida com você, (iii) a qualquer pessoa jurídica em que qualquer destes seja controlador, sócio, acionista ou participante, de forma direta ou indireta, recebimento por palestras, aulas, atuação como proctor de treinamentos, remunerações, honorários pagos por participações em conselhos consultivos, de investigadores, ou outros comitês, etc. Provenientes da indústria farmacêutica, de órteses, próteses, equipamentos e implantes, brasileiras ou estrangeiras:

- Novartis: Palestras; AstraZeneca: Palestras e Conselho Consultivo; Boehringer: Conselho Consultivo.

\section{Declaração financeira}

A - Pagamento de qualquer espécie e desde que economicamente apreciáveis, feitos a (i) você, (ii) ao seu cônjuge/ companheiro ou a qualquer outro membro que resida com você, (iii) a qualquer pessoa jurídica em que qualquer destes seja controlador, sócio, acionista ou participante, de forma direta ou indireta, recebimento por palestras, aulas, atuação como proctor de treinamentos, remunerações, honorários pagos por participações em conselhos consultivos, de investigadores, ou outros comitês, etc. Provenientes da indústria farmacêutica, de órteses, próteses, equipamentos e implantes, brasileiras ou estrangeiras:

- Pfiser, Alnylan: palestras.

Outros relacionamentos

Financiamento de atividades de educação médica continuada, incluindo viagens, hospedagens e inscrições para congressos e cursos, provenientes da indústria farmacêutica, de órteses, próteses, equipamentos e implantes, brasileiras ou estrangeiras:

- Phifesr: Participação em congresso internacional.

\section{Declaração financeira}

A - Pagamento de qualquer espécie e desde que economicamente apreciáveis, feitos a (i) você, (ii) ao seu cônjuge/companheiro ou a qualquer outro membro que resida com você, (iii) a qualquer pessoa jurídica em que qualquer destes seja controlador,

Felix José Alvarez Ramires sócio, acionista ou participante, de forma direta ou indireta, recebimento por palestras, aulas, atuação como proctor de treinamentos, remunerações, honorários pagos por participações em conselhos consultivos, de investigadores, ou outros comitês, etc. Provenientes da indústria farmacêutica, de órteses, próteses, equipamentos e implantes, brasileiras ou estrangeiras: - Novartis: Sacubitril/Nalsartana; Pfizer: Patisiran; Merck: Vericiquat; Amgen.

\begin{tabular}{ll}
\hline Fernando Bacal & Nada a ser declarado \\
\hline Flávio Henrique Valicelli & Nada a ser declarado \\
\hline Glaucia Maria Moraes de Oliveira & Nada a ser declarado \\
\hline & Declaração financeira
\end{tabular}

A - Pagamento de qualquer espécie e desde que economicamente apreciáveis, feitos a (i) você, (ii) ao seu cônjuge/ companheiro ou a qualquer outro membro que resida com você, (iii) a qualquer pessoa jurídica em que qualquer Ibraim Masciarelli Francisco Pinto destes seja controlador, sócio, acionista ou participante, de forma direta ou indireta, recebimento por palestras, aulas, atuação como proctor de treinamentos, remunerações, honorários pagos por participações em conselhos consultivos, de investigadores, ou outros comitês, etc. Provenientes da indústria farmacêutica, de órteses, próteses, equipamentos e implantes, brasileiras ou estrangeiras:

- Novo Nordisk: Diabetes

\begin{tabular}{ll}
\hline José Francisco Kerr Saraiva & Nada a ser declarado \\
\hline José Soares-Junior & Nada a ser declarado \\
\hline Ludhmila Abrahão Hajjar & Nada a ser declarado \\
\hline & Declaração financeira \\
& A - Pagamento de qualquer espécie e desde que economicamente apreciáveis, feitos a (i) você, (ii) ao seu cônjuge/ \\
& companheiro ou a qualquer outro membro que resida com você, (iii) a qualquer pessoa jurídica em que qualquer \\
& destes seja controlador, sócio, acionista ou participante, de forma direta ou indireta, recebimento por palestras, \\
& aulas, atuação como proctor de treinamentos, remunerações, honorários pagos por participações em conselhos \\
& consultivos, de investigadores, ou outros comitês, etc. Provenientes da indústria farmacêutica, de órteses, próteses, \\
& equipamentos e implantes, brasileiras ou estrangeiras: \\
& - Novartis: Insuficiência Cardíaca; AstraZeneca: Insuficiência Cardiaca. \\
& B - Financiamento de pesquisas sob sua responsabilidade direta/pessoal (direcionado ao departamento ou instituição) \\
provenientes da indústria farmacêutica, de órteses, próteses, equipamentos e implantes, brasileiras ou estrangeiras: & - Amgen: Insuficiência Cardíaca. \\
\hline
\end{tabular}




\section{Posicionamento}

Luis Eduardo P. Rohde

\section{Declaração financeira}

A - Pagamento de qualquer espécie e desde que economicamente apreciáveis, feitos a (i) você, (ii) ao seu cônjuge/ companheiro ou a qualquer outro membro que resida com você, (iii) a qualquer pessoa jurídica em que qualquer destes seja controlador, sócio, acionista ou participante, de forma direta ou indireta, recebimento por palestras, aulas, atuação como proctor de treinamentos, remunerações, honorários pagos por participações em conselhos consultivos, de investigadores, ou outros comitês, etc. Provenientes da indústria farmacêutica, de órteses, próteses, equipamentos e implantes, brasileiras ou estrangeiras:

- Pfizer: Tafamidis; Novartir: Sacubitril-Valsartan; AstraZeneca: Dpaglifozina; Boehringer Ingelheim: Empaglifozina; Merck: Bisoprolol; Amgen: Omecamtiv-Mercabil.

Outros relacionamentos

Financiamento de atividades de educação médica continuada, incluindo viagens, hospedagens e inscrições para congressos e cursos, provenientes da indústria farmacêutica, de órteses, próteses, equipamentos e implantes, brasileiras ou estrangeiras:

- AstraZeneca: Dapaglifozina; Boehringer Ingelheim: Empaglifozina.

\begin{tabular}{ll}
\hline Manoel Fernandes Canesin & Nada a ser declarado \\
\hline Marcelo Dantas Tavares de Melo & Nada a ser declarado \\
\hline Marcelo lório Garcia & Nada a ser declarado \\
\hline Marcelo Luiz Campos Vieira & Nada a ser declarado \\
\hline Marcelo Westerlund Montera & Nada a ser declarado \\
\hline
\end{tabular}

Declaração financeira

A - Pagamento de qualquer espécie e desde que economicamente apreciáveis, feitos a (i) você, (ii) ao seu cônjuge/ companheiro ou a qualquer outro membro que resida com você, (iii) a qualquer pessoa jurídica em que qualquer destes seja controlador, sócio, acionista ou participante, de forma direta ou indireta, recebimento por palestras, aulas, atuação como proctor de treinamentos, remunerações, honorários pagos por participações em conselhos consultivos, de investigadores, ou outros comitês, etc. Provenientes da indústria farmacêutica, de órteses, próteses, equipamentos e implantes, brasileiras ou estrangeiras:

- Pfizer, Alnylam, Genzyme, Ionis, Prothena, FoldRx, PTC, NIH: Ppresentação em evento científico como investigadora principal de ensaios clínicos e como consultoria.

Márcia Waddington Cruz B - Financiamento de pesquisas sob sua responsabilidade direta/pessoal (direcionado ao departamento ou instituição) provenientes da indústria farmacêutica, de órteses, próteses, equipamentos e implantes, brasileiras ou estrangeiras: - Pfizer, Alnylam, Genzyme, Ionis, Prothena, FoldRx, PTC, NIH: Apresentação em evento científico como investigadora principal de ensaios clínicos e como consultoria.

Outros relacionamentos

Financiamento de atividades de educação médica continuada, incluindo viagens, hospedagens e inscrições para congressos e cursos, provenientes da indústria farmacêutica, de órteses, próteses, equipamentos e implantes, brasileiras ou estrangeiras: - Pfizer, Alnylam, Genzyme, Ionis, Prothena, FoldRx, PTC, NIH: Apresentação em evento científico como investigadora principal de ensaios clínicos e como consultoria.

Declaração financeira

A - Pagamento de qualquer espécie e desde que economicamente apreciáveis, feitos a (i) você, (ii) ao seu cônjuge/ companheiro ou a qualquer outro membro que resida com você, (iii) a qualquer pessoa jurídica em que qualquer destes seja controlador, sócio, acionista ou participante, de forma direta ou indireta, recebimento por palestras, aulas, atuação como proctor de treinamentos, remunerações, honorários pagos por participações em conselhos consultivos,

Marcus V. Simões de investigadores, ou outros comitês, etc. Provenientes da indústria farmacêutica, de órteses, próteses, equipamentos e implantes, brasileiras ou estrangeiras:

- Novartis: Entresto; AstraZeneca: Dapagliflozina.

B - Financiamento de pesquisas sob sua responsabilidade direta/pessoal (direcionado ao departamento ou instituição) provenientes da indústria farmacêutica, de órteses, próteses, equipamentos e implantes, brasileiras ou estrangeiras: - Amgen: Omecamtiv/Mecarbil; Beringher Ingelheim: Empagliflozina.

Minna Moreira Dias Romano Nada a ser declarado

Declaração financeira

A - Pagamento de qualquer espécie e desde que economicamente apreciáveis, feitos a (i) você, (ii) ao seu cônjuge/ companheiro ou a qualquer outro membro que resida com você, (iii) a qualquer pessoa jurídica em que qualquer destes seja controlador, sócio, acionista ou participante, de forma direta ou indireta, recebimento por palestras, aulas, atuação como proctor de treinamentos, remunerações, honorários pagos por participações em conselhos consultivos, de investigadores, ou outros comitês, etc. Provenientes da indústria farmacêutica, de órteses, próteses, equipamentos e implantes, brasileiras ou estrangeiras:

- Pfizer: Tratamento para amiloidose TTR; Takeda: Doença de Fabry; Novartis: Insuficiência cardíaca; AstraZeneca; Daiichi Sankyo; Merck; Shire; Bayer.

B - Financiamento de pesquisas sob sua responsabilidade direta/pessoal (direcionado ao departamento ou instituição) provenientes da indústria farmacêutica, de órteses, próteses, equipamentos e implantes, brasileiras ou estrangeiras: - Pfizer: Tratamento para amiloidose TTR.

Outros relacionamentos

Financiamento de atividades de educação médica continuada, incluindo viagens, hospedagens e inscrições para congressos e cursos, provenientes da indústria farmacêutica, de órteses, próteses, equipamentos e implantes, brasileiras ou estrangeiras:

- AstraZeneca: Insuficiência cardíaca. 


\begin{tabular}{ll}
\hline Pedro Manoel Marques Garibaldi & Nada a ser declarado \\
\hline & Declaração financeira \\
& A - Pagamento de qualquer espécie e desde que economicamente apreciáveis, feitos a (i) você, (ii) ao seu cônjuge/ \\
companheiro ou a qualquer outro membro que resida com você, (iii) a qualquer pessoa jurídica em que qualquer & destes seja controlador, sócio, acionista ou participante, de forma direta ou indireta, recebimento por palestras, \\
& aulas, atuação como proctor de treinamentos, remunerações, honorários pagos por participações em conselhos \\
Philip Scheinberg & consultivos, de investigadores, ou outros comitês, etc. Provenientes da indústria farmacêutica, de órteses, próteses, \\
& equipamentos e implantes, brasileiras ou estrangeiras: \\
& - Novartis, Abbvie, Roche: Hematologia.
\end{tabular}

\section{Declaração financeira}

A - Pagamento de qualquer espécie e desde que economicamente apreciáveis, feitos a (i) você, (ii) ao seu cônjuge/ companheiro ou a qualquer outro membro que resida com você, (iii) a qualquer pessoa jurídica em que qualquer destes seja controlador, sócio, acionista ou participante, de forma direta ou indireta, recebimento por palestras, aulas, atuação como proctor de treinamentos, remunerações, honorários pagos por participações em conselhos consultivos, de investigadores, ou outros comitês, etc. Provenientes da indústria farmacêutica, de órteses, próteses, equipamentos e implantes, brasileiras ou estrangeiras:

- Bayer: Anticoagulante; Boehringer Ingleheim: Anticoagulação e Diabetes; Pfizer: Anticoagulação; Bristol-Myers

Renato Delascio Lopes Squibb; Daiichi Sankyo; Glaxo Smith Kline; Medtronic; Merck; Portola; Sanofi.

B - financiamento de pesquisas sob sua responsabilidade direta/pessoal (direcionado ao departamento ou instituição) provenientes da indústria farmacêutica, de órteses, próteses, equipamentos e implantes, brasileiras ou estrangeiras: - Pfizer: Apixaban; Bayer: Rivaroxaban; Novartis: Sacubitril, Valsartan.

Outros relacionamentos

Financiamento de atividades de educação médica continuada, incluindo viagens, hospedagens e inscrições para congressos e cursos, provenientes da indústria farmacêutica, de órteses, próteses, equipamentos e implantes, brasileiras ou estrangeiras:

- Bayer: Rivaroxabana; Pfizer: Apixabana

Declaração financeira

A - Pagamento de qualquer espécie e desde que economicamente apreciáveis, feitos a (i) você, (ii) ao seu cônjuge/ companheiro ou a qualquer outro membro que resida com você, (iii) a qualquer pessoa jurídica em que qualquer destes seja controlador, sócio, acionista ou participante, de forma direta ou indireta, recebimento por palestras, aulas, atuação como proctor de treinamentos, remunerações, honorários pagos por participações em conselhos consultivos, de investigadores, ou outros comitês, etc. Provenientes da indústria farmacêutica, de órteses, próteses, equipamentos e implantes, brasileiras ou estrangeiras:

- Pfizer: Amiloidose.

Roberta Shcolnik Szor B - Financiamento de pesquisas sob sua responsabilidade direta/pessoal (direcionado ao departamento ou instituição) provenientes da indústria farmacêutica, de órteses, próteses, equipamentos e implantes, brasileiras ou estrangeiras:

- Janssen-Cilag Farmacêutica Ltda.: Amiloidose de cadeia leve.

Outros relacionamentos

Financiamento de atividades de educação médica continuada, incluindo viagens, hospedagens e inscrições para congressos e cursos, provenientes da indústria farmacêutica, de órteses, próteses, equipamentos e implantes, brasileiras ou estrangeiras:

- Janssen-Cilag Farmacêutica Ltda.: Amiloidose de cadeia leve.

\section{Declaração financeira}

A - Pagamento de qualquer espécie e desde que economicamente apreciáveis, feitos a (i) você, (ii) ao seu cônjuge/ companheiro ou a qualquer outro membro que resida com você, (iii) a qualquer pessoa jurídica em que qualquer destes seja controlador, sócio, acionista ou participante, de forma direta ou indireta, recebimento por palestras, aulas, atuação como proctor de treinamentos, remunerações, honorários pagos por participações em conselhos consultivos, de investigadores, ou outros comitês, etc. Provenientes da indústria farmacêutica, de órteses, próteses,

Sandra Marques e Silva equipamentos e implantes, brasileiras ou estrangeiras:

- Sanofi, Takeda, Amicus Therapeutics: Doenças raras; Pfiser.

Outros relacionamentos

Financiamento de atividades de educação médica continuada, incluindo viagens, hospedagens e inscrições para congressos e cursos, provenientes da indústria farmacêutica, de órteses, próteses, equipamentos e implantes, brasileiras ou estrangeiras:

- Sanofi, Takeda, Amicus Therapeutics: Doenças raras; Pfiser.

\section{Declaração financeira}

A - Pagamento de qualquer espécie e desde que economicamente apreciáveis, feitos a (i) você, (ii) ao seu cônjuge/ companheiro ou a qualquer outro membro que resida com você, (iii) a qualquer pessoa juríica em que qualquer destes seja controlador, sócio, acionista ou participante, de forma direta ou indireta, recebimento por palestras, aulas, atuação como proctor de treinamentos, remunerações, honorários pagos por participações em conselhos consultivos, de investigadores, ou outros comitês, etc. Provenientes da indústria farmacêutica, de órteses, próteses, equipamentos e implantes, brasileiras ou estrangeiras: - Novartis: Sacubitril/Nalsartan; Pfizer: Doenças raras.

Outros relacionamentos

Financiamento de atividades de educação médica continuada, incluindo viagens, hospedagens e inscrições para congressos e cursos, provenientes da indústria farmacêutica, de órteses, próteses, equipamentos e implantes, brasileiras ou estrangeiras:

- Pfizer: Doenças raras 
Simões et al.

Posicionamento sobre Diagnóstico e Tratamento da Amiloidose Cardíaca - 2021

\section{Posicionamento}

Silvia Marinho Martins Alves Nada a ser declarado

Declaração financeira

A - Pagamento de qualquer espécie e desde que economicamente apreciáveis, feitos a (i) você, (ii) ao seu cônjuge/ companheiro ou a qualquer outro membro que resida com você, (iii) a qualquer pessoa jurídica em que qualquer destes seja controlador, sócio, acionista ou participante, de forma direta ou indireta, recebimento por palestras, aulas, atuação como proctor de treinamentos, remunerações, honorários pagos por participações em conselhos consultivos, de investigadores, ou outros comitês, etc. Provenientes da indústria farmacêutica, de órteses, próteses, equipamentos e implantes, brasileiras ou estrangeiras:

- Pfizer: Tafamidis; Alnylam: Patisiran; PTC: Inotersen.

Wilson Marques Junior

B - Financiamento de pesquisas sob sua responsabilidade direta/pessoal (direcionado ao departamento ou instituição) provenientes da indústria farmacêutica, de órteses, próteses, equipamentos e implantes, brasileiras ou estrangeiras:

- Pfizer: Amiloidose.

Outros relacionamentos

Financiamento de atividades de educação médica continuada, incluindo viagens, hospedagens e inscrições para congressos e cursos, provenientes da indústria farmacêutica, de órteses, próteses,

equipamentos e implantes, brasileiras ou estrangeiras:

- Pfizer: Tafamidis; Alnylam: Patisiran; PTC: Inotersen. 


\section{Sumário}

1. Introdução. 568

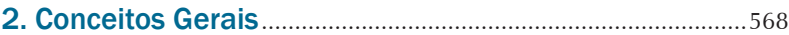

3. Manifestações Neurológicas ....................................................

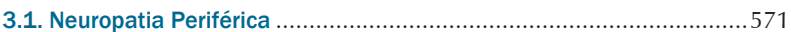

3.2. Manifestações do Sistema Nervoso Central .....................................571

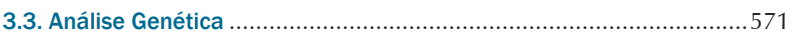

4. Manifestações Cardiovasculares...........................................572

4.1. Elevação do Grau de Suspeita da Amiloidose Cardíaca ......................572

5. Exames Complementares Diagnósticos.............................573

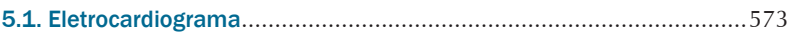

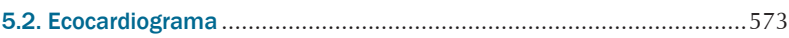

5.3. Ressonância Magnética Cardíaca..................................................574

5.3.1. Avaliação da Morfologia e da Função Cardíaca ...........................576

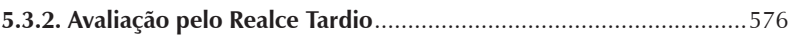

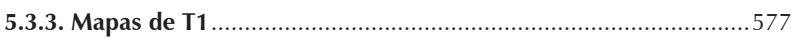

5.4. Cintilografia Cardíaca com Radiotraçadores Ósseos ........................ 578

5.4.1. Aspectos Técnicos Recomendados para Aquisição das Imagens .......578

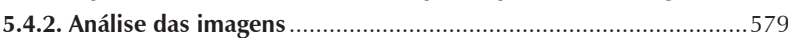

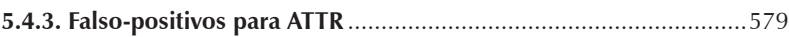

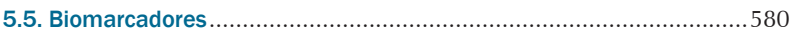

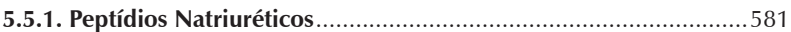

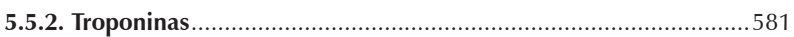

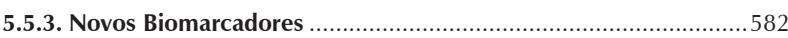

6. Abordagem Diagnóstica Racional da Amiloidose

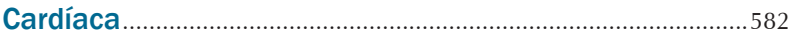

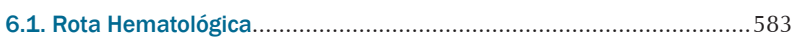

6.1.1. Participação do Hematologista e Biópsia de Tecidos Periféricos .......583

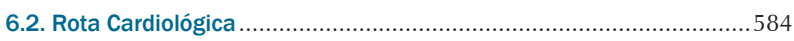

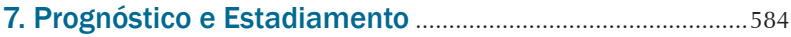

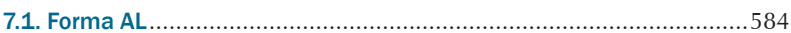

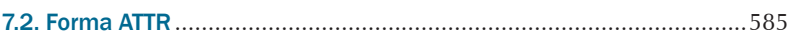

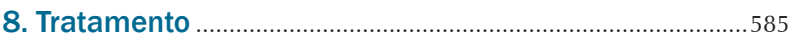

8.1. Princípios da Terapia Específica da Amiloidose AL ...........................586 8.1.1. Tratamento de Pacientes Elegíveis ao Transplante Autólogo de Células-tronco Hematopoiéticas ........................................................587 8.1.2. Tratamento de Pacientes Não Elegíveis ao TCTH/Quimioterapia Convencional ................................................................. 587

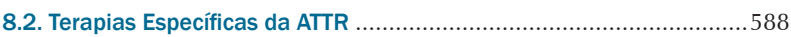

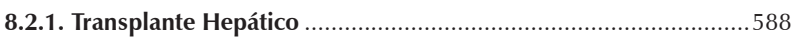

8.2.2. Estabilizadores Seletivos dos Tetrâmeros da TTR ..........................588

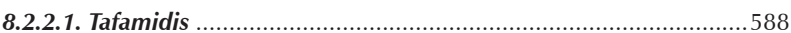

8.2.2.2. AG10

8.2.3. Inibidores da Síntese Hepática de TTR .........................................589

8.2.4. Degradação e Reabsorção das Fibrilas Amiloides ........................589

9. Manejo da Síndrome da Insuficiência Cardíaca ..............590

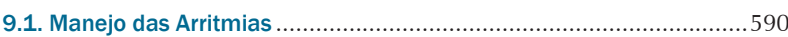

9.1.1. Arritmias Atriais e Anticoagulantes ............................................590

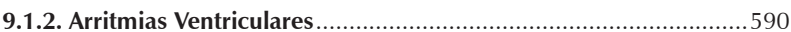

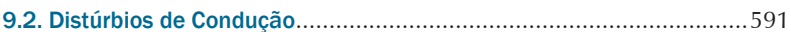

9.3. Opções Terapêuticas na Insuficiência Cardíaca Avançada .................591

10. Centros de Excelência/Referência e Novos Modelos de

Remuneração do Tratamento ...................................................592

11. Lacunas do Conhecimento e Perspectivas Futuras....592

Referências

. .593

\section{Introdução}

Nos últimos anos, foram consolidados avanços expressivos no conhecimento de amiloidose cardíaca (AC), trazendo uma profunda reformulação do seu significado clínico. Além de haver evidências convincentes de que AC seja uma causa relativamente comum de insuficiência cardíaca com fração de ejeção preservada (ICFEP), assistimos o surgimento de terapias específicas modificadoras do curso natural da doença, capazes de prolongar a sobrevida dos pacientes acometidos.

Em paralelo, relevantes progressos nas técnicas de imagem cardiovascular têm contribuído grandemente para o reconhecimento mais acurado e precoce da doença. Particularmente, o emprego da cintilografia cardíaca com radiotraçadores ósseos tornou possível o diagnóstico não invasivo da AC ligada à transtirretina (TTR), prescindindo da biópsia endomiocárdica, o que simplificou muito o fluxo diagnóstico.

Assim, o presente posicionamento tem por objetivo apresentar as recomendações mais atuais para o diagnóstico, estadiamento prognóstico e tratamento da AC, com base na revisão crítica das evidências científicas atuais.

Neste posicionamento, as tabelas de classes de recomendação e níveis de evidência foram realizadas conforme a padronização a seguir.

\section{Classes (graus) de recomendação:}

Classe I - Condições para as quais há evidências conclusivas ou, em sua ausência, consenso geral de que o procedimento é seguro e útil/eficaz

Classe Ila - Condições para as quais há evidências conflitantes e/ou divergência de opinião sobre segurança e utilidade/eficácia do procedimento. Peso ou evidência/opinião a favor do procedimento. A maioria dos estudos/especialistas aprova

Classe Illb - Condições para as quais há evidências conflitantes e/ou divergência de opinião sobre segurança e utilidade/eficácia do procedimento. Segurança e utilidade/eficácia menos bem estabelecida, não havendo predomínio de opiniões a favor

Classe III - Condições para as quais há evidências e/ou consenso de que o procedimento não é útil/eficaz e, em alguns casos, pode ser prejudicial

\section{Niveis de evidência:}

Nível A - Dados obtidos a partir de múltiplos estudos randomizados de bom porte, concordantes e/ou de metanálise robusta de estudos clínicos randomizados

Nível B - Dados obtidos a partir de metanálise menos robusta, a partir de um único estudo randomizado ou de estudos não randomizados (observacionais)

Nível C - Dados obtidos de opiniões consensuais de especialistas

\section{Conceitos Gerais}

A amiloidose sistêmica é uma doença causada pela deposição tecidual de agregados proteicos fibrilares e insolúveis em diferentes órgãos, incluindo o coração, levando à disfunção orgânica. ${ }^{1}$ Mais de 30 tipos de proteínas 
amiloidogênicas são descritas, ${ }^{2}$ e cinco delas podem acometer o coração (cadeias pesada e leve da imunoglobulina, transtirretina, amiloide A e apoA1), sendo que dois tipos são responsáveis por 95\% dos casos de AC: a cadeia leve de imunoglobulinas (forma AL) e a transtirretina (forma ATTR), tanto em suas formas selvagem ou wild type (ATTRwt) quanto hereditária ou variante (ATTRv). ${ }^{3-7}$

A transtirretina (TTR) é uma proteína composta por quatro monômeros, que circulam como um tetrâmero. ${ }^{8}$ Age como um transportador de tiroxina (T4) e de retinol (vitamina A), em condições fisiológicas. A etapa limitante na taxa de formação das fibrilas amiloides pela TTR é a dissociação do tetrâmero em monômeros, o que possivelmente envolve proteólise. Posteriormente, a desnaturação parcial do monômetro permite a montagem incorreta em várias estruturas agregadas. A amiloidose por mutação do gene da TTR (ATTRv) apresenta caráter autossômico dominante, seu gene está localizado no cromossomo 18 e mais de 140 mutações já foram descritas. Mediante a produção de TTR menos estável, leva à deposição amiloide de forma agressiva e sistêmica. ${ }^{9}$

Na ATTRwt, a sequência de aminoácidos é normal e não está completamente esclarecido o processo pelo qual a proteína selvagem se torna instável e se agrega em fibrilas amiloides. No entanto, o envelhecimento parece estar envolvido na fisiopatologia da doença. ${ }^{8,9}$

$\mathrm{Na}$ forma $\mathrm{AL}$, a cadeia leve amiloidogênica origina-se de plasmócitos ou, menos frequentemente, linfócitos B anômalos, configurando, portanto, uma doença hematológica clonal e neoplásica. No coração, o depósito de fibrilas amiloides causa dano estrutural ao aumentar a rigidez cardíaca e vascular, prejudicando a contração e o relaxamento cardíaco e gerando distúrbios de condução. Em paralelo, as cadeias leves circulantes também apresentam toxicidade direta ao miocárdio, através de disfunção lisossomal, autofagia defeituosa, produção de espécies reativas de oxigênio, disfunção celular e mitocondrial, alterações na homeostase do cálcio do cardiomiócito e, por fim, morte celular. ${ }^{10}$

A Figura 1 representa a fisiopatogênese da amiloidose cardíaca nas formas ATTR e AL.

Diferentes subtipos de amiloidose podem originar manifestações clínicas sobrepostas e, uma vez diagnosticada a amiloidose, é imprescindível caracterizar corretamente a proteína precursora para instituição do tratamento específico. ${ }^{11-13}$

A depender dos órgãos acometidos e do grau de disfunção ocasionada, um amplo espectro de manifestações clínicas pode ser observado, com evolução progressiva e potencialmente fatal. Os principais órgãos que podem ser acometidos na amiloidose sistêmica são coração, rins, olhos, sistema nervoso central e periférico e fígado. Manifestações clínicas inespecíficas são frequentemente observadas e incluem fadiga, perda ponderal, edema periférico e hipotensão ortostática. Por esse motivo, é comum o diagnóstico tardio, de modo que são necessários conhecimento sobre a doença e elevado grau de suspeição clínica para conclusão diagnóstica.

Na ATTRv, a depender da mutação, o quadro clínico é dominado por neuropatia ou cardiopatia. Na ATTRwt,

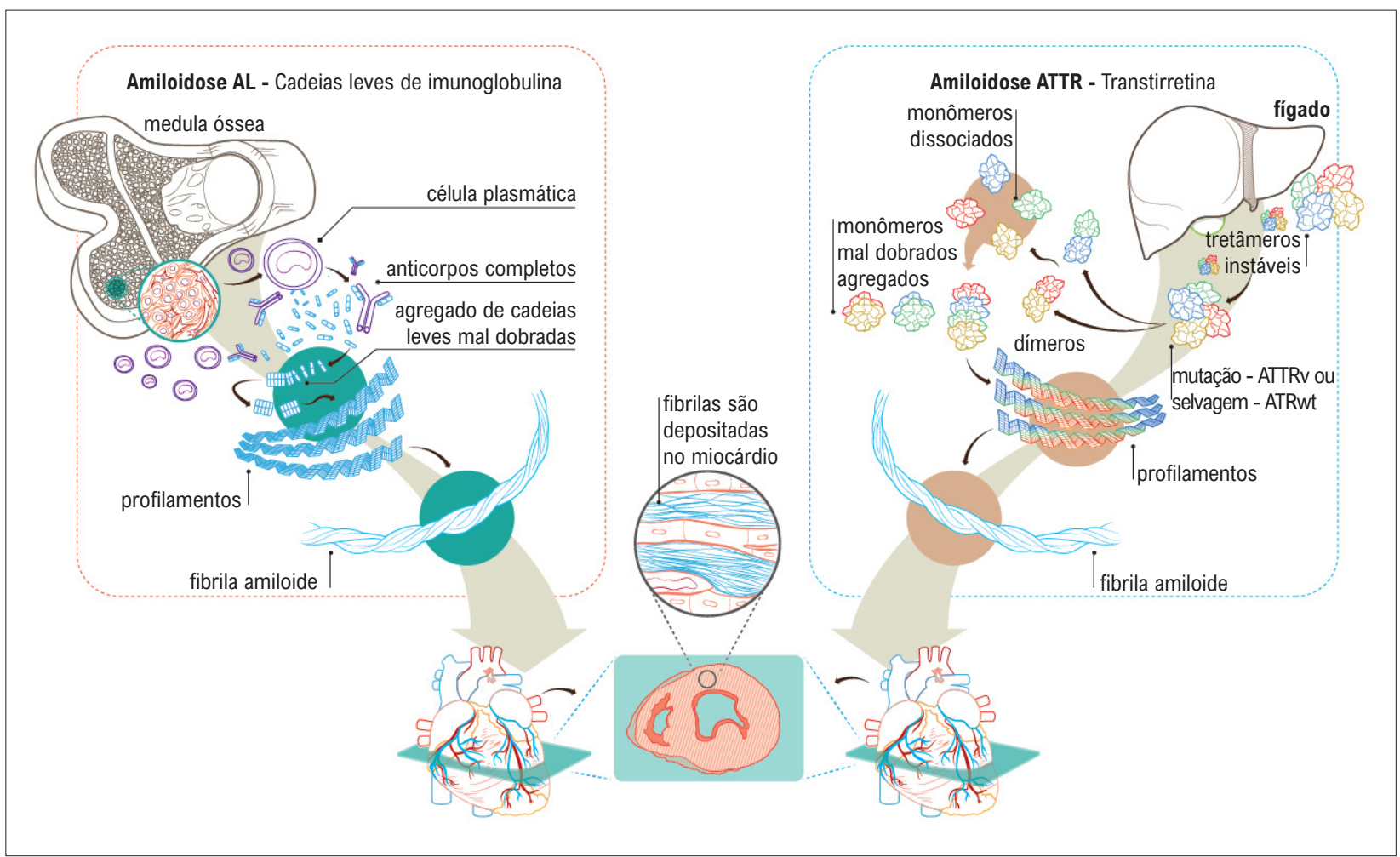

Figura 1 - Fisiopatogênese da amiloidose cardíaca. 
a cardiopatia é a principal manifestação clínica, ocorrendo principalmente em homens idosos que desenvolvem ICFEP sem fatores de risco previamente conhecidos.

Algumas alterações extracardíacas podem anteceder, em anos, o desenvolvimento da AC, destacando-se a síndrome do túnel do carpo bilateral e a ruptura espontânea do tendão do bíceps. O reconhecimento de tais sinais como parte do quadro clínico de amiloidose é fundamental, podendo levar a diagnóstico mais precoce e evitar a progressão da cardiopatia pela instituição de tratamento específico. ${ }^{14,15}$

A ATTRwt tem incidência aumentada em pacientes mais idosos, usualmente acima de 70 anos de idade; contudo, as manifestações clínicas da ATTRv também costumam ocorrer em idosos, fazendo com que a idade não deva ser levada em consideração para diferenciação entre as duas formas de ATTR. No que diz respeito ao sexo, há uma forte predominância no sexo masculino, em $80 \%$ a $90 \%$, apenas na ATTRwt.

Com relação à ATTRv, a mutação V30M é a mais disseminada pelo mundo, sendo endêmica em Portugal, Suécia e Japão e, provavelmente, a mais comum no Brasil. Outra mutação bastante frequente é a V122I, que está presente em $3,4 \%$ dos afro-americanos e relacionada ao desenvolvimento de cardiopatia em pacientes acima dos 60 anos de idade. ${ }^{7,9,16,17}$

A Tabela 1 resume as características demográficas e clínicas dos subtipos AL, ATTRv e ATTRwt.

A amiloidose cardíaca por cadeias leves ( $A L$ ) apresenta incidência de 6 a 10/milhão de pessoas/ ano e era considerada a principal causa de AC. ${ }^{18}$ Com o desenvolvimento de técnicas menos invasivas de diagnóstico de AC por ATTR $^{19}$ e a perspectiva de tratamentos efetivos, o número de casos diagnosticados, especialmente de ATTRwt, vem aumentando de forma expressiva, ${ }^{20}$ sendo atualmente a causa mais comum de AC. Estudos demonstram que $13 \%{ }^{21}$ dos pacientes com ICFEP e $25 \%$ das necropsias de idosos, ${ }^{22,23}$ principalmente do sexo masculino, apresentam depósito de ATTR no coração. ${ }^{24}$

Muito mais que uma doença rara, na verdade, a $\mathrm{AC}$ é uma condição subdiagnosticada. Dados recentes nos EUA registram o progressivo aumento na prevalência, aumentando de 18 para 55,2 (100.000 pessoas-ano), ${ }^{25}$ e fortalecem o conceito da falta do diagnóstico que equivocadamente era considerado como inexistência da doença. A jornada do paciente até o diagnóstico é longa, e estima-se que exista um atraso de mais de 2 anos do início dos sintomas até o diagnóstico, passando, em média, por cinco diferentes profissionais. ${ }^{26}$ Assim, iniciativas que disseminem o conhecimento sobre AC são fundamentais, fazendo com que os clínicos e cardiologistas pensem nessa entidade, visando a um diagnóstico mais precoce e orientação adequada da terapêutica, melhorando o prognóstico e a sobrevida dos pacientes.

Com relação ao prognóstico, a amiloidose AL causa envolvimento multiorgânico, de caráter mais agressivo em relação aos demais subtipos. O diagnóstico tardio ainda faz com que a mortalidade precoce nos primeiros 6 a 12 meses seja elevada em decorrência de complicações da cardiopatia avançada. ${ }^{7,8} \mathrm{Na}$ ATTR, a sobrevida mediana estimada para o subtipo wild type é de 3,6 anos e, na ATTRv, o prognóstico depende da mutação. Nos casos de fenótipo neurológico, a progressão da neuropatia leva à incapacidade sensitivo-motora, mas a mortalidade é mais relacionada a comprometimento cardíaco. ${ }^{2,13}$

Tabela 1 - Aspectos demográficos e de apresentação clínica, comparativo entre as formas AL, ATTRv e ATTRwt

\begin{tabular}{|c|c|c|c|}
\hline Aspectos demográficos & $A L$ & ATTRv & ATTRwt \\
\hline Idade de início (anos) & $>60$ anos & Depende do genótipo & $>70$ anos \\
\hline Gênero & Leve predominância em homens & Sem predominância & Predominância em homens \\
\hline Origem étnica & Nenhuma & $\begin{array}{c}\text { Mutação mais frequente: } \\
\text { Afrodescendentes americanos } \\
=\text { Val122lle } \\
\text { Portugueses = Val30Met }\end{array}$ & Nenhuma \\
\hline Prevalência/Incidência & $\begin{array}{c}10 \text { casos/milhão de pessoas/ano, } \\
\text { aumenta com a idade }\end{array}$ & Variável, conforme o genótipo & $\begin{array}{l}\text { Desconhecida, aumenta } \\
\text { com a idade }\end{array}$ \\
\hline \multicolumn{4}{|l|}{ Aspectos clínicos } \\
\hline ICFEP & $\sqrt{ }$ & $\sqrt{ }$ & $\sqrt{ }$ \\
\hline Neuropatia periférica e/ou autonômica & $\sqrt{ }$ & $\sqrt{ }$ & - \\
\hline Proteinúria & $\sqrt{ }$ & - & - \\
\hline Púrpura periorbitária & $\sqrt{ }$ & - & - \\
\hline Macroglossia & $\sqrt{ }$ & - & - \\
\hline Síndrome do túnel do carpo bilateral & $\sqrt{ }$ & - & $\sqrt{ }$ \\
\hline Ruptura espontânea do tendão do bíceps & - & - & $\sqrt{ }$ \\
\hline
\end{tabular}

ICFEP: insuficiência cardiaca com fração de ejeção preservada. 


\section{Manifestações Neurológicas}

Mutações no gene TTR estão associadas a uma grande variedade de manifestações clínicas, que refletem o depósito da proteína variante (TTRv) em diferentes tipos de tecidos, sendo o envolvimento cardíaco e o do sistema nervoso periférico os mais frequentes; o primeiro particularmente causado pela mutação V122I e o segundo, pela mutação V30M. ${ }^{27}$

Neste capítulo, descreveremos as principais manifestações neurológicas que deveriam levantar a possibilidade de ATTRv.

As manifestações neurológicas na ATTRv podem se dividir em: neuropatia periférica, manifestações tardias de acometimento do sistema nervoso central (SNC) ligadas à angiopatia amiloide e manifestações do SNC associadas à infiltração oculomeníngea.

\subsection{Neuropatia Periférica}

A forma clássica de acometimento dos nervos periféricos na ATTRv é a polineuropatia axonal, autonômica-sensitivamotora de evolução comprimento dependente, ou seja: afeta inicialmente segmentos mais distais dos membros, sobretudo os inferiores, e evolui para o acometimento de segmentos proximais e para os membros superiores. ${ }^{28,29}$

$\mathrm{Na}$ forma de início precoce ( $<50$ anos), em geral associada à mutação ATTRv V30M (V50M), as fibras finas, pouco ou não mielinizadas (fibras autonômicas, do calor, do frio e da dor) são as acometidas inicialmente, seguindose, à medida que a doença progride, comprometimento das fibras grossas, muito mielinizadas, responsáveis pelas sensibilidades vibratória, cinético-postural e pela motricidade. Assim, os primeiros sintomas são disfunção erétil, saciedade precoce, náuseas, vômitos, diarreia, constipação, alternância de diarreia com constipação, hipotensão ortostática, síncopes, arritmias, alteração da condução atrioventricular, olho seco, retenção ou incontinência urinária, dor neuropática, perda das sensibilidades ao calor e ao frio e uma importante perda ponderal. Já nessa fase inicial, podem surgir lesões indolores, mal perfurante plantar e suas repercussões, tais como infecções localizadas, celulite, osteomielite e até septicemia. Após alguns anos, surgem instabilidade à marcha e fraqueza por atrofia muscular, sempre evoluindo de distal para proximal. ${ }^{28,29}$

Já nas formas tardias, a neuropatia, desde o início, compromete todos os tipos de fibras, e a disautonomia não é tão importante, pelo menos na fase inicial da doença. Estas formas tanto podem estar associadas à mutação TTRv V30M quanto a várias outras mutações, e a evolução costuma ser mais agressiva. Em estudo brasileiro, 26 \% dos pacientes com ATTRv V30M tiveram início tardio. ${ }^{30}$

A síndrome do túnel do carpo bilateral é uma manifestação frequente na ATTRv, podendo ser a manifestação inicial. Está associada a qualquer mutação, mas é particularmente importante em algumas delas, incluindo a TTR V122I, que aparenta ser particularmente frequente no Brasil, associada à doença cardíaca, a quem pode preceder por vários anos. ${ }^{31}$

\subsection{Manifestações do Sistema Nervoso Central}

O prolongamento da sobrevida, inicialmente associada ao transplante hepático e agora pelos novos medicamentos, tem possibilitado o aparecimento de manifestação que antes eram incomuns. A produção de TTR pelo plexo coroide (apenas 2\% do total), a longo prazo, tanto está associada a uma angiopatia amiloide como à infiltração meníngea. A angiopatia amiloide se manifesta como episódios focais tanto do tipo deficitário stroke-like, TIA-like, ou aura-like, quanto do tipo irritativo epilético. Nos casos mais graves, pode se instalar isquemia ou mesmo hemorragia intracraniana. Dentre outras manifestações neurológicas, destacam-se: comprometimento auditivo; migrânia; demência; síndrome cerebelar; mielopatia e radiculopatia.

Algumas mutações raras têm predileção pelo acometimento oculocerebral e constituem quadros de amiloidose oculoleptomeníngea (ATTR Y69H: oculocerebral; Val30Gly: oculoleptomeníngea). ${ }^{32}$

Estágios da neuropatia: Os estágios de Coutinho para ATTRv são demarcados pela polineuropatia. O estágio 1 é aquele em que a polineuropatia sensitivo-motora afeta a marcha, mas o paciente não necessita de apoio para deambular. No estágio 2, um ou mais apoios são necessários para a deambulação. No estágio 3, o paciente está restrito à cadeira de rodas ou ao leito.

\subsection{Análise Genética}

A ATTRv é uma doença de herança autossômica dominante, mas que apresenta penetrância variável, que é ao mesmo tempo mutação dependente, idade dependente e também sofre influência regional. ${ }^{33}$ A mutação TTRv V30Met, por exemplo, tem penetrância em Portugal de 80\% aos 50 anos e de $91 \%$ aos 70 anos. Na Suécia, a mesma mutação tem os valores de $11 \%$ e $36 \%$, respectivamente.

Pelo menos 140 diferentes mutações foram descritas até o momento, mas nem todas são patogênicas. Algumas são polimorfismos já bem determinados, enquanto outras ainda têm significado indeterminado. ${ }^{34}$ Essas duas características implicam que o teste diagnóstico deve ser sempre o sequenciamento completo de gene TTR e que a interpretação das variantes raras ou ainda não descritas deve ser cuidadosa. Dentre as mutações patogênicas, existem as que causam preferentemente neuropatia (TTRv V30Met), as que causam preferentemente cardiopatia (TTRv V122I) e as que causam tanto neuropatia como cardiopatia (Leu58Hist) (Figura 2). ${ }^{35}$ Deve-se considerar, no entanto, que a correlação genotípica/ fenotípica não é estrita.

Um capítulo especial dentre os aspectos genéticos é o teste pré-sintomático, ou seja, o teste de parentes de pessoas sabidamente afetadas. Diferentemente do teste diagnóstico, ele deve ser feito por pessoas treinadas e deve haver uma equipe de suporte, incluindo psicólogo. Deve incluir obrigatoriamente uma fase de preparação, pré-diagnóstica, o teste genético e uma fase de suporte, pós-resultado. Não deve ser realizado em crianças, e somente deve ser aplicado quando o candidato manifestar expressamente que esta é sua vontade e for considerado psicologicamente preparado. ${ }^{36}$ 


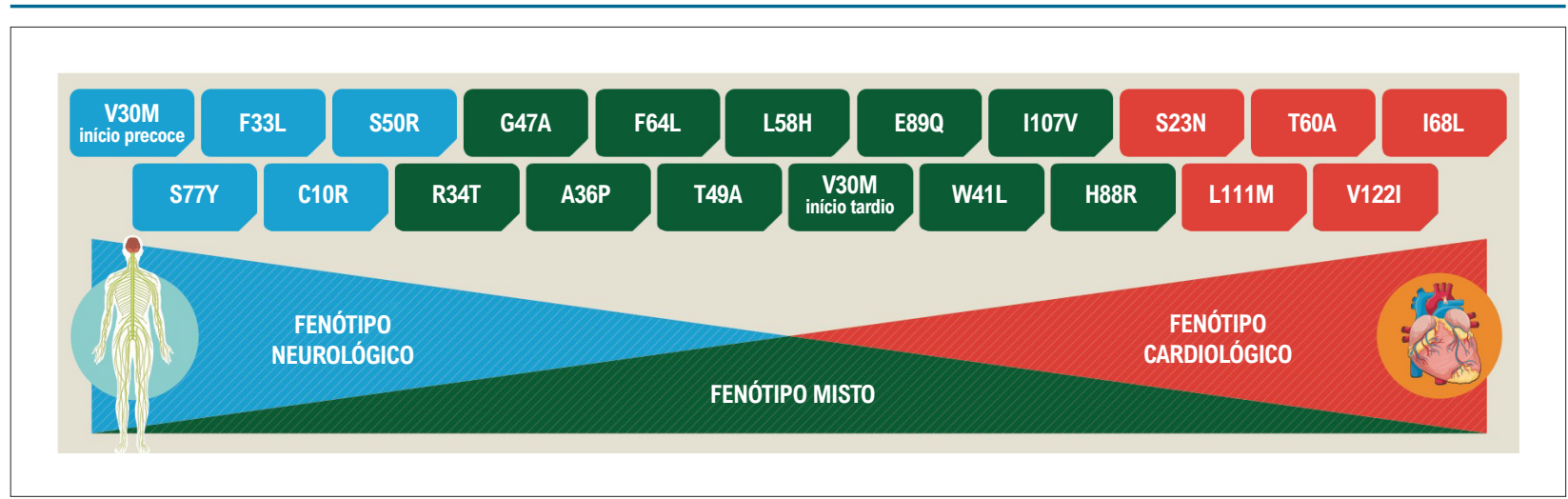

Figura 2 - Distribuição das diferentes mutações da ATTRv associadas a fenótipos neurológicos, cardiológicos ou mistos.

\section{Manifestações Cardiovasculares}

A AC cursa com infiltração da matriz extracelular cardíaca por fibrilas amiloides, resultando em um aumento progressivo da espessura da parede ventricular e aumento acentuado na rigidez da câmara, acarretando em comprometimento da função diastólica, levando à insuficiência cardíaca com fisiologia restritiva. ${ }^{37} \mathrm{~A}$ função sistólica também é comprometida, normalmente refletida por tensão longitudinal anormal, apesar de uma fração de ejeção normal, que pode se encontrar preservada até os estágios finais da doença. ${ }^{38-40}$ É frequente a infiltração amiloide atrial, levando à disfunção contrátil. Os depósitos também podem ocorrer nas válvulas cardíacas, geralmente sem causar disfunções importantes, e na região perivascular. ${ }^{3}$

Dessa forma, a manifestação clínica mais frequente é a síndrome de insuficiência cardíaca, mais comumente com fração de ejeção preservada (ICFEP), mas que pode evoluir com queda da fração de ejeção nas fases mais avançadas da doença. A síndrome clínica pode se apresentar com sintomas predominantes de IC esquerda, com congestão pulmonar (dispneia, ortopneia, dispneia paroxística noturna), ou sintomas de IC direita (edema, ascite, hematomegalia, aumento do volume abdominal, saciedade precoce, fadiga severa) ou ambos os conjuntos de sintomas. A amiloidose cardíaca deve ser considerada no diagnóstico diferencial da etiologia da ICFEP em homens idosos, ${ }^{41}$ particularmente quando a história pregressa de hipertensão arterial sistêmica (HAS) não é evidente ou há aumento da espessura do septo interventricular $\geq 12 \mathrm{~mm}$, levantando a possibilidade de miocardiopatia infiltrativa. ${ }^{21}$

Síncope e hipotensão ortostática são sintomas comuns e indicam a presença de disautonomia. Um aspecto clínico característico que pode levantar a suspeita de amiloidose é a necessidade de reduzir a dose ou descontinuar medicamentos anti-hipertensivos em pacientes com diagnóstico prévio de HAS, principalmente betabloqueadores e inibidores da enzima conversora da angiotensina/bloqueadores dos receptores de angiotensina. ${ }^{15}$

Pode ainda ocorrer infiltração amiloide causando doença do sistema de condução cardíaco desde as fases precoces da doença, com graus variáveis de bloqueio atrioventricular, resultando, em alguns casos, em bradicardia de alto risco, com necessidade de implante de marca-passo. Outra alteração importante é decorrente do endurecimento das paredes atriais, com taxas elevadas de arritmias atriais, incluindo a fibrilação atrial, e presença de trombos atriais, sendo o acidente vascular encefálico cardioembólico uma manifestação clínica comum, mesmo em indivíduos com ritmo sinusal. Arritmias ventriculares complexas parecem ser frequentes nas fases avançadas da doença, aspecto mais bem documentado na amiloidose AL.

\subsection{Elevação do Grau de Suspeita da Amiloidose Cardíaca}

A amiloidose cardíaca, particularmente na forma ATTR, é frequentemente subdiagnosticada por razões associadas à avaliação médica e por características da própria doença, incluindo: conhecimento fragmentado entre diferentes especialidades e subespecialidades, escassez de centros e especialistas dedicados ao manejo dessa doença, conhecimento equivocado acreditando-se ser uma doença rara e incurável, heterogeneidade fenotípica e genotípica nas formas ATTR. ${ }^{42}$ Vale ressaltar que o diagnóstico precoce da amiloidose cardíaca é fundamental, pois o prognóstico piora rapidamente com a deposição contínua da proteína amiloide e subsequente avanço da disfunção dos órgãos.

Dessa forma, o reconhecimento de "sinais de alerta" pode auxiliar na presunção do diagnóstico da amiloidose cardíaca nos pacientes com IC, ${ }^{35,43}$ sendo os mais relevantes resumidos na Tabela 2.

Síndrome do túnel do carpo bilateral é muitas vezes um dos primeiros indicadores de ATTR, é a manifestação não cardíaca mais comum e pode preceder os sintomas de insuficiência cardíaca em vários anos. Um estudo recente observou que aproximadamente $50 \%$ dos indivíduos com ATTRwt apresentava síndrome do túnel do carpo 5 a 7 anos antes do diagnóstico. ${ }^{44}$ Estenose lombar e ruptura atraumática do tendão do bíceps também foram identificados como manifestações clínicas de deposição extracardíaca na ATTRwt. A ruptura do tendão do bíceps pode estar presente em até 33\% dos casos de ATTRwt. ${ }^{45}$ Por outro lado, na forma AL, a presença de macroglossia e a púrpura periorbitária são altamente específicas, porém ocorrem em apenas $15 \%$ dos casos. ${ }^{46} \mathrm{~A}$ presença de polineuropatia sentitivo/motora ou disautonomia em pacientes com IC deve levantar a suspeita de AC. ${ }^{47,48}$ 
Tabela 2 - Pistas clínicas que podem levantar a suspeita de amiloidose cardíaca em pacientes com manifestações de insuficiência cardíaca

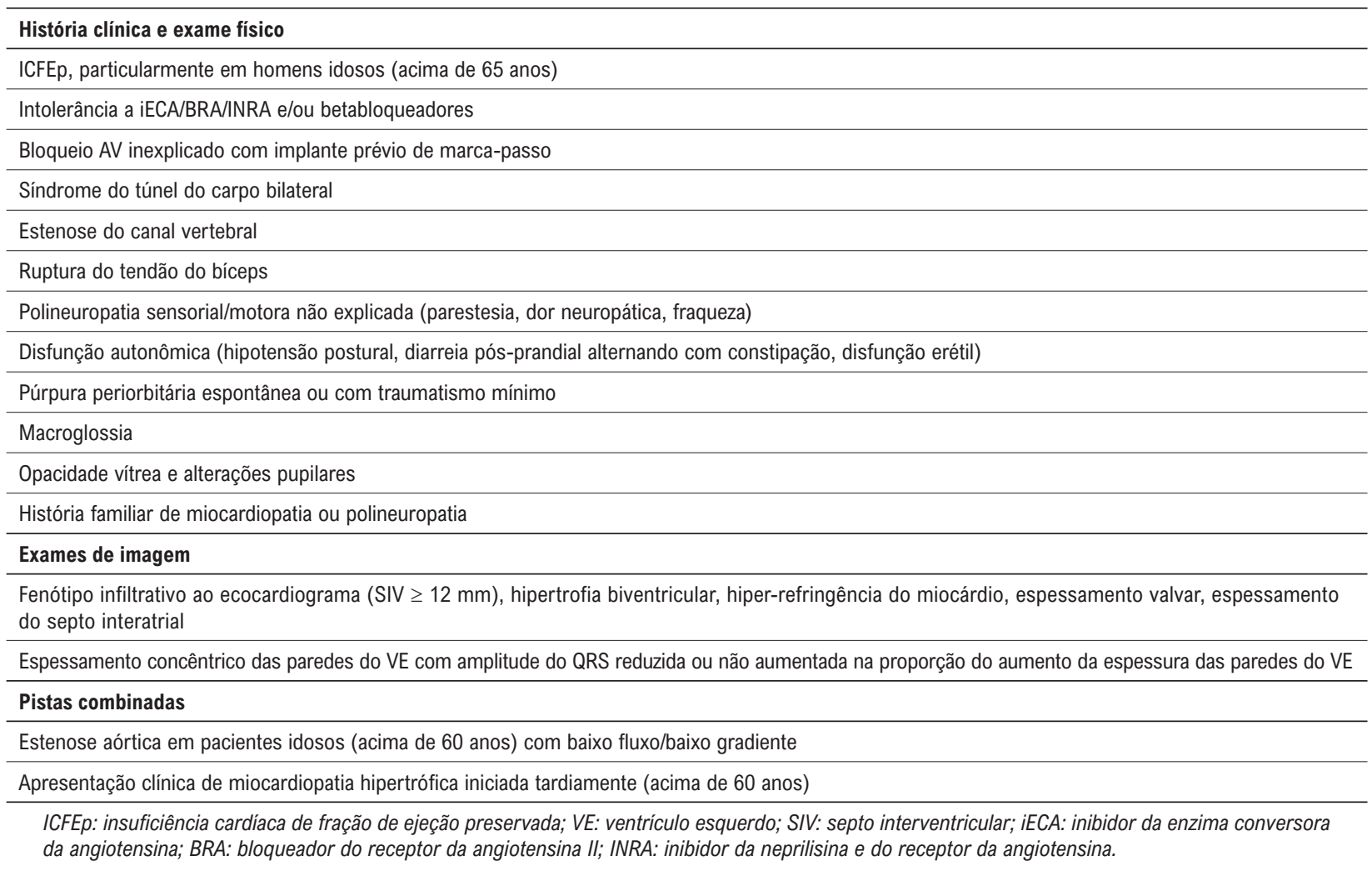

Outros sinais de alerta para a doença podem emergir de alterações típicas nos exames complementares cardiológicos de rotina, e são abordadas em tópicos específicos deste documento.

Vale salientar, ainda, que a amiloidose cardíaca pode muitas vezes apresentar-se simulando outras cardiopatias. A amiloidose deve ser considerada como uma das possíveis etiologias de pacientes que apresentam fenótipo de cardiomiopatia hipertrófica, particularmente se iniciada em fases tardias da vida (> 60 anos). O padrão assimétrico de hipertrofia miocárdica (HVE) nos pacientes com amiloidose ATTR difere dos pacientes com forma $A L$, geralmente simétrico. Em estudo de 263 pacientes com AC por ATTR confirmada e comparados com 50 pacientes com a forma $A L$, observou-se na forma ATTR presença de hipertrofia assimétrica em $79 \%$ dos casos, simétrica em $18 \%$ e 3\% sem HVE. ${ }^{49}$

Pacientes idosos portadores de estenose aórtica grave de baixo fluxo e baixo gradiente podem exibir AC em até 10\% a $15 \%$ dos casos, com prognóstico desfavorável. ${ }^{50}$

\section{Exames Complementares Diagnósticos}

\subsection{Eletrocardiograma}

O eletrocardiograma (ECG) é um exame essencial na avaliação diagnóstica e no planejamento terapêutico dos pacientes, sendo importante sua interpretação em conjunto com as informações clínicas e ecocardiográficas. Embora o achado de sinais de baixa voltagem ao ECG tenha grande especificidade no diagnóstico de infiltração miocárdica secundária à $A C$, este não é o achado mais prevalente na doença. A ausência de progressão de ondas $\mathrm{R}$ em derivações precordiais, simulando uma zona elétrica inativa anterosseptal (padrão de pseudoinfarto) é achado muito mais frequente, chegando à prevalência de $60 \%$ a $70 \%$ dos casos com diagnóstico confirmado, independentemente do tipo de amiloidose (Figura 3).

Nos casos de AC por ATTR, menos de $40 \%$ dos pacientes com diagnóstico confirmado por biópsia apresentam sinais de baixa voltagem ao ECG. ${ }^{51}$

Assim, a ausência de critérios de baixa voltagem ao ECG, ou mesmo a presença de sinais de sobrecarga de VE, não deve afastar a suspeita diagnóstica de AC, especialmente a ATTR. A desproporção da voltagem em relação à espessura miocárdica também é sinal de alerta importante e alcança prevalência de $73 \%$ a $80 \%$ em pacientes com AC, independentemente de seu tipo. ${ }^{52,53}$

Dentre as alterações do ritmo cardíaco, a fibrilação atrial é mais prevalente em pacientes com ATTR, assim como os bloqueios atrioventriculares.

\subsection{Ecocardiograma}

A ecocardiografia deve ser realizada em todos os pacientes com suspeita clínica da doença. Os achados clássicos de AC 


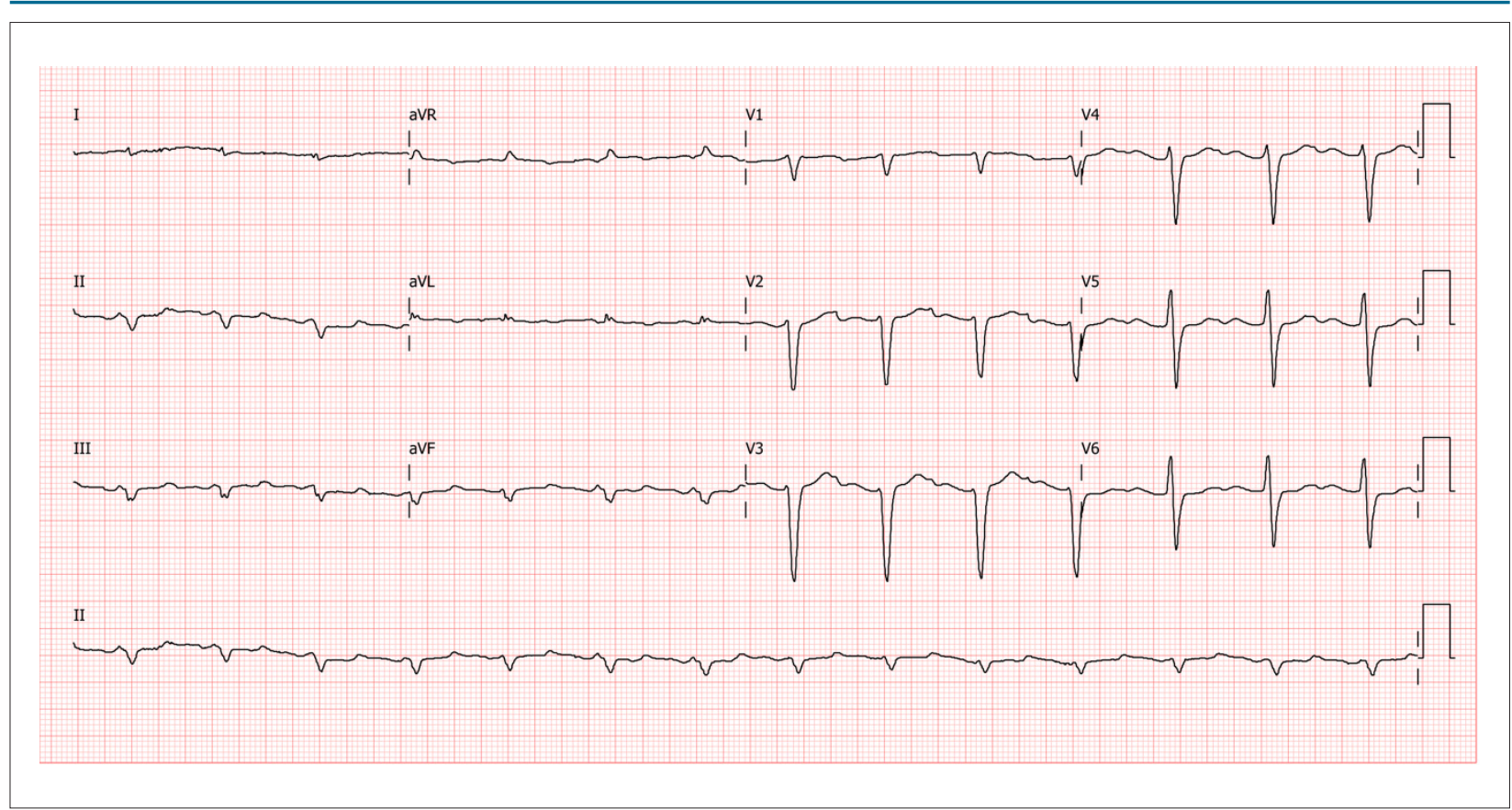

Figura 3 - Imagem ilustrativa de eletrocardiograma (ECG) de paciente com amiloidose cardíaca (AC) forma ATTRwt, mostrando baixa voltagem em derivações periféricas, ausência de progressão de R em derivações precordiais V1 a V3 (padrão de pseudoinfarto) e BAV de I grau. (Imagem de arquivo pessoal dos autores)

geralmente estão presentes em uma fase avançada da doença e englobam as características de uma cardiomiopatia restritiva, do tipo infiltrativa. As dimensões do ventrículo esquerdo (VE) não são aumentadas, os volumes são normais ou reduzidos e há aumento da espessura de paredes ventriculares. O aumento de dimensões atriais é comum, refletindo uma disfunção diastólica precoce e progressiva, com aumento das pressões de enchimento. As valvas atrioventriculares podem estar espessadas e as regurgitações valvares (mitral e tricúspide) são funcionais. Pode, ainda, haver sinais sugestivos de infiltração do septo interatrial e também elevação da pressão sistólica da artéria pulmonar. O ventrículo direito também pode estar acometido. É muito comum a presença de derrames pleurais e pericárdicos e, em casos em que há intensa infiltração tecidual, é possível observar o clássico, embora subjetivo, aspecto granular da imagem de paredes miocárdicas (granular sparkling) (Figura 4) $)^{35,54}$

Na AC, a fração de ejeção do VE (FEVE) permanece normalmente preservada até os estágios mais avançados da doença, mas a função contrátil longitudinal é reduzida precocemente. ${ }^{55}$ Quantitativamente, a função sistólica pode ser avaliada pelo modo 2D (bidimensional), utilizando cálculo de volumes e FEVE e por técnicas derivadas do Doppler como a estimativa do $\mathrm{dP} / \mathrm{dT}$ do ventrículo esquerdo. ${ }^{56}$

A avaliação do padrão de enchimento diastólico dos ventrículos é essencial e frequentemente demonstra algum grau de disfunção diastólica. Nas fases iniciais, é possível observar alterações compatíveis com disfunção diastólica tipo I (inversão da relação das ondas E/A do influxo mitral, prolongamento do tempo de relaxamento isovolumétrico e diminuição da rampa de desaceleração diastólica inicial. No registro das velocidades miocárdicas pelo Doppler tissular, observa-se redução da velocidade da onda e') (Figura 5).

Com a progressão da doença, pode se instalar padrão pseudonormal de disfunção diastólica (relação E/A preservada e pelo tempo de desaceleração normal) por consequência da elevação da pressão no átrio esquerdo.

$\mathrm{Na}$ fase mais adiantada da doença, observa-se o padrão restritivo do enchimento ventricular (aumento da relação E/A $>2$, diminuição do tempo de relaxamento e acentuação da inclinação da rampa de desaceleração da onda E).

O estudo da deformação miocárdica permite identificar, precocemente em relação à FEVE, sinais de disfunção miocárdica. ${ }^{57-59} \mathrm{~A}$ deformação sistólica global longitudinal (GLS) - função predominantemente exercida pelo endocárdio - encontra-se precocemente reduzida. ${ }^{60} \mathrm{O}$ padrão regional da deformação miocárdica também está frequentemente alterado apresentando o padrão de apical sparing, ${ }^{61,62}$ traduzido como o padrão de "cereja do bolo". A melhor visualização desse aspecto é possível na imagem paramétrica do VE, conhecida como bulls eye (Figura 6).

Outras análises da deformação miocárdica - tais quais a capacidade em estudar a função sistólica de $\mathrm{VD}^{63}$ a função atrial ${ }^{65} \mathrm{e}$, ainda, estimar o trabalho sistólico miocárdico ${ }^{59}$-têm sido aplicadas a pacientes com AC e vêm demonstrando boa acurácia diagnóstica.

\subsection{Ressonância Magnética Cardíaca}

A ressonância magnética cardiovascular (RMC) dispõe de técnicas que permitem avaliar de forma precisa as alterações 


\section{Posicionamento}
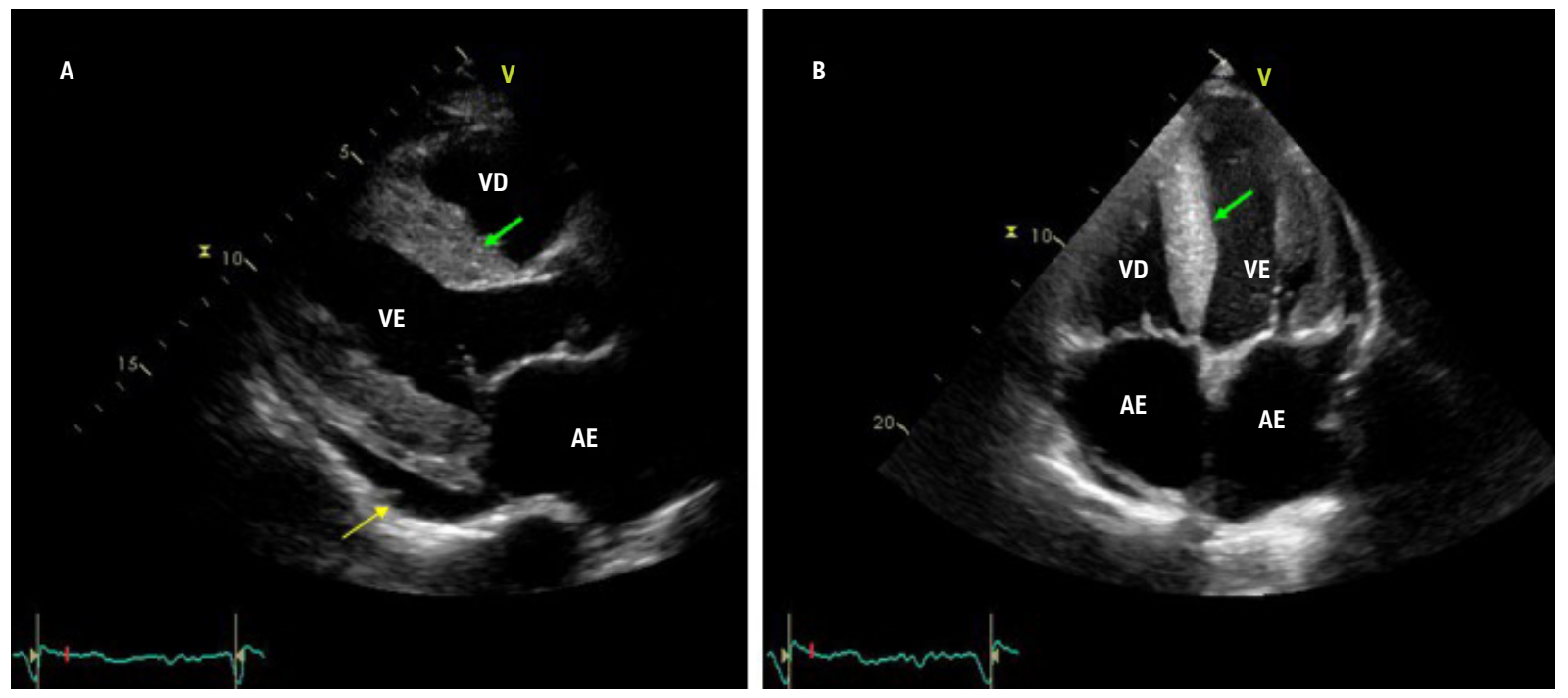

Figura 4-Apresentação ecocardiográfica clássica de amiloidose cardíaca (AC). Em A, a projeção paraesternal longitudinal apresenta o ventrículo esquerdo (VE) de tamanho normal, mas com espessura de paredes aumentada e aspecto granulado em septo interventricular (seta verde). Há, ainda, sinais de aumento do átrio esquerdo (AE) e leve derrame pericárdico (seta amarela). Em B, a projeção apical 4c evidencia os átrios grandes, ventrículos de dimensões normais e aumento de espessura de paredes, também com aspecto granulado do septo interventricular (seta verde). As valvas mitral e tricúspide são levemente espessadas. VE: ventrículo esquerdo; VD: ventrículo direito; AD: átrio direito. (Imagens de arquivo pessoal dos autores).

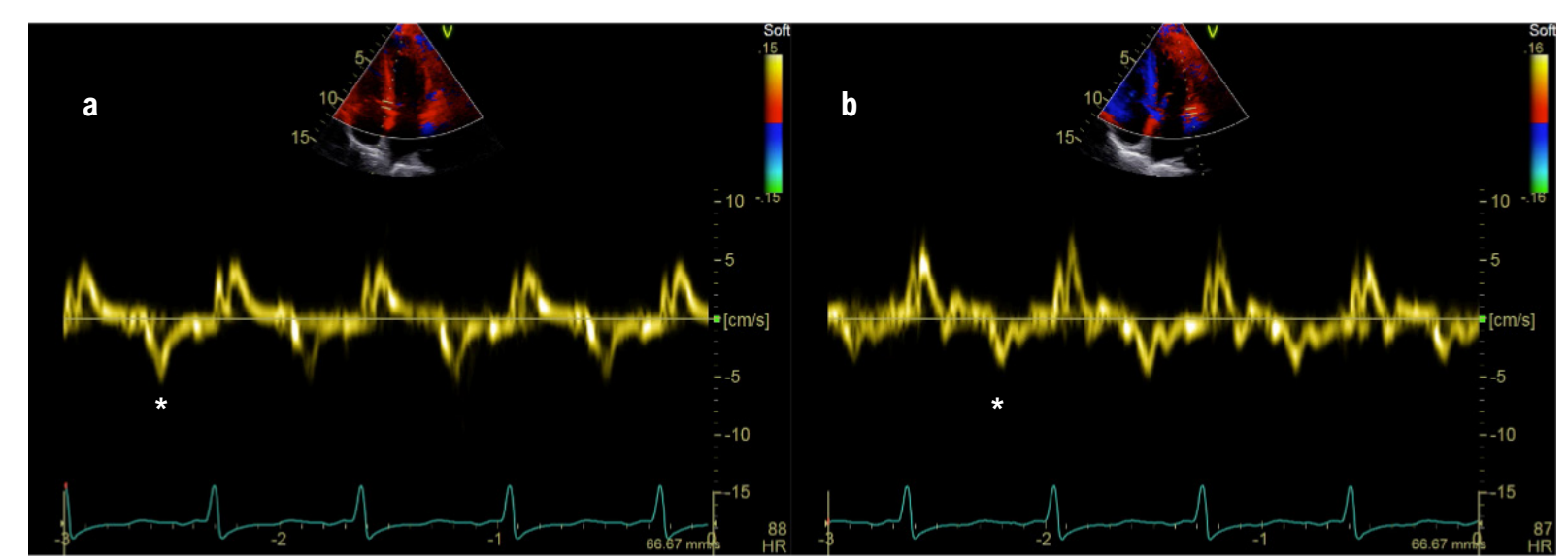

Figura 5 - Imagens de Doppler tecidual em anel mitral. Há redução da velocidade da onda e'( $\left.{ }^{*}\right)$ tanto no Doppler tecidual do anel mitral medial (a) quanto no do lateral (b). Ambas as velocidades se encontram abaixo de $4 \mathrm{~cm} / \mathrm{s}(V R>8 \mathrm{~cm} / \mathrm{s})$. (Imagens de arquivo pessoal dos autores).

teciduais miocárdicas que ocorrem na AC. ${ }^{65}$ Classicamente, o depósito de miofibrilas leva ao aumento de espessura da parede miocárdica do VE e do septo interatrial, que podem ser visualizadas pelas técnicas morfológicas de RMC. ${ }^{66,67}$ Outra alteração tecidual é o aumento do conteúdo total de água no miocárdio, que pode ser derivado do aumento do volume extracelular (VEC) causado diretamente pelo depósito proteico e sua atração osmótica de água, assim como o aumento de água intracelular em miócitos sofrendo a agressão citotóxica do depósito ou mesmo diminuição da perfusão miocárdica (distância aumentada dos capilares e/ou obstrução destes pelo depósito).
O aumento global de água tecidual miocárdica leva a aumento dos tempos médios de relaxamento do hidrogênio, sejam eles T1 (longitudinal) ou T2 (transversal). ${ }^{68}$ No entanto, a alteração tecidual miocárdica mais dramática e relevante na AC é o aumento extremo do VEC miocárdico, causado nas fases clínicas da doença, não só pelo depósito de fibrilas amiloides, mas também pela fibrose miocárdica de reparação.

Assim, o conjunto do depósito de miofibrilas e fibrose intersticial pode ser facilmente detectado de forma muito precisa, e até mesmo quantificado pelas técnicas de realce tardio $(\mathrm{RT})^{67,69}$ e cálculo do volume extracelular do 


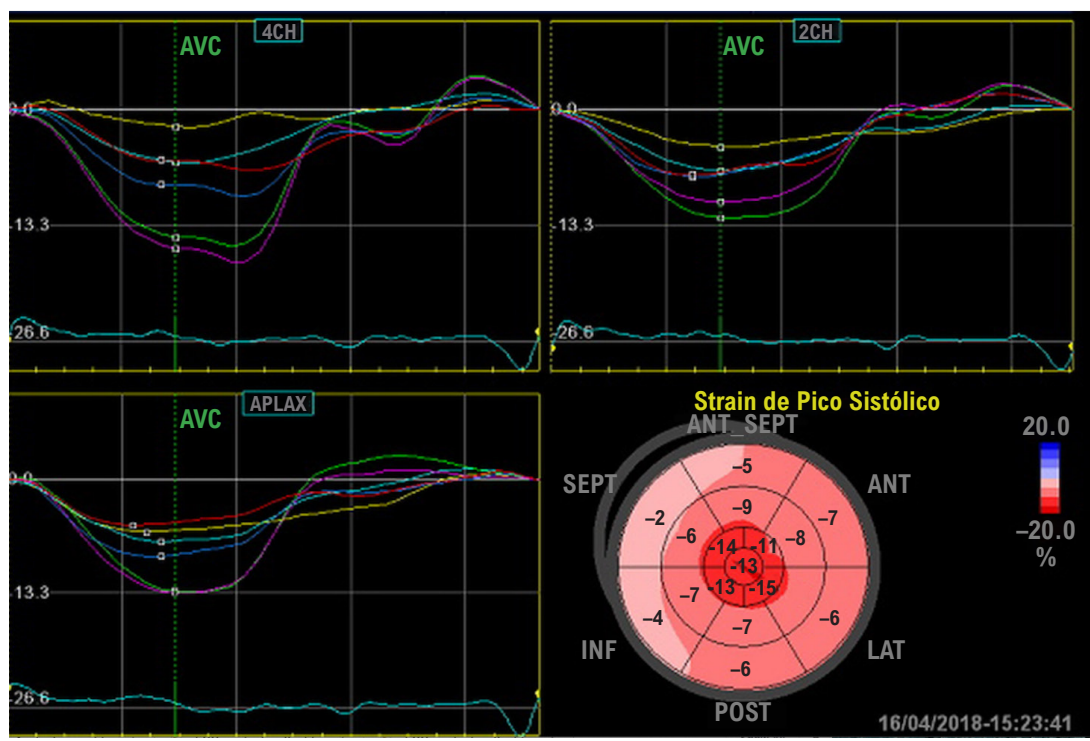

Figura 6 - Análises da deformação miocárdica global e regional de VE em paciente com amiloidose cardiaca, mostrando a representação gráfica paramétrica, conhecida como bulls eye, demonstram os segmentos apicais em vermelho-escuro (valores preservados), e os segmentos basais em vermelho-claro (valores reduzidos) com o padrão de "cereja no bolo". (Imagem de arquivo pessoal dos autores).

miocárdio. ${ }^{70-72}$ Apenas como exemplo inicial, valores de espaço extracelular do miocárdio normal estão em torno de $25 \%$, enquanto, na AC, pode atingir valores tão altos quanto $60 \%$ (principalmente na ATTR). ${ }^{72,73}$

O contraste utilizado na RMC baseia-se em gadolínio que, por sua vez, é ligado a um quelante macromolecular que não permite sua passagem pela membrana celular íntegra, distribuindo-se assim exclusivamente no VEC do miocárdio. A imagem de RT permite levantar a suspeita de AC pelo seu padrão de distribuição (global subendocárdico, não envolvimento apical do VE e de distribuição que não respeita território vascular coronariano). ${ }^{67}$

\subsubsection{Avaliação da Morfologia e da Função Cardíaca}

A AC pode modificar a aparência de todas as câmaras cardíacas. ${ }^{74,75}$ Desde as etapas iniciais, podem ser observadas alterações no plano atrial, com dilatação daquelas cavidades e aparente espessamento do septo interatrial que, na maior parte das vezes, é composta por gordura. ${ }^{74} \mathrm{Em}$ etapas mais adiantadas de comprometimento cardíaco, quando há diminuição da função atrial, observam-se sinais de fluxo lento e de trombos no apêndice atrial esquerdo, que podem não ser observados à ressonância no caso de haver artefatos de ritmo e de não se utilizarem séries específicas para este fim.

A AC também é habitualmente associada à presença de aumento da espessura miocárdica, que é, na maior parte das vezes, mais expressiva do que nos casos secundários à hipertensão, e a espessura do músculo cardíaco geralmente é maior nos casos de ATTR do que nos casos AL. ${ }^{52,76}$ Este aumento de espessura pode ser concêntrico ou excêntrico, ${ }^{74,75}$ e pode envolver o ventrículo direito. ${ }^{74,75}$ Durante muito tempo, a fração de ejeção pode estar preservada, e as modificações mais precoces da função ventricular incluem restrição diastólica e alterações da deformidade ventricular (strain). ${ }^{75,76}$

Em consequência da disfunção diastólica, não é raro observar derrame pericárdico ou pleural. ${ }^{74}$ As características morfológicas avaliadas pela ressonância (Figura 7) são úteis e podem sugerir o diagnóstico; contudo, na maior parte das vezes, há a necessidade de se realizar a caracterização tecidual, pelas técnicas de realce tardio e de mapa T1, como discutiremos em outras seções deste documento.

\subsubsection{Avaliação pelo Realce Tardio}

A técnica de RT após injeção do contraste gadolínio tem sido amplamente reconhecida como um dos pilares no diagnóstico por imagem da AC. ${ }^{77,78} \mathrm{O}$ contraste de gadolínio ao atravessar o espaço intersticial no tecido normal não sofre atrasos e rapidamente o deixa, ficando o tecido normal escuro. Em casos em que há presença de deposição amiloide no espaço intersticial, este passa a reter o trânsito do contraste à base de gadolínio, e o miocárdio brilha (realce) nas sequências dedicadas, e foi demonstrada correlação anatomopatológica. ${ }^{65}$ Foram descritos padrões de infiltração amiloide: subendocárdico, transmural e focal, sendo este último menos frequente (Figura 8). ${ }^{67}$ Metanálise recente estabeleceu em $85 \%$ a sensibilidade e em $92 \%$ a especificidade do realce tardio na amiloidose. ${ }^{79}$

Em série com 250 pacientes com amiloidose de distintas formas, a presença de RT com padrão transmural esteve associada a um risco de morte 5,4 vezes maior (IC:2,1-13,7; $\mathrm{p}<0,0001) .{ }^{80}$ Além disso, o RT apresenta efeito prognóstico incremental aos marcadores cardíacos na $\mathrm{AC}$ forma $\mathrm{AL}^{81}$ ou de forma isolada. ${ }^{82}$ 


\section{Posicionamento}

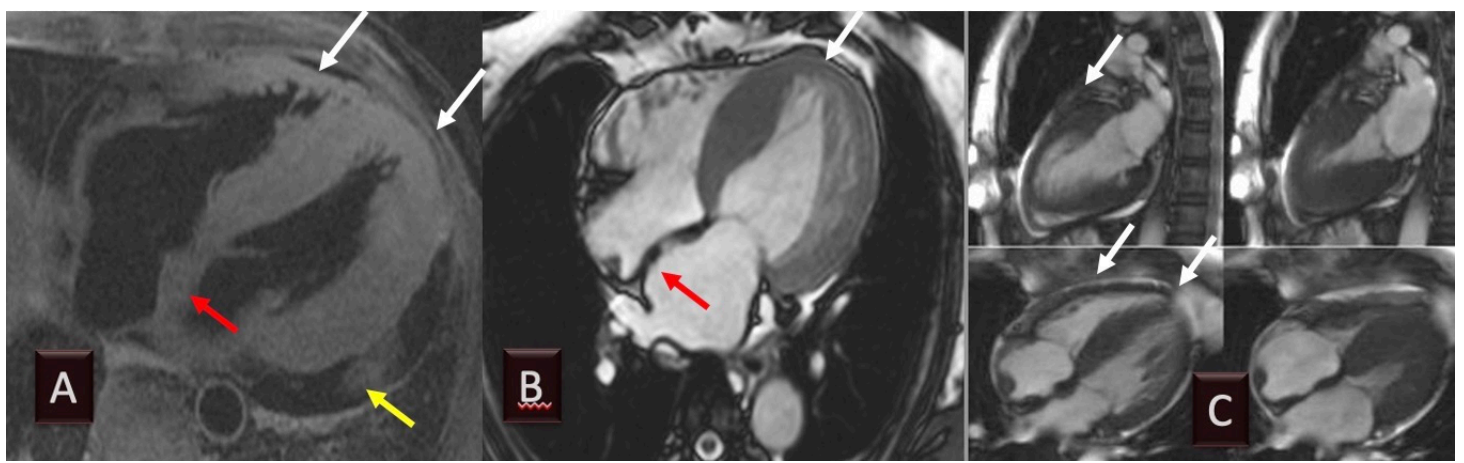

Figura 7 - Exemplo de RMC de pacientes com amiloidose por TTR, mostrando derrame pericárdico (A, seta amarela e C), aumento das dimensões dos átrios ( $A$ e $B$ ), aumento da espessura do septo interatrial ( $A$ e $B$, setas vermelhas) e das paredes ventriculares ( $A$ a $C$, setas brancas). A função diastólica é diminuída, mas a contratilidade pode estar preservada até as fases mais avançadas da doença. (Imagem de arquivo pessoal dos autores).

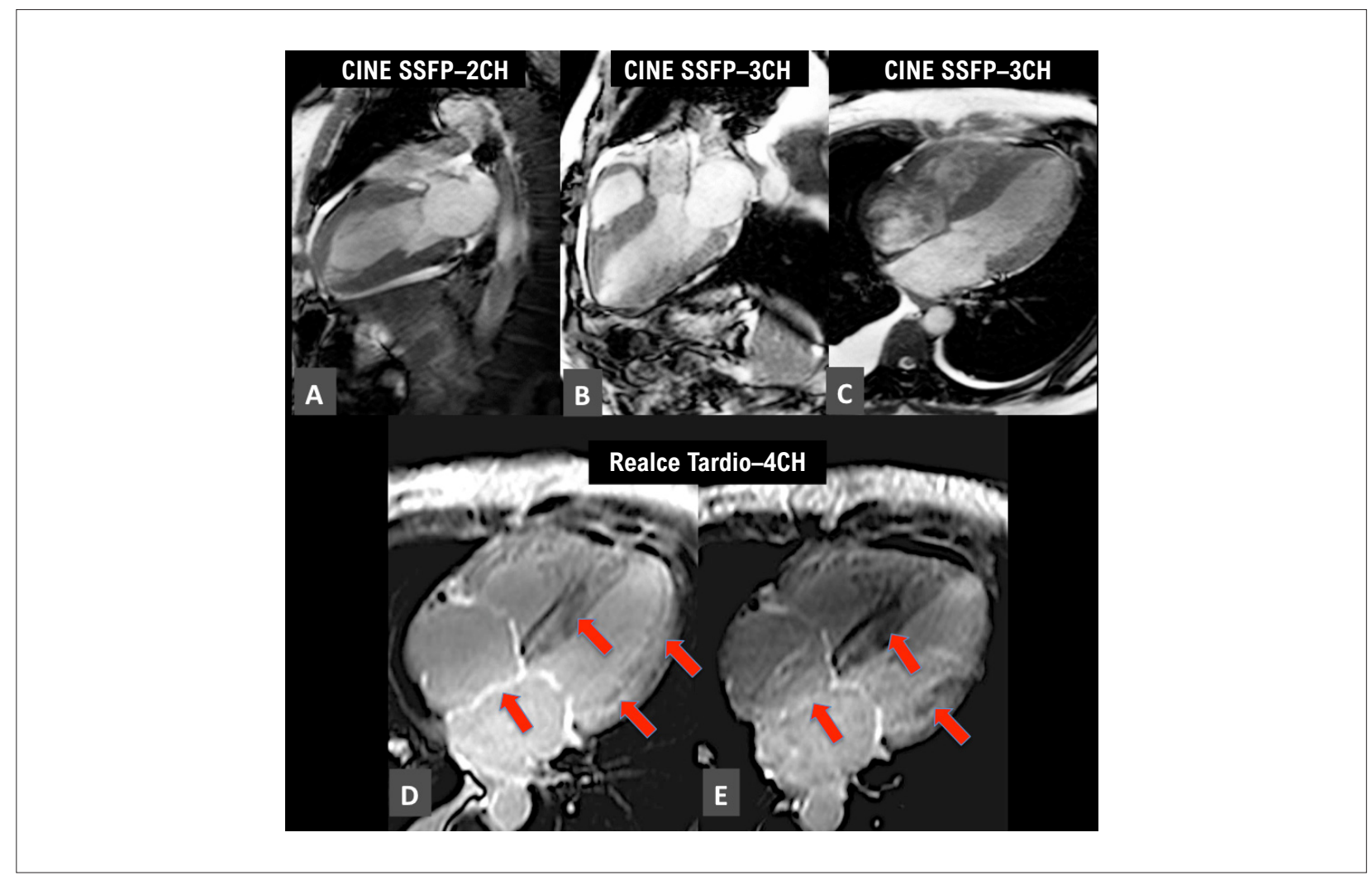

Figura 8 - Exemplo de paciente com amiloidose tipo TTR com hipertrofia concêntrica de ventrículo esquerdo (VE) e aumento de ambos os átrios nas imagens em cine ( $A$ a C). Realce tardio apresenta padrão predominantemente transmural difuso (setas vermelhas, D e E). (Imagem de arquivo pessoal dos autores).

\subsubsection{Mapas de $\mathrm{T} 1$}

Diferentes grupos têm investigado a utilidade de mapas de T1 derivados da RMC para melhorar o desempenho diagnóstico e prognóstico na AC..$^{70,71,73,83,84}$ Tanto os dados de T1 nativo, que não necessitam de administração de contraste, assim como os dados de VEC, têm identificado com eficácia pacientes com AC, mostrando valores marcadamente elevados para o T1 nativo e VEC comparado a pacientes-controles saudáveis ${ }^{70,73,83}$ - alterações que podem ser detectadas antes da presença de RT. ${ }^{70,72,73}$ Portanto, combinar mapeamento T1 nativo e medições de VEC pode ajudar a delinear a carga amiloide e confirmar o diagnóstico de AC.$^{85,86}$ 


\subsection{Cintilografia Cardíaca com Radiotraçadores Ósseos}

Os radiotraçadores marcados com tecnécio-99m derivados do bifosfonato, originalmente desenvolvidos para imagens ósseas, encontraram um novo papel como ferramenta diagnóstica não invasiva da AC por ATTR. ${ }^{1-7}$ As imagens com radiotraçadores ósseos permitem, de modo seguro, o diagnóstico não invasivo de AC por ATTR, uma vez excluída a presença de gamopatia monoclonal. ${ }^{91}$

Os principais radiotraçadores ósseos marcados com ${ }^{99 m}$ TC utilizados para o diagnóstico da AC por ATTR são o ${ }^{99 m}$ Tc-pirofosfato, o ${ }^{99 m}$ Tc-DPD (ácido 3,3-difosfono-1,2-propanodicarboxílico) e o ${ }^{99 \mathrm{~m} T c-H M D P}$ (hidroximetilenodifosfonato marcado com ${ }^{99 m} \mathrm{TC}$ ). ${ }^{1-7}$ O ${ }^{99 m}$ Tc-pirofosfato é o único disponível no Brasil. É importante ressaltar que o ${ }^{99 \mathrm{~m}} \mathrm{Tc}-\mathrm{MDP}$ (metilenodifosfonato marcado com ${ }^{99 \mathrm{~m}} \mathrm{Tc}$ ), apesar de comprovadamente eficiente para a realização da cintilografia óssea, apresenta baixa sensibilidade para o diagnóstico da AC por ATTR e não deve ser usado para esta finalidade. ${ }^{89}$

Embora o componente estrutural do depósito amiloide ao qual o ${ }^{99 \mathrm{~m}}$ Tc-pirofosfato se liga no coração não seja conhecido, um mecanismo de captação cálcio-dependente é amplamente aceito. ${ }^{93} \mathrm{Em}$ animais, verificou-se a existência de vários sítios de ligação: microcalcificações, depósitos de cálcio, pirofosfato intracelular e macromoléculas intracelulares. Provavelmente, o mecanismo de captação de ${ }^{99 m}$ Tc-pirofosfato no miocárdio esteja relacionado à presença de microcalcificações. ${ }^{88}$ A AC por ATTR apresenta mais microcalcificações que a AL e apresenta maior captação de ${ }^{99 m}$ Tc-pirofosfato, enquanto a amiloidose cardíaca $\mathrm{AL}$ tem mínima ou nenhuma avidez pelos radiotraçadores ósseos; além disso, a AC por ATTR apresenta evolução mais indolente, o que propicia mais microcalcificações e, consequentemente, maior acúmulo do radiotraçador.

Embora os achados do ecocardiograma e da RMC possam ser indicativos de $\mathrm{AC}$, eles não são capazes de diferenciar a forma ATTR da forma AL. Esta é a principal vantagem da cintilografia cardíaca com ${ }^{99 \mathrm{~m} T c-p i r o f o s f a t o: ~ u m ~}$ método simples, de fácil execução, amplamente disponível, com baixa dosimetria, capaz de diferenciar de forma não invasiva e com alta especificidade a AC por ATTR da AL, orientando assim a conduta. Esta diferenciação é útil, pois as formas AL e ATTR têm implicações prognósticas e terapêuticas completamente diversas.

O papel dos radiotraçadores ósseos na ATTR foi recentemente reavaliado por um grupo internacional de vários centros com expertise em AC: em análise cumulativa de 1.217 pacientes, sendo 867 com amiloidose confirmada por biópsia e 360 portadores de cardiomiopatia não amiloide, a cintilografia foi altamente sensível (99\%) e específica (86\%) para ATTR. ${ }^{19}$ Neste estudo, demonstrou-se ainda que o achado combinado de uma cintilografia com radiotraçador ósseo positiva em pacientes sem evidência de proteína monoclonal detectável na urina ou soro (utilizando medida sérica de cadeias leves livres e eletroforese com imunofixação) foi 100\% específica para AC por ATTR, levando os autores a concluir que a cintilografia permite a detecção de modo acurado sem a necessidade de biópsia cardíaca. ${ }^{19}$ Outro estudo recente com casos agrupados de três centros dos EUA mostrou que, entre um total de 171 pacientes (121 ATTR, 34 AL e 16 ICFEP não amiloide), ${ }^{99 m}$ Tc-pirofosfato apresentou sensibilidade de $88 \%$ e especificidade de $88 \%$ para ATTR quando se utilizou apenas a avaliação visual (escore $\geq 2$ ) ${ }^{94}$ Quando se utilizou a análise semiquantitativa (relação de contagens coração/contralateral $>1,6$ ), a sensibilidade foi de $91 \%$ e a especificidade, $92 \%$, para a detecção de ATTR. Além disso, ao levar em conta todas as variáveis, uma relação de contagens coração/contralateral $\geq 1,6$ foi preditiva de pior prognóstico, ou seja, associada com pior sobrevida em pacientes com AC por ATTR ${ }^{94}$ Vraniam et al. ${ }^{95}$ também demonstraram que, em pacientes com suspeita de AC, a intensidade de captação cardíaca de ${ }^{99 m} \mathrm{Tc}$-pirofosfato foi preditiva de mortalidade geral e hospitalização por IC. Nesses estudos, a combinação da intensidade de captação do radiotraçador no miocárdio (relação coração/contralateral) com variáveis anatômicas, funcionais e biomarcadores melhorou a estratificação de risco.

\subsubsection{Aspectos Técnicos Recomendados para Aquisição} das Imagens

Não é necessário preparo. As imagens são obtidas após a administração venosa de 10 a 25 mCi (370 a $925 \mathrm{Mbq}$ ) de ${ }^{99 \mathrm{~m}} \mathrm{Tc}$-pirofosfato (dosimetria: 3,2 mSv para corpo inteiro para $15 \mathrm{mCi}$ ). Imagens planas e tomográficas do tipo SPECT (single photon emission computed tomography) do tórax são realizadas 1 e $3 \mathrm{~h}$ após a administração do radiofármaco.

- Imagens planas do tórax: podem ser obtidas nas projeções anterior, oblíqua anterior esquerda e lateral esquerda, utilizando o fotopico do ${ }^{99 \mathrm{~m} T c}$ (140 keV, janela de 15\%), colimador de baixa energia/alta resolução e matriz de $256 \times 256,500-750$ mil contagens.

- Imagens SPECT do tórax: obtidas com matriz de 128×128 (64×64 é aceitável), rotação de 180 graus de oblíqua anterior direita a oblíqua posterior esquerda (360 graus é aceitável), 1 imagem a cada 3 a 6 graus. Se disponíveis, imagens SPECT/CT (SPECT associado à tomografia computadorizada) proporcionam maior segurança na interpretação das imagens.

- Imagens mínimas recomendadas: SPECT de $1 \mathrm{~h}$ e imagens planas de 1 e $3 \mathrm{~h}$ na projeção anterior. Recomenda-se a utilização de imagens SPECT, para diferenciar captação difusa no miocárdio de persistência do radiofármaco no pool sanguíneo, captação focal por infarto do miocárdio e sobreposição óssea. Além disso, imagens planas de 1 e 3 h são úteis para a quantificação e para acompanhar o whashout do pool sanguíneo, que é variável, sendo, por exemplo, bem mais lento em pacientes com insuficiência renal.

\subsubsection{Análise das imagens}

- Análise semiquantitativa (imagem plana de 1h): a análise semiquantitativa foi definida para o radiofármaco ${ }^{99 m}$ Tc-pirofosfato como sendo a razão entre a captação na projeção cardíaca e a captação no hemitórax contralateral, medidas na imagem plana de $1 \mathrm{~h}$ na 
incidência anterior. Para isso, é desenhada uma área de interesse (AI) circular (ou elíptica) sobre a projeção cardíaca, sem incluir o esterno, evitando a inclusão tanto do pulmão adjacente como de áreas de hipercaptação focal em arcos costais. Uma Al idêntica ("em espelho") é colocada no hemitórax contralateral, com os mesmos cuidados. As contagens no interior da Al cardíaca dividem-se pelas contagens da $\mathrm{Al}$ contralateral, obtendo-se, assim, a relação $\mathrm{C} / \mathrm{CL}$ (coração/contralateral). $\mathrm{A} C / \mathrm{CL} \geq 1,5$ à $1 \mathrm{~h}$ identifica ATTR com elevada acurácia, caso a amiloidose AL sistêmica tenha sido excluída ${ }^{90,91}$ (Figura 9).

- Graduação visual (imagem de 3h): a graduação visual é feita comparando-se a captação cardíaca com a captação fisiológica nos arcos costais adjacentes, e pode ser realizada tanto nas imagens planas na projeção anterior como nas imagens SPECT ou mesmo nas imagens de corpo inteiro, obtidas $3 \mathrm{~h}$ após a injeção do radiofármaco. A intensidade da captação é numericamente definida como grau 0 (sem captação miocárdica), 1 (captação miocárdica inferior à dos arcos costais adjacentes), 2 (captação semelhante à dos arcos costais) e 3 (superior à dos arcos costais). Intensidades de captação graus 2 ou 3 são fortemente sugestivas de ATTR, se gamopatia monoclonal tiver sido excluída (Figura 9).

\subsubsection{Falso-positivos para ATTR}

As características operacionais diagnósticas da cintilografia com traçadores ósseos são muito favoráveis para o seu uso clínico, com uma especificidade de 100\% para o diagnóstico de ATTR quando a captação é de intensidade 2 ou 3, na ausência de gamopatia monoclonal. Entretanto, é sempre necessário enfatizar que falhas em excluir gamopatia monoclonal (quer por uso inadequado ou interpretação falha dos exames laboratoriais) implicam risco de diagnósticos imprecisos. A causa mais comum de diagnóstico errôneo de ATTR é a amiloidose AL. Estudos recentes apontam que até $22 \%$ dos pacientes com AC da forma AL podem apresentar captação grau 2 ou 3 na cintilografia com ${ }^{99 m}$ Tc-pirofosfato. ${ }^{6}$ Também é importante lembrar que a utilização de imagens cintilográficas tomográficas (SPECT) é crucial na diferenciação de captação miocárdica anormal de captação residual no pool sanguíneo (Figura 10). A Tabela 3 lista as principais causas de falso-positivo com uso da cintilografia com ${ }^{99 m}$ Tc-pirofosfato

Finalmente, é importante considerar que o estudo cintilográfico não é recomendado para o seguimento dos pacientes, visto que, até o momento, não se evidenciou correlação entre a alteração no padrão evolutivo das imagens e progressão da doença ou a resposta ao tratamento. ${ }^{87,90}$

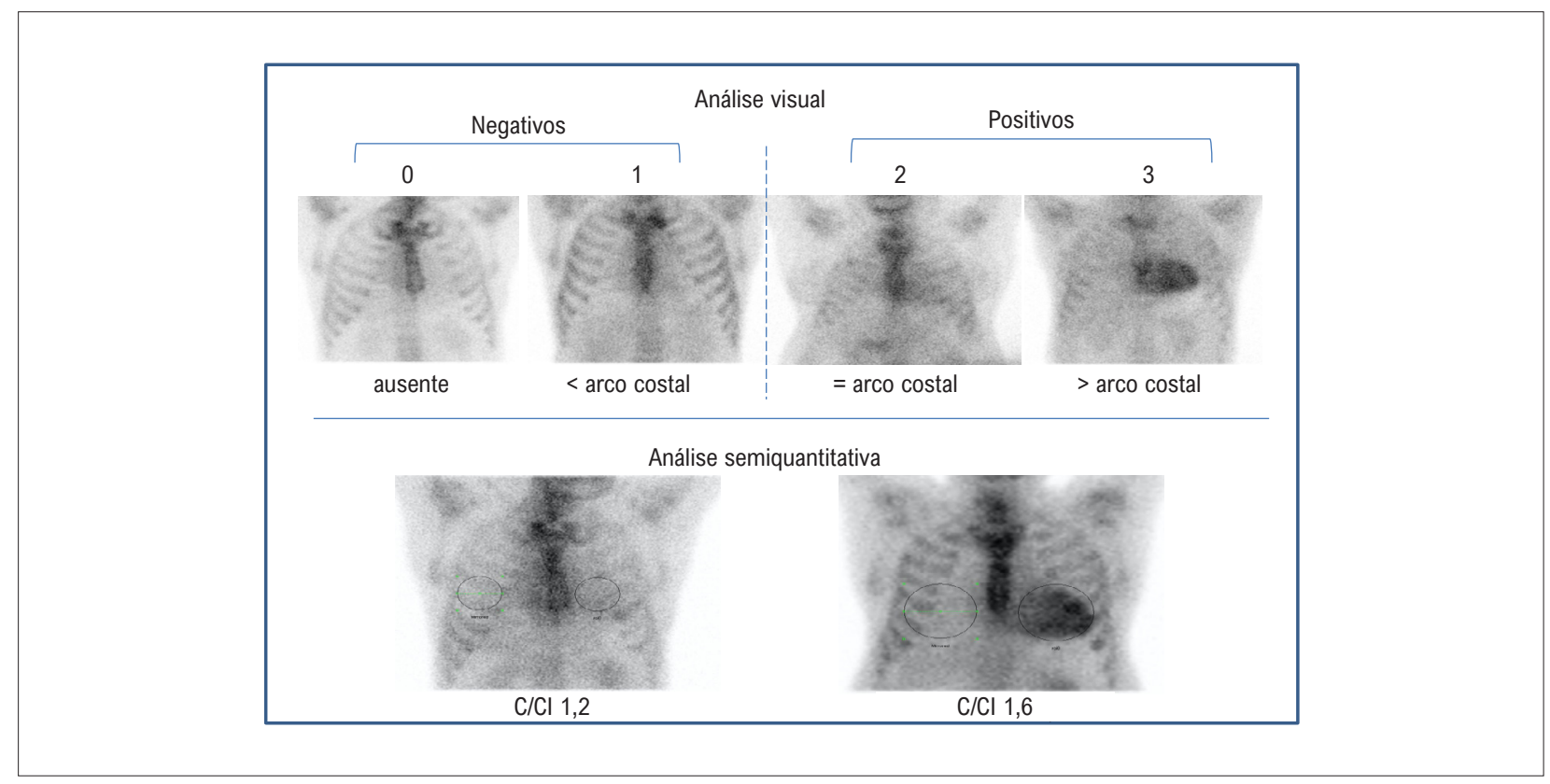

Figura 9 - Cintilografias cardiacas com ${ }^{99} \mathrm{mTc}$-pirofosfato em pacientes com suspeita de amiloidose cardíaca (imagens planas na incidência anterior do tórax obtidas 3h após a administração do radiofármaco) mostrando exemplos de casos negativos e positivos para amiloidose cardíaca por ATTR. Análise visual: imagens à esquerda: casos negativos para ATTR (análise visual graus 0 e 1); imagens à direita: casos positivos para ATTR (análise visual graus 2 e 3). Análise semiquantitativa: à esquerda, caso negativo para AC por ATTR (relação coração/contralateral = 1,2 - nesse caso, as imagens de SPECT mostraram atividade no pool sanguíneo e não nas paredes do coração); à direita, caso positivo para ATTR (relação coração/contralateral = 1,6 - com imagens de SPECT que confirmaram captação nas paredes do VE). Na interpretação visual, valoriza-se para diagnóstico da ATTR a intensidade de captação cardíaca igual (grau 2) ou maior (grau 3) que intensidade de captação nos arcos costais. Na análise semiquantitativa, a relação de contagens coração/contralateral $\geq 1,5$ nas imagens de $1 \mathrm{~h}$ e $\geq 1,3$ nas imagens de $3 \mathrm{~h}$ são consideradas altamente sugestivas de ATTR, quando confirmadas pelas imagens de SPECT. (Imagens de arquivos pessoais dos autores) 

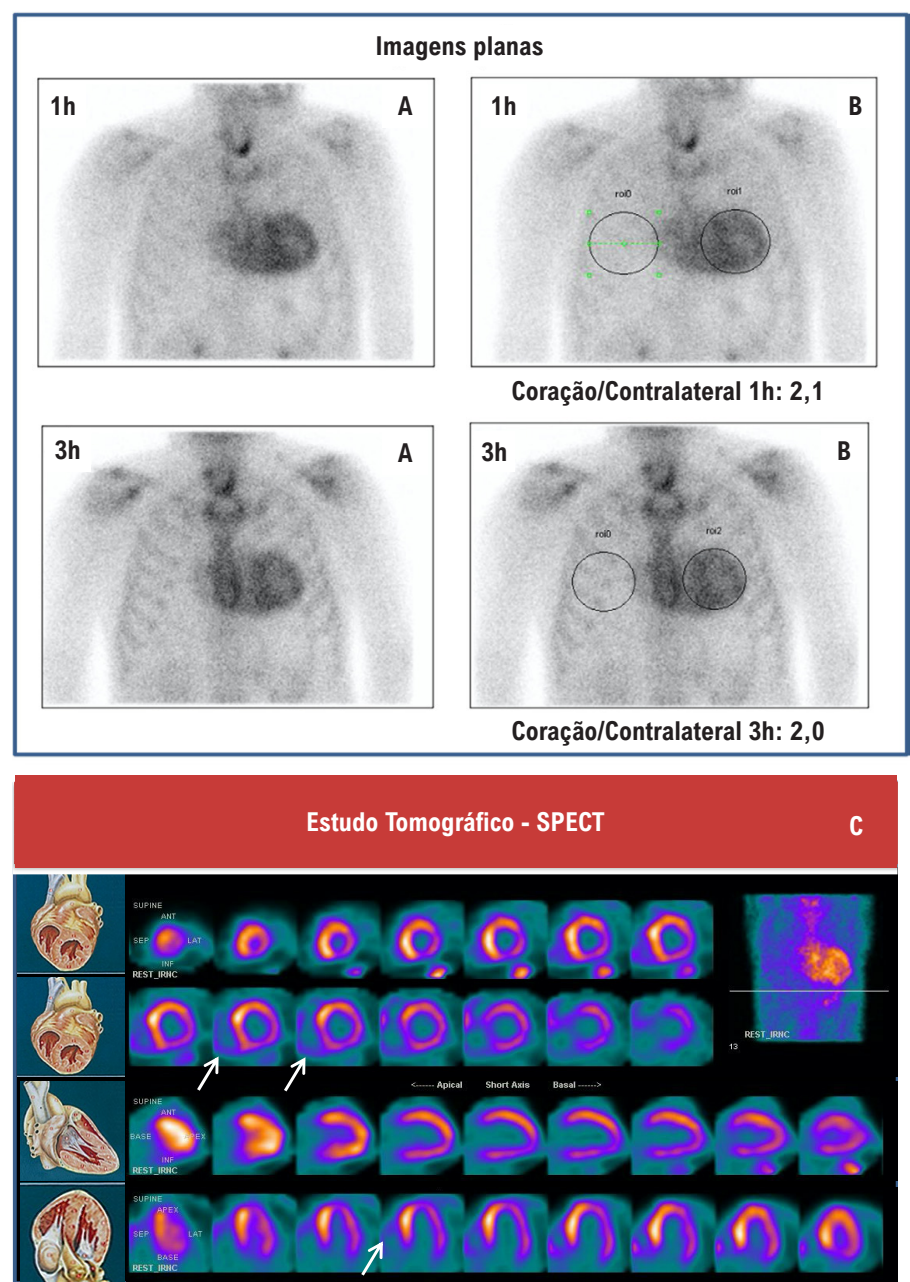

Figura 10 - Imagens ilustrativas de paciente masculino de 76 anos com amiloidose cardíaca por ATTRv (VAL3OMET). A cintilografia cardiaca com ${ }^{99 m} T c$-pirofosfato (imagens planas $A$ e B) mostrou intensa captação de radiotraçador nas imagens de 1 h e de $3 \mathrm{~h}$. $A$ análise visual (A) mostrou captação grau 3 tanto nas imagens de $1 \mathrm{~h}$ quanto nas imagens de $3 \mathrm{~h}$ (intensidade de captação miocárdica do radiofármaco maior que a dos arcos costais). A análise semiquantitativa (B) mostrou relação coração/contralateral em $1 \mathrm{~h}=2,1 \mathrm{e}$ em $3 \mathrm{~h}=2,0.0$ estudo tomográfico (SPECT) mostrou que a captação do radiofármaco se distribui em todas as paredes do VE e confirmou acometimento do VD, já evidenciado nas imagens planas (setas). Os achados da cintilografia cardíaca com ${ }^{99 m}$ TC-pirofosfato indicam estudo altamente sugestivo de AC por ATTR. (Imagens de arquivos pessoais dos autores).

Tabela 3 - Causas de cintilografia com ${ }^{99 m} \mathrm{Tc}$-pirofosfato falso-positiva (captação miocárdica de ${ }^{99 \mathrm{~m} T c}$-pirofosfato que não é associada à ATTR)

\section{Amiloidose cardíaca por cadeias leves (AL)}

2. Captação em pool sanguíneo (imagens planares)

3. Fraturas de costelas (imagens planares)

4. Infarto do miocárdio (agudo ou subagudo)

5. Cardiotoxicidade por hidroxicloroquina

6. Formas raras de amiloidose cardíaca

Fonte: adaptada de Hanna et al. ${ }^{91}$
A Tabela 4 resume os principais achados e orientações práticas para aquisição e análise das imagens para o diagnóstico de AC.

\subsection{Biomarcadores}

Não existe um marcador laboratorial específico para o diagnóstico de AC.

A troponina e os peptídios natriuréticos têm se mostrado úteis para avaliar acometimento cardíaco pela amiloidose, permitindo auxílio diagnóstico não invasivo, acessível e relativamente de baixo custo. ${ }^{96}$ A detecção de alterações persistentes desses biomarcadores é sinal de alerta da presença de acometimento cardíaco pela amiloidose. 
Tabela 4 - Resumo dos principais achados sugestivos de amiloidose cardíaca nos exames complementares

\begin{tabular}{|c|c|}
\hline Exames - achados sugestivos de amiloidose cardíaca (AC) & Dicas práticas - detalhes diagnósticos \\
\hline \multicolumn{2}{|l|}{ Eletrocardiograma (ECG) } \\
\hline $\begin{array}{l}\text { Padrão de pseudoinfarto } \\
\text { Voltagem do QRS desproporcional ao grau de espessamento das paredes } \\
\text { Baixa voltagem dos complexos QRS } \\
\text { Arritmias atriais - fibrilação atrial } \\
\text { Distúrbios de condução }\end{array}$ & $\begin{array}{l}\text { Padrão clássico de baixa voltagem é mais comum na forma AL (até 70\% } \\
\text { dos casos), mas pouco comum na ATTR (apenas 30\% dos casos) } \\
\text { É muito importante interpretar o ECG juntamente com os dados clínicos e } \\
\text { do ecocardiograma } \\
\text { BAV ou FA podem ser manifestação inicial de AC }\end{array}$ \\
\hline
\end{tabular}

\begin{tabular}{|c|c|}
\hline Ecocardiograma & \\
\hline $\begin{array}{l}\text { Aumento da espessura ventricular (SIV > } 12 \mathrm{~mm} \text { ) } \\
\text { Aspecto granuloso/hiper-refringente do miocárdio espessado } \\
\text { Espessamento das paredes do VD, além do VE } \\
\text { Dilatação biatrial } \\
\text { Espessamentos valvulares e de septo interatrial } \\
\text { Disfunção diastólica (padrão restritivo) } \\
\text { Deformação miocárdica longitudinal alterada de padrão regional poupando } \\
\text { o ápice (apical sparing) }\end{array}$ & $\begin{array}{c}\text { Além das informações estruturais e funcionais do ecocardiograma } \\
\text { convencional, a análise de deformação miocárdica é importante para } \\
\text { identificar disfunção miocárdica mesmo com FE normal e o padrão de } \\
\text { apical sparing }\end{array}$ \\
\hline Ressonância magnética cardíaca (RMC) & \\
\hline $\begin{array}{l}\text { Valores elevados de mapa T1 nativo } \\
\text { Aumento acentuado do volume extracelular } \\
\text { Realce tardio difuso transmural ou subendocárdico } \\
\text { Realce tardio em paredes atriais } \\
\text { Aumento da espessura das paredes de VDNE e septo interatrial }\end{array}$ & $\begin{array}{l}\text { Além as informações estruturais e funcionais cardíacas que podem } \\
\text { ser muito sugestivas, informações de realce tardio, mapa T1 e volume } \\
\text { extracelular são importantes para sugerir presença de AC } \\
\text { A RMC não permite diferenciar as formas de amiloidose AL e ATTR } \\
\text { A RMC pode ser útil para identificar outras formas de cardiomiopatia infiltrativa }\end{array}$ \\
\hline Cintilografia cardíaca com radiotraçadores ósseos & \\
\hline $\begin{array}{l}\text { Captação miocárdica igual ou superior à óssea (grau } 2 \text { ou } 3 \text { ) } \\
\text { Relação de captação coração/contralateral } \geq 1,5 \\
\text { Captação de } \\
\text { imagmens de SPECT }\end{array}$ & 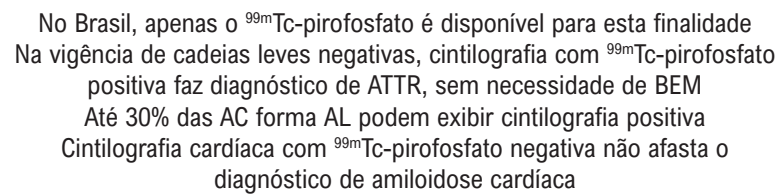 \\
\hline
\end{tabular}

BEM: biópsia endomiocárdica; SIV: septo interventricular; GLS: strain global longitudinal; SPECT: cintilografia pelo método tomográfico de emissão; VD: ventrículo direito; VE: ventrículo esquerdo.

\subsubsection{Peptídios Natriuréticos}

Análise de dados do registro THAOS (Transthyretin Amyloidosis Outcomes Survey), com pacientes acometidos por ATTR, demonstrou que a dosagem dos peptídios natriuréticos pode ser utilizada para auxílio diagnóstico, e foram observados valores mais elevados nos pacientes com mutações de acometimento preferencialmente cardíaco, como a V122I e V30M-tardia, do que nas formas de predomínio neurológico, como a V30M-precoce. Também foram observados maiores níveis dos biomarcadores na ATTRwt quando comparada com as formas hereditárias de predomínio neurológico. Porém, observou-se que, mesmo nos pacientes com fenótipo predominantemente neurológico, 45\% a 90\% apresentavam alterações desses biomarcadores, indicando algum grau de acometimento miocárdico subclínico. ${ }^{97}$

Observam-se maiores valores de NT-proBNP na forma AL, em comparação à ATTR. Isso se deve ao fato de as cadeias leves amiloidogênicas modularem a proteína cinase ativada por mitógeno p38 (MAPK), que diretamente promove a expressão do NT-proBNP, de forma que, para um mesmo grau de alterações hemodinâmicas nas duas formas de amiloidose, os níveis séricos da NT-proBNP podem ser maiores na forma AL. ${ }^{98}$
Vale ressaltar que os pacientes com ICFEP causada por ATTR apresentam valores de NT-ProBNP desproporcionalmente elevados em relação à gravidade da síndrome de $\mathrm{IC}$, quando comparados aos pacientes com ICFEP não amiloide. ${ }^{99}$

\subsubsection{Troponinas}

Elevação discreta e persistente dos níveis de troponina é frequentemente observada e sugere dano miocárdico subclínico em várias cardiomiopatias não isquêmicas. ${ }^{100}$ Contudo, tem sido relatado que os níveis são mais elevados em pacientes com AC ao se comparar a outras formas de cardiomiopatia. ${ }^{21}$ Estudo em pacientes com cardiomiopatia hipertrófica submetidos à biópsia endomiocárdica identificou níveis marcadamente mais elevados de troponina nos pacientes que tinham amiloidose em comparação com aqueles com cardiopatia livre de depósito amiloide, com alta sensibilidade diagnóstica. ${ }^{101}$

Vários mecanismos para justificar a elevação das troponinas nesses pacientes têm sido postulados: isquemia miocárdica, estresse de parede aumentado, lesão direta do miócito por citocinas inflamatórias e/ou estresse oxidativo, ativação neuro-hormonal e disfunção coronariana microvascular na 
insuficiência cardíaca. A disfunção microvascular na amiloidose é causada, presumidamente, por depósito intersticial e na região perivascular, pressão de enchimento ventricular aumentada e disfunção endotelial por toxicidade induzida pelas imunoglobulinas, na forma AL. Além disso, também é descrito efeito cardiotóxico direto das cadeias leves, independentemente do depósito extracelular de fibrilas, podendo justificar os níveis mais elevados de troponina em pacientes com forma AL do que em pacientes com ATTR, nos quais geralmente se observa elevação discreta e persistente. ${ }^{101}$

Vale ressaltar que, entre os pacientes com ATTR, muitos apresentam comorbidades, como miocardiopatia isquêmica, o que pode causar valores alterados de troponina. Sendo assim, a dosagem de troponina não deve ser utilizada para afastar ou confirmar acometimento cardíaco, mas sim como um potencial sinal de alerta para a doença, que será mais bem avaliada com exames mais específicos.

\subsubsection{Novos Biomarcadores}

Uma série de outros biomarcadores tem sido estudada, alguns com alta especificidade para subtipos de amiloidose, como a dosagem de proteína carreadora de retinol 4 para a amiloidose hereditária pela mutação Val142Ile. No entanto, ainda mais estudos são necessários, assim como a disponibilização comercial dos testes para análises de rotina. ${ }^{102}$

\section{Abordagem Diagnóstica Racional da Amiloidose Cardíaca}

Evidências recentes indicam que a AC, particularmente na forma ATTRwt, é uma condição mais prevalente do que anteriormente se estimava, e que, em parte, isso decorre de um amplo subdiagnóstico e do fato de esta doença mimetizar outras cardiopatias, tais como a miocardiopatia hipertrófica, a ICFEP não amiloide e a estenose aórtica de baixo fluxo e baixo gradiente. ${ }^{42}$ Tais aspectos indicam a necessidade de se assumir uma postura de alta suspeição da presença de doença nos diferentes cenários clínicos, para que se possa desencadear um processo diagnóstico racional..$^{54}$ A Figura 11 traz um fluxograma diagnóstico para AC, cujas etapas são comentadas a seguir. As principais recomendações e classes de evidência para o diagnóstico da AC estão listadas na Tabela 5.

A etapa preliminar e fundamental é o estabelecimento da suspeita clínica, baseada na história clínica, exame físico (ver Tabela 2), com achados sugestivos de AC ao ECG, ecocardiograma e RMC (ver Tabela 4).

A seguir, em casos com alta suspeita clínica, deve-se proceder a investigação das cadeias leves monoclonais de imunoglobulinas para uma triagem efetiva da presença de amiloidose $A L$, pois o diagnóstico da forma $A L$ é uma urgência médica, devendo-se evitar ao máximo o retardo para o início do tratamento, o que se associa à acentuada piora do prognóstico.

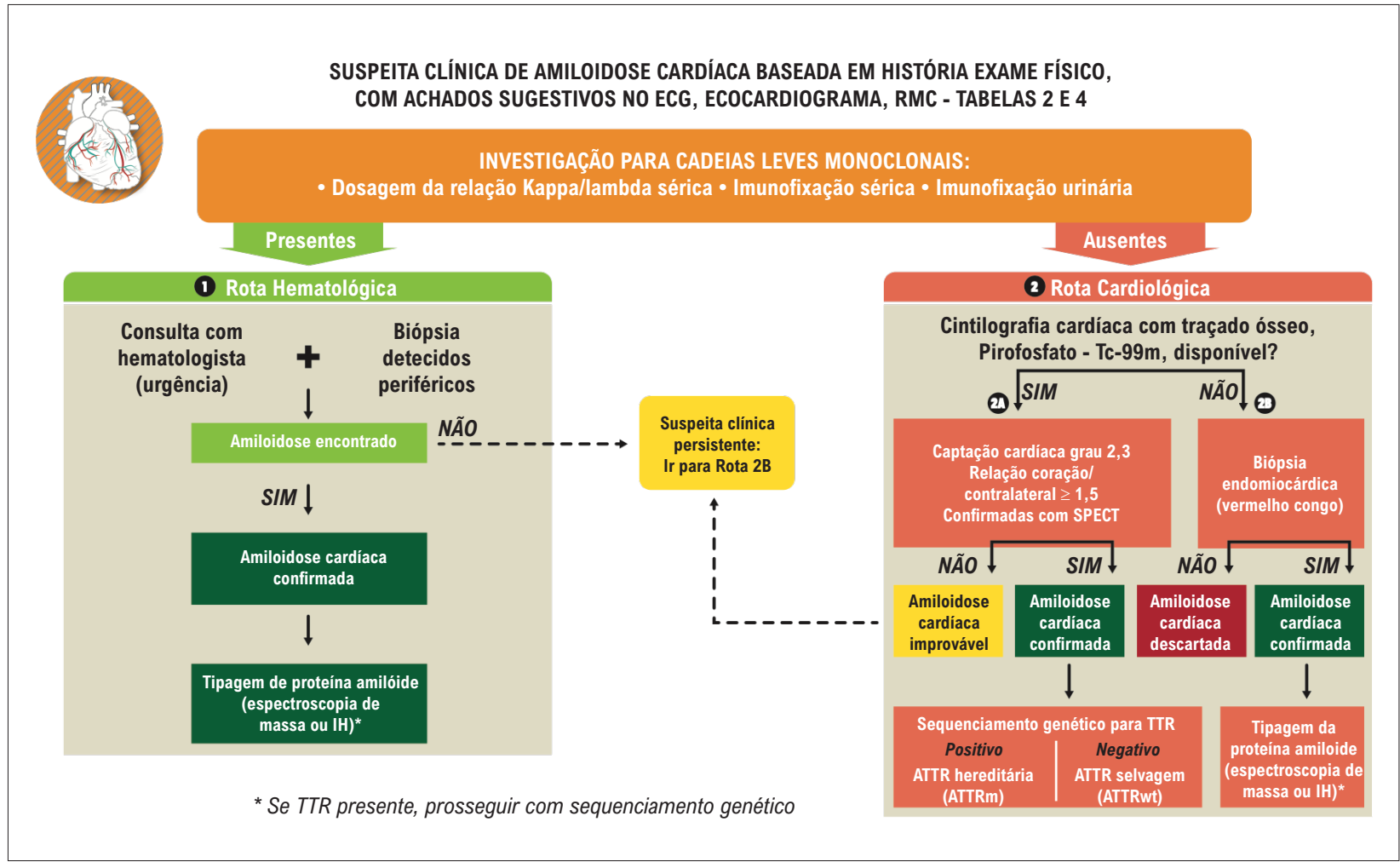

Figura 11 - Fluxograma para o diagnóstico de amiloidose cardíaca. 
Tabela 5 - Recomendações para investigação diagnóstica da amiloidose cardíaca

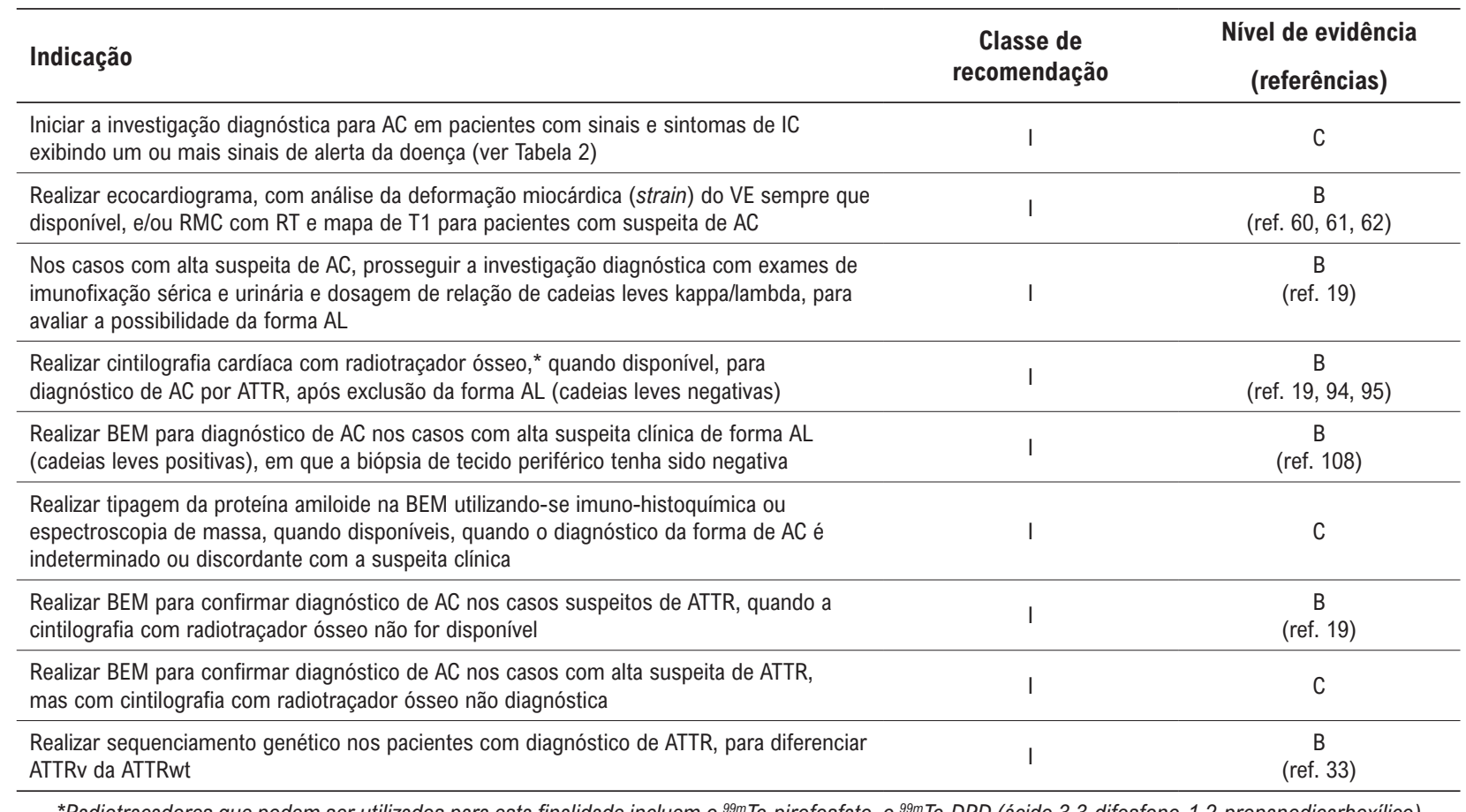

${ }^{*}$ Radiotraçadores que podem ser utilizados para esta finalidade incluem o ${ }^{99 m} T c$-pirofosfato, o ${ }^{99 m} T c-D P D$ (ácido 3,3-difosfono-1,2-propanodicarboxilico) e o ${ }^{99 m}$ Tc-HMDP (hidroximetilenodifosfonato), sendo que o ${ }^{99 m}$ Tc-pirofosfato é o único disponivel e aprovado para uso no Brasil.

A eletroforese de proteína não é um teste de screening adequado, uma vez que o componente monoclonal pode não ser detectado no sangue e/ou urina por esse método. Dessa forma, é importante a realização da imunofixação no sangue e urina, a qual aumenta a sensibilidade de detecção de cadeias leves clonais para em torno de $90 \% .{ }^{103}$ A adição da dosagem da relação das cadeias leves livres (free light chain), com detecção de uma relação anormal entre as cadeias kappa/lambda (maior que 1,65 ou menor que 0,26 ), aumenta a sensibilidade de detecção para acima de $99 \% .{ }^{103,104}$ Portanto, o conjunto dos 3 testes, eletroforese com imunofixação no sangue e urina associada ao teste de dosagem da relação das cadeias leves livres, representa o melhor método não invasivo para detecção de cadeias leves clonais, que indicam a presença de AL.

A detecção de cadeias leves monoclonais torna necessário o encaminhamento do paciente para avaliação com hematologista, seguindo-se a rota hematológica no fluxograma, e a realização de biópsia tecidual, procedimento fundamental para confirmar o depósito de proteína amiloide e a elaboração da estratégia terapêutica.

\subsection{Rota Hematológica}

\subsubsection{Participação do Hematologista e Biópsia de Tecidos Periféricos}

O diagnóstico de amiloidose AL dever ser confirmado através de biópsia.

Deve-se dar preferência, inicialmente, à biópsia de gordura abdominal, um método simples e seguro. ${ }^{105}$ A coloração de vermelho-congo com birrefringência sob a luz polarizada é o método usado na determinação de proteína amiloide tecidual.

Em casos de amiloidose sistêmica, em que há acometimento de vários órgãos ou tecidos, a biópsia de gordura abdominal com essas colorações específicas apresenta sensibilidade de $60 \%$ a $80 \%$ e especificidade de $90 \%$ a $100 \%$ no diagnóstico de amiloidose, ${ }^{106}$ e tem uma forte associação com a carga corporal total de depósito amiloide. ${ }^{37}$ Contudo, em casos de amiloidose localizada, restrita a um órgão ou tecido, a biópsia de tecido gorduroso subcutâneo é infrequentemente positiva. ${ }^{107} \mathrm{Em}$ geral, a positividade da biópsia extracardíaca é maior quando o sitio da biópsia é a gordura abdominal e o tipo de amiloidose é a $\mathrm{AL}$, seguida da ATTRv e, por último, a ATTRwt. ${ }^{37}$ Em uma serie de 131 pacientes com diagnóstico de AC por transtirretina confirmado em biópsia endomiocárdica, a biópsia de gordura abdominal foi positiva em $67 \%$ dos pacientes com ATTR hereditária e só $14 \%$ dos pacientes com ATTRwt. ${ }^{8}$ Portanto, apesar de a gordura abdominal ser o local inicial preferencial de biópsias extracardíacas, um resultado negativo não deve excluir o diagnóstico, e uma biópsia endomiocárdica deve ser realizada. ${ }^{37}$ Nesses casos, biópsia do órgão afetado oferece sensibilidade e especificidade de 100\%.

Vale ressaltar que a coloração vermelho-congo permite a confirmação da infiltração amiloide nos tecidos, porém não identifica o tipo da proteína precursora. Além disso, 40\% dos pacientes com ATTR podem ter uma gamopatia monoclonal de significado indeterminado (GMSI), apresentando investigação positiva para cadeias leves monoclonais. ${ }^{109}$ 
Considerando esses aspectos, para identificação do tipo do depósito amiloide, aspecto fundamental para o tratamento apropriado, torna-se necessária a realização de imuno-histoquímica ou, preferencialmente, de microdissecção a laser do material amiloide da biópsia com realização de espectrometria de massa. A imuno-histoquímica permanece o método mais amplamente disponível para identificação do tipo de depósito; contudo, quando o tipo de amiloidose é o de cadeias leves, os resultados não são sempre conclusivos, frequentemente com coexistência de positividade para mais de um tipo de antissoro, geralmente TTR e cadeia kappa ou lambda. A espectrometria de massa tornou-se, portanto, o novo "padrão-ouro" para a identificação do tipo do depósito amiloide. ${ }^{37,54,110}$

Perante resultados negativos para cadeias leves monoclonais, situação em que o diagnóstico de ATTR é mais provável, ainda que outras formas mais raras de AC também possam ser diagnosticadas, a investigação deve seguir pela rota cardiológica, tomando-se duas sub-rotas de acordo com a disponibilidade da cintilografia cardíaca com marcadores ósseos.

\subsection{Rota Cardiológica}

No cenário de disponibilidade da cintilografia com marcadores ósseos (sub-rota 2A), desde que as cadeias leves monoclonais estejam ausentes, o achado de cintilografia cardíaca mostrando captação acentuada, graus 2 ou 3 da classificação de Perugini (captação cardíaca equivalente ou superior à captação vista nos arcos costais) e relação de captação na área cardíaca em relação à área contralateral do tórax $\geq 1,5$, confirmando-se que a captação aumentada encontra-se nas paredes ventriculares por imagens tomográficas de emissão (SPECT), a AC por ATTR está confirmada sem a necessidade de realização de biópsia endomiocárdica. A seguir, o sequenciamento genético da TTR deve ser realizado para definição do caso se ATTR hereditária ou selvagem.

A diferenciação entre ATTR hereditária ou wild-type tem implicações prognósticas e terapêuticas, sendo também importante para potencial screening familiar e aconselhamento genético.

Na vigência de cintilografia cardíaca com marcadores ósseos negativa e associada à ausência de cadeias leves monoclonais, o diagnóstico de AC é improvável. Contudo, quando a suspeita clínica persiste, baseada principalmente nos resultados de outros métodos de imagem muito sugestivos de amiloidose, a biópsia endomiocárdica tem um papel diagnóstico relevante e deve ser solicitada. Nesse caso, podemos estar diante de
ATTRv com algumas mutações com depósitos amiloides que não captam marcador ósseo, como a V30M de início precoce e a P64I, além de outros tipos não usuais de amiloidose. ${ }^{111}$

No cenário de indisponibilidade da cintilografia com marcadores ósseos (sub-rota 2B), a biópsia endomiocárdica também está indicada para elucidar o diagnóstico.

\section{Prognóstico e Estadiamento}

\subsection{Forma AL}

Portadores de AC forma AL exibem depósitos amiloides mais tóxicos e de formação mais acelerada se comparados aos casos pela forma ATTR. Como consequência, aumentos mensais da espessura miocárdica da monta de 1,45 a 2,16 mm podem ser observados associados a elevações mais acentuadas de biomarcadores como troponina e BNP, ${ }^{112}$ bem como ao desenvolvimento de sintomas de insuficiência cardíaca e óbito em média dentro de 6 meses após o diagnóstico. ${ }^{113}$

A somatória desses achados às informações obtidas graças aos recentes avanços tecnológicos e laboratoriais permitiu estabelecer como principal determinante do prognóstico da amiloidose $\mathrm{AL}$ a extensão do envolvimento cardíaco pelo material amiloide, ${ }^{114}$ bem como a elaboração de escores de sobrevida. O mais amplamente utilizado é o da Clínica Mayo modificado, exibido na Tabela 6, e que atribui pontos à presença de troponina $T \geq 0,025 \mathrm{ng} / \mathrm{mL}$; NT-ProBNP $\geq 1,800 \mathrm{pg} / \mathrm{mL}$; diferença entre as cadeias leves $\geq 18 \mathrm{mg} / \mathrm{dL}$ para indicar indivíduos de mais alto risco. ${ }^{115}$

Adicionalmente, achados ecocardiográficos, tais como aumento acentuado da espessura das paredes, disfunção diastólica, disfunção do VE, espessamento das valvas e redução do strain global longitudinal do VE combinados aos biomarcadores BNP e troponina e status hematológico são preditores de maior mortalidade. ${ }^{116}$ Recentemente, uma técnica nova de avaliação miocárdica não invasiva que avalia a rigidez do coração, a elastografia miocárdica, demonstrou boa correlação com a massa ventricular, espessura miocárdica, biomarcadores com BNP, pressões de enchimento, piora de classe funcional e da disfunção diastólica. ${ }^{117}$

A RMC também fornece elementos que se correlacionam com a sobrevida em pacientes com AC..$^{84,119-121}$ A presença e a extensão de fibrose miocárdica, detectada pela técnica de realce tardio com gadolínio, são marcadores de mau prognóstico. ${ }^{118-119}$ Estudo recente mostra que medidas de mapa T1 acima de $1.044 \mathrm{~ms}$ e do ECV (extracellular volume)

Tabela 6 - Estadiamento prognóstico da amiloidose AL, segundo os critérios revisados da Clínica Mayo ${ }^{115}$

\begin{tabular}{lcc}
\hline Valor de corte dos biomarcadores & $\begin{array}{c}\text { Estadiamento } \\
\text { (número de biomarcadores } \\
\text { com valores elevados) }\end{array}$ & Sobrevida média \\
\hline Troponina-T $\geq 0,025 \mathrm{ng} / \mathrm{mL}$ & Estágio I: nenhum biomarcador & 94 meses \\
$\mathrm{NT}-\mathrm{proBNP}>1.800 \mathrm{pg} / \mathrm{mL}$ & Estágio II: 1 biomarcador & 40 meses \\
$\mathrm{DCL}>18 \mathrm{mg} / \mathrm{dL}$ & Estágio III: 2 biomarcadores & 14 meses \\
& Estágio IV: 3 biomarcadores & 6 meses
\end{tabular}

DCL: diferença da dosagem das cadeias leves; NT-proBNP: N-terminal pro-B-type natriuretic peptide. 
calculado na fase de equilíbrio do contraste superiores a 0,45 associam-se a aumento da mortalidade cardiovascular de 5,84 e 3,48 vezes, respectivamente. ${ }^{9,10}$

Os biomarcadores apresentam não apenas um papel no estadiamento desses doentes, mas também possibilitam avaliação da resposta ao tratamento, que na prática clínica é sempre um desafio, principalmente para a forma $\mathrm{AL}$, uma vez que a quimioterapia pode ser um fator adicional para lesão miocárdica. O que se tem bem estabelecido na literatura é a concordância entre redução dos níveis de NT-proBNP e resposta hematológica ao tratamento, assim como melhora de classe funcional NYHA. O inverso também é verdadeiro, como o aumento dos níveis de NT-proBNP, troponina e redução da fração de ejeção. (ver Tabela 9 - tópico sobre tratamento da AC forma $\mathrm{AL}$ )

\subsection{Forma ATTR}

A AC por ATTR exibe um perfil evolutivo mais benigno e de maior sobrevida se comparado à forma AL. ${ }^{121}$ Além do tipo específico de depósito amiloide, outros fatores como genótipo, dados clínicos, biomarcadores laboratoriais e achados radiológicos fornecem instrumentos que auxiliam o planejamento terapêutico e permitem inferir o prognóstico. ${ }^{13}$

Nos casos de ATTR hereditária, o perfil genético determina o fenótipo clínico e a evolução da doença, ainda que a penetrância do gene possa variar em diferentes populações. Nesse sentido, variantes patogênicas de acometimento predominantemente miocárdico como a V122I apresentam sobrevida menor comparativamente à ATTRwt e às variantes mistas ou de predomínio neuropático como a V30M. ${ }^{20,122,123}$

Do ponto de vista clínico, o surgimento de sintomas de insuficiência cardíaca e a duração dos sintomas apresentam valor prognóstico. ${ }^{124}$ Observa-se uma redução da sobrevida quanto mais prolongada a descompensação clínica e quanto mais avançada a classe funcional da NYHA. ${ }^{125,126}$ As sobrevidas medianas observadas para cada classe funcional foram: I $=4,6$ anos,
II = 4,1 anos, III = 2,1 anos e IV = 1,3 ano. Apesar de o gênero, a idade ao diagnóstico e a presença de comorbidades como valvopatia aórtica ou taquiarritmias não demonstrarem efeito direto sobre a mortalidade, uma maior associação com desfechos cardíacos compostos desfavoráveis é observada em pacientes idosos do sexo masculino e com doenças associadas. ${ }^{127}$

Os resultados de exames laboratoriais de baixo custo, de realização rápida e de fácil interpretação têm sido usados em diferentes propostas para estadiamento da doença, obtendo bom nível de correlação com a expectativa de vida (Tabela 7). ${ }^{128-130}$ Os níveis séricos de troponinas T e I, do NT-proBNP e a taxa de filtração glomerular refletem a toxicidade dos depósitos amiloides nos órgãos-alvos tanto por ação direta quanto por ativação de processos de estresse oxidativo e inflamação. ${ }^{131}$ As recomendações para estratificação de risco/estadiamento da AC e monitoramento da resposta ao tratamento são mostradas na Tabela 8 .

Achados em exames de imagem, como o ecocardiograma, a cintilografia cardíaca com Tecnécio-pirofosfato ( ${ }^{99 \mathrm{~m} T \mathrm{TC}-\mathrm{PYP})}$ e a RMC, fornecem dados complementares que auxiliam na estratificação prognóstica. ${ }^{9,80,94,132-134}$ (12-17). (Tabela 9). Além disso, a crescente qualidade das imagens obtidas, associada ao maior detalhamento quantitativo dos depósitos amiloides, diminuiu a necessidade de realização de biópsia miocárdica como elemento prognosticador de doença. ${ }^{9}$

\section{Tratamento}

O tratamento da AC compreende medidas específicas direcionadas para reduzir ou evitar a progressão dos depósitos de fibrilas amiloides, sendo abordadas neste texto separadamente, para as formas AL e ATTR. Além destas, são também necessárias medidas gerais de manejo das anormalidades clínicas e hemodinâmicas causadas pela doença, incluindo a insuficiência cardíaca e os distúrbios do ritmo cardíaco, sendo aplicáveis para ambas as formas, AL e ATTR.

Tabela 7 - Propostas de estadiamento da amiloidose ATTR utilizando biomarcadores

\begin{tabular}{|c|c|c|c|c|}
\hline $\begin{array}{l}\text { Proposta de } \\
\text { estadiamento }\end{array}$ & Forma de $A C$ & $\begin{array}{l}\text { Ponto de corte dos } \\
\text { biomarcadores }\end{array}$ & Estadiamento & $\begin{array}{c}\text { Sobrevida média } \\
\text { (meses) }\end{array}$ \\
\hline $\begin{array}{l}\text { Grogan et al. } \\
(2016)\end{array}$ & ATTRwt & $\begin{array}{l}\text { NT-proBNP }>3.000 \mathrm{ng} / \mathrm{L} \\
\text { Troponina-T } \geq 0,05 \mu \mathrm{g} / \mathrm{L}\end{array}$ & $\begin{array}{c}\text { Estágio I } \\
\text { NT-proBNP }<3.000 \mathrm{ng} / \mathrm{L} \\
\text { TncT }<0,05 \mu \mathrm{g} / \mathrm{L} \\
\text { Estágio II } \\
\text { NT-proBNP ou TncT acima do } \\
\text { ponto de corte } \\
\text { Estágio III } \\
\text { NT-proBNP e TncT acima do ponto de corte }\end{array}$ & $\begin{array}{l}\text { Estágio I = } 66 \\
\text { Estágio II = } 40 \\
\text { Estágio III = } 20\end{array}$ \\
\hline $\begin{array}{l}\text { Gillmore et al. } \\
(2018)\end{array}$ & $\begin{array}{l}\text { ATTRwt } \\
\text { ATTRv }\end{array}$ & $\begin{array}{c}\text { NT-proBNP }>3.000 \mathrm{ng} / \mathrm{L} \\
\text { eGFR }<45 \mathrm{~mL} / \mathrm{min}\end{array}$ & $\begin{array}{c}\text { Estágio I } \\
\text { NT-proBNP } \leq 3.000 \mathrm{ng} / \mathrm{L} \\
\text { eGFR } \geq 45 \mathrm{~mL} / \mathrm{min} \\
\text { Estágio II } \\
\text { NT-proBNP }>3.000 \mathrm{ng} / \mathrm{L} \text { ou } \\
\text { eGFR }<45 \mathrm{~mL} / \mathrm{min} \\
\text { Estágio III } \\
\text { NT-proBNP }>3.000 \mathrm{ng} / \mathrm{L} \text { e } \\
\text { eGFR }<45 \mathrm{~mL} / \mathrm{min}\end{array}$ & $\begin{array}{l}\text { Estágio I = 69,2 } \\
\text { Estágio } I I=46,7 \\
\text { Estágio } I I I=24,1\end{array}$ \\
\hline
\end{tabular}

ATTRwt: amiloidose ATTR forma selvagem; ATTRv: amiloidose ATTR forma hereditária; NT-proBNP: N-terminal pro-B-type natriuretic peptide; eGFR: taxa de filtração glomerular estimada; FEVE: fração de ejeção ventricular esquerda. ${ }^{11}$ 
Tabela 8 - Recomendações para a estratificação de risco/estadiamento da amiloidose cardíaca (AC) e monitoramento da resposta ao tratamento e/ou progressão da doença

\begin{tabular}{lcc}
\hline Indicação & $\begin{array}{c}\text { Classe de recomendação } \\
\text { (referências) }\end{array}$ & $\begin{array}{c}\text { B } \\
\text { Estratificar o risco dos pacientes com AC utilizando-se sistemas de estadiamento } \\
\text { validados, incluindo biomarcadores como BNP/NT-ProBNP e/ou troponinas }\end{array}$ \\
\hline $\begin{array}{l}\text { Monitorar a progressão da AC e/ou resposta ao tratamento específico utilizando-se } \\
\text { ecocardiograma ou ressonância magnética cardíaca e biomarcadores* }\end{array}$ & I \\
\hline
\end{tabular}

${ }^{*}$ A periodicidade da avaliação depende da forma da AC e da evolução clínica.

Tabela 9 - Parâmetros de exames de imagem com valor prognóstico na amiloidose cardíaca ATTR

\begin{tabular}{lcc}
\hline Ecocardiograma & Cintilografia com ${ }^{99 \mathrm{~m} T c-p i r o f o s f a t o}$ & Ressonância magnética cardíaca \\
\hline$\downarrow$ FEVE & & TAPSE \\
$\downarrow$ FCM & Relação C/CL $\geq 1,6$ & $\downarrow$ Volume de ejeção indexado \\
$\downarrow$ SGL & & Realce tardio com gadolínio \\
Apical Sparing & $\uparrow$ Volume extracelular \\
$\downarrow$ Stroke Volume ${ }_{\mid}^{(17)}$ & $\uparrow \mathrm{T} 1$ nativo \\
\hline
\end{tabular}

FEVE: fração de ejeção do ventrículo esquerdo; FCM: fração de contração miocárdica (FCM = VSNOL VE); SGL: strain global longitudinal; $S_{\text {i: indice }}$ de volume sistólico; C/CL: relação coração e região torácica contralateral; TAPSE: excursão sistólica do anel tricúspide.

\subsection{Princípios da Terapia Específica da Amiloidose AL}

A amiloidose AL é uma doença causada pela produção aberrante da cadeia leve da imunoglobulina (kappa ou lambda). Com isso, a base do tratamento específico consiste em eliminar a sua produção por meio da erradicação do clone de plasmócitos na medula óssea. A redução rápida e, idealmente, normalização dos níveis de cadeias leves são alguns dos principais objetivos no tratamento da amiloidose $\mathrm{AL}$, sendo denominada resposta hematológica. Já a reversão da lesão nos tecidos e órgãos acometidos pelo depósito amiloide é chamada de resposta orgânica, e compreende o segundo maior objetivo do tratamento. Outros objetivos do tratamento são melhorar a qualidade de vida e a sobrevida geral. ${ }^{135}$

Após confirmado o diagnóstico de amiloidose sistêmica $A L$, o plano terapêutico deve ser definido pelo hematologista. No entanto, a identificação e o manejo das disfunções orgânicas são essenciais, sendo imprescindível o trabalho multidisciplinar, incluindo acompanhamento conjunto com o cardiologista e outros especialistas (Tabela 12). O comprometimento cardíaco é o principal fator prognóstico na amiloidose $\mathrm{AL}$, determinando não só a sobrevida, mas também a tolerabilidade aos tratamentos citotóxicos. O impacto do comprometimento cardíaco na sobrevida é bem estabelecido na literatura, e sistemas de estadiamento já validados auxiliam na estratificação de risco do paciente, sendo utilizados em conjunto com outros parâmetros para guiar diferentes estratégias terapêuticas. ${ }^{135}$

A sobrevida na amiloidose AL está relacionada à produção de cadeias leves amiloidogênicas e à lesão de órgão-alvo, principalmente o coração. Com isso, o estadiamento inclui biomarcadores que estão relacionados a essas ocorrências, ${ }^{104,115,136}$ conforme descrito em tópico anterior (ver Tabela 5).

O valor dessa estratificação prognóstica foi observado tanto em indivíduos tratados com transplante de células-tronco hematopoiéticas (TCTH) autólogo quanto naqueles tratados sem esse procedimento. A sobrevida mediana segundo essa estratificação prognóstica foi de 55, 19, 12 e 5 meses em pacientes que tiveram ao diagnóstico estágios I, II, III e IV, respectivamente, e que não receberam ou tiveram falha no TCTH e 97, 58 e 22 meses, para os estágios II, III e IV, respectivamente, naqueles submetidos ao TCTH. ${ }^{115}$

Pacientes avaliados como baixo risco são candidatos à terapia com quimioterapia (QT) em altas doses seguidas de TCTH autólogo (Tabela 12). Atualmente, esta é considerada a estratégia mais eficaz para erradicação do clone de plasmócitos. ${ }^{135}$ Pacientes de risco intermediário geralmente recebem QT em doses convencionais e, caso apresentem melhora clínica e laboratorial, podem se tornar candidatos ao TCTH autólogo. Por último, pacientes idosos, mais frágeis, com comprometimento de mais de um órgão ou com cardiomiopatia avançada são tratados com QT em doses ajustadas, representando um grupo de prognóstico desfavorável, uma vez que geralmente não toleram o tratamento. ${ }^{135}$

Após 3 meses do término do tratamento, as respostas hematológica e orgânica devem ser avaliadas com exames específicos relacionados à detecção de gamopatia monoclonal e comprometimento de cada órgão acometido no diagnóstico. Os critérios de resposta hematológica e orgânica estão resumidos nas Tabelas 10 e 11. ${ }^{136,137}$ 


\section{Tabela 10 - Critérios de resposta hematológica ao tratamento}

\begin{tabular}{l} 
Resposta completa (RC): normalização das cadeias leves livres, \\
imunofixação no sangue e urina negativa (sem presença de \\
componente clonal) \\
\hline Resposta parcial muito boa: redução na diferença entre cadeia leve livre \\
envolvida e não envolvida para < $40 \mathrm{mg} / \mathrm{L}$ \\
\hline Resposta parcial (RP): redução $>50 \%$ na diferença entre cadeia leve \\
livre envolvida e não envolvida \\
Sem resposta: não obtenção de uma RP \\
\hline Doença progressiva: aumento de cadeia leve livre em $50 \%$ ou para > \\
100 mg/L. Em pacientes que obtiveram uma RC, reaparecimento de \\
um componente clonal na imunofixação ou nas cadeias leves livres. \\
Em pacientes que obtiveram uma RP, aumento em $50 \%$ do componente \\
monoclonal no sangue ou urina
\end{tabular}

Mesmo alcançando resposta hematológica completa, a melhora das disfunções se dá mais lentamente, podendo ocorrer até meses a anos após a normalização das cadeias leves. ${ }^{19}$

8.1.1. Tratamento de Pacientes Elegíveis ao Transplante Autólogo de Células-tronco Hematopoiéticas (TCTH)

Apenas 20\% dos pacientes diagnosticados com amiloidose AL apresentam condições clínicas para o TCTH, e o número de pacientes elegíveis pode aumentar se houver resposta orgânica após esquemas de indução contendo terapias antiplasmocitárias eficazes (bortezomibe, daratumumabe). ${ }^{135,139,140}$

A avaliação de elegibilidade ao TCTH é ponto-chave para se obter sucesso terapêutico com essa estratégia. Um único estudo prospectivo randomizado comparou o TCTH com QT convencional, não havendo benefício de sobrevida global deste em relação à estratégia menos intensiva. Neste estudo, porém, a alta taxa de mortalidade associada ao TCTH (24\%) foi relacionada aos critérios de inclusão, inexperiência do centro transplantador e uso de dose subterapêutica de melfalano. ${ }^{141}$

Uma vez que não há critérios precisos bem estabelecidos e validados prospectivamente na literatura, cada centro estabelece seus próprios critérios de elegibilidade ao TCTH. Embora a avaliação subjetiva seja relevante, alguns fatores podem guiar a indicação do TCTH: "idade fisiológica" $\leq 70$ anos, $\mathrm{ClCr}>30 \mathrm{~mL} / \mathrm{min}$ (exceto aqueles em diálise crônica), troponina $\mathrm{T}<0,06 \mathrm{ng} / \mathrm{mL}$, escala de performance ECOG (Eastern Cooperative Oncology Group) $\leq 2$, classe funcional da New York Heart Association I ou II e pressão arterial sistólica $>90 \mathrm{mmHg}$. A adequada estratificação de risco pré-tratamento concomitante ao desenvolvimento de melhores condições de suporte tais como antibioticoterapia e terapia intensiva tem levado à redução da mortalidade associada ao TCTH nas últimas décadas, com taxas de 2,4\% a 3,4\% em análises retrospectivas. ${ }^{142-148}$

Dessa forma, o TCTH deve ser recomendado como terapia de primeira linha nos indivíduos classificados como elegíveis (Tabela 12). Essa recomendação se deve à obtenção de altas taxas de resposta hematológica, levando à redução da produção e potencial reabsorção do
Tabela 11 - Critérios de resposta órgão-específica ao tratamento

Resposta cardíaca: redução $>30 \%$ e $>300 \mathrm{ng} / \mathrm{L}$ em pacientes com NT-proBNP $\geq 650 \mathrm{ng} / \mathrm{L}$ ou melhora funcional de pelo menos duas classes de acordo com a New York Heart Association

Resposta renal: diminuição da proteinúria $\geq 50 \%$ (redução de ao menos $0,5 \mathrm{~g} / 24 \mathrm{~h}$ ) em 6 meses sem piora do eGFR em $\geq 25 \%$. Análises retrospectivas recentes sugerem que redução $\geq 30 \%$ na proteinúria está associada a melhor prognóstico, mas esse critério (de $\geq 30 \%$ ) ainda não foi incorporado em recomendações formais ${ }^{18}$

Resposta hepática: redução em fosfatase alcalina em pelo menos $50 \%$ e redução da dimensão do fígado em pelo menos $2 \mathrm{~cm}$

Sistema nervoso periférico: melhora da velocidade de neurocondução pela eletroneuromiografia

amiloide, com consequente melhora da disfunção orgânica, performance status, aumento da sobrevida e qualidade de vida. Como exemplo, em uma série de 672 pacientes com amiloidose $\mathrm{AL}$ submetidos a TCTH, 84\% apresentaram resposta hematológica, sendo $39 \%$ de RC, e a sobrevida alcançada foi $>50 \%$ em 15 anos. ${ }^{146,147,149}$

O TCTH pode ser realizado logo após diagnóstico (upfront) em pacientes com $<10 \%$ de plasmócitos clonais na medula óssea ou ser precedido de terapia de indução com esquemas contendo bortezomibe e/ou anticorpo monoclonal anti-CD38. Esse último cenário deve ser considerado quando há associação com mieloma múltiplo, atraso previsível para realização do TCTH, baixa performance que pode melhorar com a terapia de indução e presença de $>10 \%$ de infiltração por plasmócitos clonais na medula óssea, a qual está associada a pior prognóstico. ${ }^{135,150}$

Os principais esquemas utilizados como terapia prétransplante são ciclofosfamida, bortezomibe e dexametasona (CyBorD) e daratumumabe, bortezomibe, ciclofosfamida e dexametasona (Dara-CyBorD). ${ }^{139}$

Dado o novo cenário de surgimento de novas terapias no tratamento da amiloidose AL e a escassez de estudos randomizados consolidando o papel do transplante, serão necessários novos estudos para entender se o TCTH permanecerá sendo a terapia mais eficaz nas próximas décadas.

\subsubsection{Tratamento de Pacientes Não Elegíveis ao TCTH/} Quimioterapia Convencional

A maior parte dos pacientes diagnosticados com amiloidose $\mathrm{AL}$ não é elegível à terapia de maior intensidade com TCTH autólogo devido a comorbidades, como doença cardíaca avançada, insuficiência renal, envolvimento de mais de dois órgãos ou idade avançada. Dessa forma, nesse grupo de pacientes, terapias quimioterápicas com medicações antiplasmocitárias são a base do tratamento (Tabela 12). Os esquemas utilizados são, em sua maioria, com base naqueles empregados para o mieloma múltiplo.

O esquema combinando ciclofosfamida, bortezomibe e dexametasona (CyBorD) demonstrou-se altamente eficaz (resposta hematológica $81 \%$ a 94\%), bem tolerado e capaz de 
gerar resposta hematológica rápida (em até 3 meses) em dois estudos retrospectivos com pequeno número de pacientes ( $n=17$ e 43). A sobrevida global em 2 anos chegou a 92\% nesses estudos. ${ }^{151,152}$ A maior casuística com este esquema incluiu 230 pacientes, com 60\% de resposta hematológica, sendo $23 \%$ de resposta completa. Entretanto, resposta orgânica cardíaca e renal foi observada em somente 17\% e $25 \%$ dos pacientes, respectivamente. Dentre os pacientes com cardiopatia avançada, menor taxa de resposta hematológica foi observada (42\% global e $14 \%$ completa), sendo a mediana de sobrevida global de 7 meses para este grupo ${ }^{153}$ A possibilidade do CyBorD de tornar pacientes inicialmente inelegíveis ao TCTH autólogo em elegíveis (após resposta hematológica e melhora clínica) é um ponto importante a ser considerado no desenvolvimento do plano terapêutico. ${ }^{153-155}$

Recentemente, dois estudos randomizados instituíram combinações de QT como possíveis novos tratamentos de escolha em pacientes com amiloidose $\mathrm{AL}$ não elegíveis a TCTH. O primeiro comparou o esquema bortezomibe, melfalano e dexametasona (BMD) a MD, demonstrando benefício da adição do bortezomibe a MD com maior taxa de resposta hematológica global após 3 meses (79\% vs. $52 \%)$, resposta orgânica cardíaca (38\% vs. 28\%) e melhora de sobrevida global, com redução de 2 vezes na taxa de mortalidade. ${ }^{156} \mathrm{O}$ maior estudo randomizado em amiloidose $\mathrm{AL}$ (andromeda) associou um anticorpo monoclonal anti-CD38 (daratumumabe) ao esquema CyBorD, com resultados promissores. ${ }^{139}$ Resposta hematológica global de $92 \%$ foi alcançada no grupo Dara-CyBorD versus $77 \%$ no grupo-controle que recebeu CyBorD sem daratumumabe, com RC de $53 \%$ versus $18 \%$, e mediana de 2 meses para atingir esta resposta. Melhora de função orgânica foi também observada no grupo que recebeu o anticorpo monoclonal, com melhora da sobrevida livre de progressão. É importante ressaltar que pacientes com cardiopatia avançada (classificados como estadiamento IIIb) foram excluídos de ambos os estudos randomizados citados, sendo que o tratamento para este grupo permanece um desafio na prática clínica.

\subsection{Terapias Específicas da ATTR}

Várias etapas do processo fisiopatogênico de formação e deposição das fibrilas amiloides no tecido cardíaco são potenciais alvos terapêuticos na ATTR, como ilustrado na Figura 12, incluindo-se: 1) transplante hepático; 2) estabilizadores dos tetrâmeros da TTR; 3 ) inibidores da síntese hepática de TTR; e 4) degradação e reabsorção das fibrilas amiloides depositadas.

\subsubsection{Transplante Hepático}

O transplante hepático foi, no passado, proposto como tratamento curativo potencial para pacientes com polineuropatia associada à ATTRv. ${ }^{157} \mathrm{O}$ transplante hepático, ao remover a fonte de produção das moléculas mutadas de TTR, associa-se a aumento da sobrevida, com relatos de taxa de sobrevida em 20 anos de 55,3\%. Contudo, a deposição de TTR pode continuar após o transplante hepático e associar-se à progressão da cardiopatia, provavelmente porque a presença de fibrilas amiloides já acumuladas no miocárdio promove deposição adicional de TTR selvagem ao longo do tempo. ${ }^{158,159}$ Dessa forma, transplante duplo de coração e fígado pode ser possível e parece associado a melhor prognóstico em comparação a transplante de um dos órgãos isoladamente. ${ }^{160}$ Considerando a reduzida disponibilidade de órgãos e centros de transplante, além dos riscos representados pela imunossupressão ao longo da duração da vida, o desenvolvimento de novas terapias capazes de bloquear a síntese hepática de TTR deve substituir o transplante hepático como alternativa de tratamento para suprimir a produção de TTR.

\subsubsection{Estabilizadores Seletivos dos Tetrâmeros da TTR}

\subsubsection{Tafamidis}

Tafamidis é uma molécula pequena que inibe seletivamente a dissociação dos tetrâmeros de TTR ao ligar-se aos sítios de ligação da tiroxina (T4) e, assim,

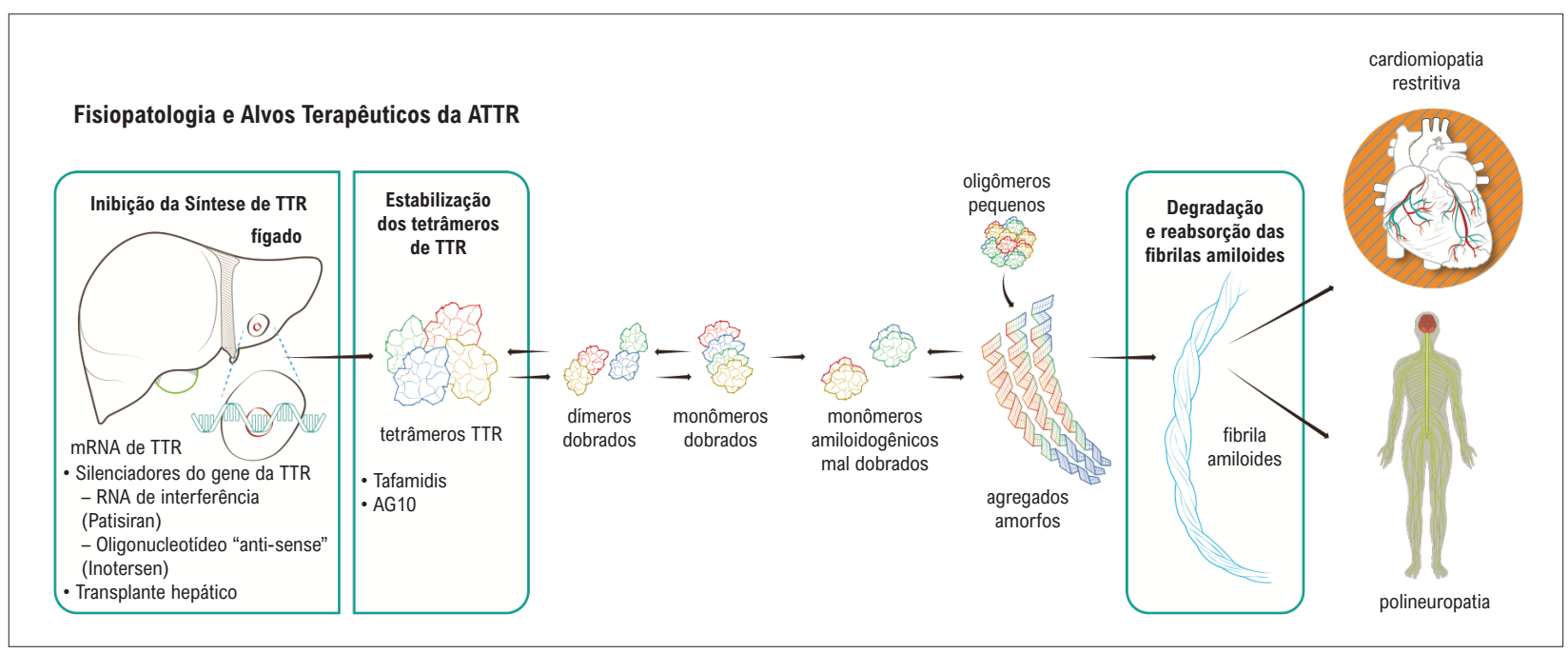

Figura 12 - Ilustração mostrando a fisiopatogênese da deposição de fibrilas amiloides na ATTR e alvos terapêuticos reconhecidos. 
inibindo efetivamente a cascata que resulta na formação das fibrilas amiloides. ${ }^{161}$ Quando testado em estudo clínico fase 3, tafamidis se mostrou eficaz em reduzir a progressão de manifestações neurológicas em pacientes em estágios precoces da polineuropatia por ATTRh. ${ }^{162}$

Tafamidis é o único fármaco, até o momento, que foi especificamente testado em pacientes com AC em um estudo clínico multicêntrico prospectivo, randomizado e placebo controlado, o estudo ATTR-ACT. ${ }^{163}$ Este estudo fase 3 incluiu 441 pacientes (18 a 90 anos de idade) com diagnóstico de cardiomiopatia por ATTR hereditária ou selvagem, caracterizada por história de insuficiência cardíaca, espessura do septo interventricular $>12 \mathrm{~mm}$ ao ecocardiograma, demonstração de depósitos amiloides por TTR (biópsia ou cintilografia com marcadores ósseos positiva), NT-Pró-BNP $>600$ pg/mL, distância percorrida no teste de caminhada de 6 minutos $(\mathrm{TC} 6 \mathrm{~m})>100$ metros. Os principais critérios de exclusão foram: classe funcional IV da NYHA, presença de amiloidose $\mathrm{AL}$, TFG $<25 \mathrm{~mL} / \mathrm{min} / 1,73 \mathrm{~m}^{2}$. Os pacientes foram randomizados para receber tafamidis na dose de $80 \mathrm{mg} / \mathrm{dia}$, tafamidis $20 \mathrm{mg} /$ dia ou placebo nas proporções de 2:1:2. O desfecho primário do estudo avaliou de forma hierárquica mortalidade por qualquer causa, seguida pela frequência de hospitalização cardiovascular ao longo de 30 meses de seguimento. Os desfechos secundários principais foram a mudança da distância percorrida no TC6m e do escore de qualidade de vida obtido no Kansas City Cardiomyopathy Questionnaire (KCCQ). Para análise estatística, agruparam-se os resultados dos grupos de pacientes recebendo as doses de tafamidis de $80 \mathrm{mg}$ e $20 \mathrm{mg}$. Os resultados reportados mostraram que os pacientes recebendo tafamidis $(n=264)$ exibiram redução de $30 \%$ no risco relativo de mortalidade por qualquer causa quando comparados aos pacientes recebendo placebo $(n=177)[(R R=0,70$ [IC 95\%: 0,51 $0,96]), 32 \%$ na redução de internações cardiovasculares (RR $=0,68$ [IC95\%: 0,56-0,81]) e redução da taxa de declínio da distância percorrida no TC6m $(p<0,001)$ e menor taxa de declínio do escore do KCCQ $(p<0,001)$. As curvas de sobrevida de Kaplan-Meier mostraram que tafamidis resultou em redução da mortalidade por qualquer causa, com as curvas divergindo após cerca de 18 meses de tratamento, resultado concordante com o conceito de que tafamidis é um fármaco modificador da história natural da doença. A substância foi bem tolerada, com incidência similar dos diferentes efeitos adversos nos grupos tafamidis e placebo. $\mathrm{Na}$ análise de subgrupos de pacientes, tafamidis associou-se à redução da mortalidade por qualquer causa em comparação ao placebo de maneira independente à classe funcional da NYHA, ou genótipo da ATTR, se hereditária ou selvagem. Contudo, os pacientes exibindo classe funcional III da NYHA no momento da inclusão no estudo, alocados no grupo tafamidis, apresentaram maiores taxas de hospitalização quando comparados aos pacientes recebendo placebo, resultado provavelmente explicado por uma sobrevida mais longa durante uma fase de doença mais grave. Essa análise de subgrupos levanta a necessidade de um estudo com tamanho amostral adequado para avaliar especificamente o efeito do tafamidis em pacientes com ATTR e sintomas mais avançados de insuficiência cardíaca.
Mais recentemente, foram publicados os resultados do estudo de extensão e aberto do estudo ATTRACT mostrando que a dose de 80 mg/dia de tafamidis em comparação à dose de $20 \mathrm{mg} /$ dia associou-se a aumento significativo da sobrevida $\left[R R=0,70\right.$ (IC 95\%: 0,50-0,979)], $p=0,0374 .{ }^{164}$

Com base nessas evidências, recomenda-se o uso de tafamidis na dose de $80 \mathrm{mg} /$ dia para tratamento de pacientes com AC por ATTRv ou ATTRwt, para pacientes com insuficiência cardíaca, em CF I a III da NYHA, sem disfunção renal grave, devendo-se iniciar a terapia nas fases mais precoces da doença (Tabela 12). No Brasil, tafamidis na dose de $80 \mathrm{mg} /$ dia recebeu a aprovação da Anvisa para tratamento da AC por ATTR.

\subsubsection{2. $A G 10$}

AG10 é um estabilizador seletivo dos tetrâmeros da TTR, desenhado para mimetizar a influência estrutural da mutação protetora superestabilizadora T119M, que reduz significativamente a taxa de dissociação dos tetrâmeros. ${ }^{165}$ Essa droga foi avaliada em estudo multicêntrico fase 2, randomizado, duplo cego, placebo-controlado envolvendo 49 pacientes com cardiomiopatia por ATTR sintomáticos, em classe funcional II ou III da NYHA. O tratamento se mostrou bem tolerado e demonstrou estabilização da TTR quase completa. ${ }^{166} \mathrm{Um}$ estudo clínico multicêntrico fase 3 testando o efeito do AG10 em pacientes com AC encontra-se em andamento. (ClinicalTrial.gov - Identificador: NCT03860935).

\subsubsection{Inibidores da Síntese Hepática de TTR}

Terapias baseadas no silenciamento da expressão dos genes que codificam a produção hepática de TTR são muito promissoras, incluindo estratégias com RNA de interferência (Patisiran) e oligonucleotídeos anti-sense (Inotersen). Ambos os fármacos foram testados em estudos multicêntricos fase $3 \mathrm{em}$ pacientes com polineuropatia por ATTRv e se mostraram efetivos em reduzir a progressão das manifestações neurológicas. ${ }^{167,168}$ Análises post hoc de subgrupos de pacientes com AC incluídos nesses estudos sugerem efeitos positivos sobre a progressão da cardiomiopatia. Ambas as classes de silenciadores de expressão gênica estão atualmente sendo testadas em estudos multicêntricos fase 3 em pacientes com diagnóstico de AC-ATTR (ClinicalTrials.gov Identifiers: NCT03997383 e NCT04136171).

\subsubsection{Degradação e Reabsorção das Fibrilas Amiloides}

Alguns compostos com base em moléculas hidrofóbicas mostraram-se efetivos em estudos in vitro e experimentais para promover a desagregação das fibras amiloides depositadas nos tecidos, permitindo a reabsorção dos seus depósitos pelo sistema macrofágico. ${ }^{169} \mathrm{~A}$ doxiciclina, um antibiótico da família das tetraciclinas, mostrou ser efetiva para esta finalidade em estudos experimentais, ${ }^{170}$ com efeitos sinérgicos quando empregada junto com o ácido tauro-urso-desoxicólico. ${ }^{171}$ Ainda que esta abordagem se mostre promissora quando são contemplados os estudos pré-clínicos, a experiência clínica com uso desta combinação de medicamentos é muito limitada e não permite estabelecer sua eficácia ou embasar recomendações para seu uso. 


\section{Manejo da Síndrome da Insuficiência Cardíaca}

Além da terapia específica para amiloidose, pode ser necessário tratamento de suporte para IC. A AC apresenta-se inicialmente como IC de fração de ejeção preservada (ICFEp) e padrão restritivo do enchimento ventricular esquerdo, podendo ocorrer, tardiamente, a progressão da doença e redução da fração de ejeção. Esse mecanismo fisiopatológico pode explicar as dificuldades de manejo clínico do paciente com amiloidose cardíaca ao se usar medicações consagradas para IC de fração de ejeção reduzida (ICFEr). ${ }^{20,21}$

A manutenção da euvolemia, com restrição hídrica e medicamentos, é o foco. A medicação mais utilizada é o diurético de alça, indicado para reduzir a congestão pulmonar e sistêmica, podendo associar-se os antagonistas da aldosterona (Tabela 12). O uso de diuréticos buscando a euvolemia pode ser um desafio, visto que o excesso pode prejudicar a função renal e/ou resultar em baixo débito cardíaco devido à redução da pré-carga em um coração com volume sistólico ejetado já reduzido. ${ }^{172,173}$ Além disso, em pacientes com polineuropatia autonômica, a presença de hipotensão pode dificultar o uso de diuréticos devido à précarga lábil. ${ }^{172}$

Em relação aos fármacos modificadores de prognóstico usados para o tratamento da ICFER, os antagonistas neuro-hormonais como inibidores da enzima de conversão da angiotensina II (iECA), bloqueadores dos receptores de angiotensina II (BRA) e betabloqueadores (BB), ou até mesmo substâncias recentemente descritas como os inibidores da neprilisina e antagonistas do receptor de angiotensina II (INRA) e inibidores de SGLT2, não há evidências científicas de benefício na amiloidose cardíaca, além de haver risco de hipotensão associada à disfunção autonômica. Aimo et al. ${ }^{173}$ observaram, em um estudo retrospectivo, unicêntrico com 99 pacientes com AC (33\% com amiloidose AL e 67\% com amiloidose TTR) que iECA/BRA e antagonistas mineralocorticoides (AMR) podem ser utilizados com segurança, com ajuste gradual da dose, se ausência de contraindicações, e que BB são menos tolerados em pacientes com amiloidose $A L$, disfunção de ventrículo esquerdo e direito. $\mathrm{O}$ uso de $\mathrm{BB}$ e bloqueadores de cálcio (BCC) não di-hidropiridínicos normalmente não é bem tolerado, pois, devido ao volume sistólico ejetado baixo, esses pacientes dispõem apenas da frequência cardíaca para manutenção do débito cardíaco. Além disso, o uso de BCC não di-hidropiridínicos em amiloidose por cadeias leves deve ser evitado, pois eles se ligam às fibrilas amiloides, podendo resultar em bloqueios avançados e choque cardiogênico. ${ }^{172,173}$

\subsection{Manejo das Arritmias}

As arritmias são muito comuns em pacientes com amiloidose cardíaca, e geralmente são sintomáticas e pouco toleradas. A avaliação de arritmias nesta população deve envolver três diferentes situações: arritmias atriais; arritmias ventriculares e doença do sistema de condução.

\subsubsection{Arritmias Atriais e Anticoagulantes}

O depósito amiloide leva a espessamento atrial com alteração de relaxamento atrial, aumento das pressões intracavitárias, gerando dilatação atrial que, em associação à fibrose atrial, predispõe à fibrilação atrial (FA) ou a outras arritmias atriais. A prevalência de FA pode variar de $11 \%$ a $71 \%$ em pacientes com AC, sendo ainda mais elevada em pacientes com AC por ATTR, possivelmente por acometer pacientes mais idosos do sexo masculino. ${ }^{174,175}$

O manejo da FA nesses pacientes é, em geral, difícil, uma vez que costumam não tolerar os principais fármacos utilizados para o controle de frequência, tais como BB, BCC ou digitálicos, por precipitarem hipotensão postural e descompensação da IC. Diante da necessidade de uso dessas medicações, aconselhase uso de baixas doses com monitoramento hemodinâmico cauteloso, além de controle de nível sérico, se digoxina for utilizada. Para o controle de ritmo, uma análise retrospectiva não mostrou diferença em relação à sobrevida quando comparados pacientes que receberam fármacos antiarrítmicos com pacientes que foram tratados apenas com controle de frequência. ${ }^{176}$ Dados recentes sugerem que a ablação por cateter pode se associar à redução de mortalidade em pacientes com AC, especialmente quando realizada precocemente. No entanto, esses dados são oriundos de estudos observacionais retrospectivos pequenos que também demostraram alta taxa de recorrência de FA. ${ }^{177}$

Por fim, a redução da contratilidade atrial provocada pela infiltração amiloide no tecido atrial pode ainda contribuir para a formação de trombos, dado este demonstrado em estudos de autópsia que revelam a presença de até 33\% de trombos intracavitários em pacientes com $\mathrm{AC}^{178}$ e estudos retrospectivos revelando prevalência de trombo intracavitário de 15\% a $33 \% .{ }^{179,180}$ Diante disso, a anticoagulação está indicada em pacientes com AC que desenvolvam FA, independentemente dos cálculos de escores de risco (Tabela 12). Além disso, trombo atrial esquerdo tem sido descrito em até 30\% dos pacientes submetidos ao ecocardiograma transesofágico realizado antes de uma cardioversão elétrica programada mesmo em vigência de anticoagulação adequada. ${ }^{181,182}$ Assim, recomenda-se a realização de ecocardiograma transesofágico em todo paciente candidato à cardioversão elétrica. O papel da anticoagulação em pacientes em ritmo sinusal ainda é incerto. Porém, mesmo na presença de ritmo sinusal, a alteração da contratilidade atrial é comum e está associada a formação de trombo atrial, especialmente em pacientes com amiloidose AL. ${ }^{180,182}$

\subsubsection{Arritmias Ventriculares}

Arritmias ventriculares são frequentes em pacientes com AC, especialmente amiloidose AL. Estudos prévios têm detectado a presença de arritmias ventriculares complexas em pelo menos $50 \%$ dos pacientes com $A C$ forma $A L$, sendo taquicardia ventricular não sustentada (TVNS) a arritmia mais frequente e associada a menor sobrevida. ${ }^{183,184}$

Neste contexto, discute-se o papel do uso de cardiodesfibrilador implantável (CDI) na prevenção de morte súbita de pacientes com AC. Na presença de taquicardia ventricular instável ou sobreviventes de parada cardíaca sem causa reversível com expectativa de vida maior que 1 ano com qualidade significativa, sugere-se potencial benefício do uso de CDI. ${ }^{185-187}$

No entanto, como prevenção primária, a indicação de CDI é mais difícil por diferentes motivos. O primeiro deles é que a maioria das causas de morte súbita descritas relaciona-se à dissociação eletromecânica e não arritmias ventriculares; ${ }^{188} \mathrm{O}$ 
segundo é a histórica baixa expectativa de vida de pacientes com $A C$, especialmente $A L$, e, por fim, as ferramentas de estratificação de risco tradicionais, tais como fração de ejeção reduzida, não parecem de fato aplicáveis a pacientes com AC, uma vez que disfunção sistólica grave está associada a estágios finais da doença em que predomina a falência de bomba como causa de morte. O desafio é, portanto, identificar o paciente em risco na fase precoce da doença quando arritmia predomina e pode potencialmente ser corrigida pelo uso do CDI. Estudos prospectivos são necessários para definir quando a indicação de CDI pode ser benéfica em pacientes com AC. ${ }^{189}$

\subsection{Distúrbios de Condução}

Doença do sistema de condução é altamente prevalente entre pacientes com AC, sendo a condução atrioventricular mais comumente afetada do que o nó sinusal. A fisiopatologia envolvida não está totalmente definida, embora estudos pequenos sugiram envolvimento do sistema de condução por proteína amiloide. ${ }^{190}$ Há evidências de que essas alterações são a causa de óbito em um número considerável de pacientes com amiloidose cardíaca, ${ }^{191}$ sendo o marca-passo (MP) frequentemente indicado, especialmente em pacientes com AC por ATTR. ${ }^{178} \mathrm{Em}$ uma coorte em Columbia, MP foi indicado em 43\% dos pacientes com ATTRwt (wild type) e 36\% dos pacientes com ATTRv. ${ }^{192}$ A indicação de MP nessa população deve seguir as recomendações tradicionais para implante. ${ }^{193}$

\subsection{Opções Terapêuticas na Insuficiência Cardíaca Avançada}

Na IC avançada associada à AC, o uso de estratégias avançadas de suporte incluindo dispositivos de assistência circulatória mecânica e transplante apresenta desafios e particularidades, especialmente por se tratar de doença multissistêmica. Além disso, pelo tamanho reduzido da cavidade do ventrículo esquerdo e o frequente acometimento do ventrículo direito, pode haver limitação ao uso de dispositivos de assistência circulatória mecânica de longa duração. ${ }^{193,194}$ Apesar de, historicamente, o transplante cardíaco apresentar uma pior curva de sobrevida na $A C,{ }^{191}$ os resultados mais recentes estão semelhantes às outras etiologias. ${ }^{195}$ Esta mudança está relacionada a uma melhor seleção dos pacientes e estratégias específicas, como o transplante duplo na AC por ATTRv e o transplante cardíaco precedendo o transplante de medula óssea na AL. ${ }^{196}$

A Tabela 12 resume as recomendações para o tratamento da AC.

\section{Centros de Excelência/Referência e Novos Modelos de Remuneração do Tratamento}

O acesso ao cuidado comprometido com melhoria contínua da qualidade assistencial é pilar fundamental para alcançar resultados de excelência, sendo item crítico nos casos das doenças complexas como a AC. Os gestores públicos e privados, pacientes, profissionais de saúde e todos envolvidos no cuidado ao paciente

Tabela 12 - Recomendações para tratamento da amiloidose cardíaca (AC)

\begin{tabular}{|c|c|c|}
\hline Recomendação & $\begin{array}{l}\text { Classe de } \\
\text { recomendação }\end{array}$ & $\begin{array}{c}\text { Nível de evidência } \\
\text { (referências) }\end{array}$ \\
\hline \multicolumn{3}{|l|}{ Recomendações para o tratamento da insuficiência cardíaca } \\
\hline Diuréticos de alça para controle das manifestações congestivas & 1 & $\mathrm{C}$ \\
\hline Evitar uso de substâncias bradicardizantes, salvo situações especiais & 1 & $\mathrm{C}$ \\
\hline $\begin{array}{l}\text { Uso rotineiro dos fármacos modificadores do prognóstico utilizados para o tratamento da } \\
\text { ICFER: betabloqueador, iECA, BRA, INRA, iSGLT2, ARM }\end{array}$ & III & C \\
\hline $\begin{array}{l}\text { Anticoagulação oral para pacientes com AC e fibrilação atrial, independentemente do risco } \\
\text { calculado de AVE ou embolia sistêmica }\end{array}$ & I & C \\
\hline $\begin{array}{l}\text { Oferecer aos pacientes com diagnóstico confirmado de AC o encaminhamento para um } \\
\text { centro especializado }\end{array}$ & 1 & C \\
\hline \multicolumn{3}{|l|}{ Recomendações para o tratamento específico para ATTR } \\
\hline $\begin{array}{l}\text { Tafamidis } 80 \mathrm{mg} / \text { dia, para o tratamento específico de pacientes com AC confirmada por ATTRv } \\
\text { ou ATTRwt, com insuficiência cardíaca, em CF I a III da NYHA, sem disfunção renal grave, para } \\
\text { redução da mortalidade e redução da taxa de progressão da incapacidade física e da perda da } \\
\text { qualidade de vida }\end{array}$ & I & $\begin{array}{c}\text { B } \\
\text { (ref. 162, 163) }\end{array}$ \\
\hline
\end{tabular}

Recomendações para o tratamento específico para AL

Avaliação conjunta com hematologista nos casos suspeitos ou

confirmados de $\mathrm{AL}$, para definição do tratamento:

Considerar o transplante de células-tronco hematopoiéticas (TCTH), para pacientes com AL classificados como elegíveis: não exibindo comorbidades graves, sem doença cardíaca avançada, sem insuficiência renal grave, sem envolvimento de mais de dois órgãos ou idade avançada

Iniciar terapia quimioterápica com medicações antiplasmocitárias para pacientes com AL não candidatos ao TCTH.

I B

$148,149)$

(ref. 147, 148, 149)

A

(ref. 139,156)

CF: classe funcional; NYHA: Sociedade Nova-iorquina de Cardiologia; AVE: acidente vascular encefálico; iECA: inibidor da enzima de conversão da angiotensina; BRA: bloqueador do receptor da angiotensina-II; iSGLT2: inibidor do cotransportador de sódio-glicose-2; ARM: antagonista do receptor de mineralocorticoide. 
com amiloidose estão hoje comprometidos na construção de uma jornada que possibilite o cuidado certo e no lugar certo.

A AC deve ser abordada tendo como ponto fundamental o rápido diagnóstico, particularmente nas formas $\mathrm{AL}$, e a disponibilidade de equipes multidisciplinares com comprovada experiência e utilizando protocolos clínicos embasados nas melhores evidências científicas. Ao lado disso, é necessário promover cuidado integral e monitorar e publicar os resultados assistenciais. Nesses centros de referência, deve-se observar um modelo de prática integrada e colaborativa, com estrutura de telemedicina para apoiar o diagnóstico de centros mais distantes, monitorar o paciente e promover pesquisa clínica, base para incorporação futura de novas tecnologias (terapias emergentes). Essa iniciativa está disponível em vários lugares do mundo e está sendo implementada com sucesso em algumas regiões do nosso país. ${ }^{187-199}$

Adicionalmente, é relevante considerar que os centros de referência devem ser os pilares para a construção de um Registro Nacional de Amiloidose Cardíaca, permitindo melhor conhecimento da epidemiologia no nosso meio e da qualidade do cuidado, além de mensurar os desfechos clínicos centrados no paciente, de forma a contribuir para elaboração de políticas públicas.

A construção de novos modelos de financiamento dos medicamentos de alto custo para doenças raras vem sendo discutida, testada em estudos de farmacoeconomia e implementada ao redor do mundo. ${ }^{200}$ Acoplar uma estratégia de compartilhamento de risco entre as empresas farmacêuticas, fontes pagadoras e provedores de saúde, com base na avaliação de desfechos clínicos e no impacto de protocolos clínicos, deve envolver pesquisa clínica. Esse novo paradigma começa a ser delineado e discutido em nosso país no contexto das doenças raras e pode ser empregado na AC. ${ }^{201,202}$ A sustentabilidade do sistema de saúde e a garantia de acesso ao tratamento de excelência aos pacientes com AC envolve, cada vez mais, o papel da Sociedade Brasileira de Cardiologia (SBC) e dos seus departamentos científicos/grupos de estudos. A SBC está promovendo debate sobre as boas práticas assistenciais em todas essas dimensões críticas para a construção de um sistema de saúde centrado nas necessidades do paciente e combatendo desperdícios.

De acordo com a avaliação da incorporação de novos tratamentos no Sistema Único de Saúde (SUS) para as doenças raras com o apoio da CONITEC (Comissão Nacional de Incorporação Tecnológica), foram incorporados cerca de 52\% dos medicamentos avaliados. Nossa visão é que estamos construindo um novo cenário de tal forma, que o embasamento técnico, à luz de dados robustos e com o apoio de protocolos clínicos e centros de referência, possa substituir o modelo da busca de acesso via judicialização e seus impactos sobre os gastos da União. ${ }^{197}$

\section{Lacunas do Conhecimento e Perspectivas Futuras}

Apesar dos amplos avanços recentemente alcançados no entendimento da $\mathrm{AC}$, ainda há inúmeras lacunas do conhecimento em torno desta doença complexa e plurifacetada que necessitam ser elucidadas. O diagnóstico da amiloidose, assim como seu tratamento, é uma área em franca evolução, o que pode ser ilustrado pelos 638 estudos recentemente completados ou em andamento registrados no site https://www.clinicaltrials.gov.

$\mathrm{Na}$ área da imagem cardiovascular para diagnóstico da AC, além da cintilografia cardíaca com radiotraçadores ósseos, como o ${ }^{99 m}$ Tc-pirofosfato, que permite a obtenção de imagens moleculares do acúmulo de fibras amiloides no miocárdio, temos como perspectivas futuras o uso de imagens de PET usando ${ }^{18} \mathrm{~F}$-Florbetapir em nervos periféricos e/ou outros locais extracardíacos como mais uma ferramenta diagnóstica, porém ainda não disponível no Brasil. ${ }^{203,204}$ Elastografia, ultrassonografia e RMC também estão sendo usadas para avaliação do grau de fibrose miocárdica e poderão ser ferramentas adicionais e promissoras para auxiliar no diagnóstico e prognóstico.

Trabalhos recentes têm se concentrado na análise do transcriptoma, em busca de diferenças de expressão entre indivíduos saudáveis e doentes, com análise molecular e genômica integrativa. O transcriptoma de pacientes com amiloidose AL é mais semelhante ao dos pacientes com gamopatia monoclonal de significado indeterminado. Além disso, o nível de microRNA circulante, que conhecido por se correlacionar com dano cardíaco, é aumentado nos pacientes AL. Por meio da análise de componentes principais, têm sido demonstrados perfis fenotípicos altamente sobrepostos entre $\mathrm{AL}$ e gamopatia monoclonal de significado indeterminado e mieloma múltiplo. ${ }^{205,206}$

Adicionalmente, a inteligência artificial (IA) aplicada na análise de dados disponíveis de banco de dados de prontuários médicos emerge como uma estratégia promissora para identificar indivíduos com sinais de alerta e permitir o diagnóstico mais precoce da AC, com potencial para reduzir o atraso para o início dos tratamentos modificadores da evolução da doença.

O desenvolvimento de novas terapias específicas para AC por ATTR é um campo intenso de investigação. Terapias de silenciamento gênico da TTR que se mostraram efetivas para o tratamento da polineuropatia amiloide hereditária estão sendo atualmente testadas em grandes estudos multicêntricos em pacientes com AC por ATTR, incluindo as plataformas de RNA de interferência, com o patisiran no estudo APOLLO-B (ClinicalTrials.gov Identifier: NCT03997383); e a tecnologia de oligonucleotídeos anti-sense no ensaio clínico CARDIOTTRansform, testando um novo fármaco de segunda geração, AKCEA-TTR-LRx (ClinicalTrials.gov Identifier: NCT04136171).

Devido ao potencial arritmogênico e à lesão do sistema de condução associados ao depósito amiloide, é frequente o uso de dispositivos implantáveis como marca-passo ou cardiodesfibriladores implantáveis como estratégia de redução de mortalidade e aumento de sobrevida nessa população. Por outro lado, os indivíduos com AC e fibrilação ou flutter atrial exibem alto risco de eventos cardioembólicos e tem sido recomendado o tratamento com anticoagulantes. Essas intervenções, apesar de terem um racional fisiopatológico para aplicação em pacientes com amiloidose, ainda precisam ser testadas em ensaios clínicos adequados, sendo áreas importantes para investigação clínica futura. Além disso, o transplante cardíaco tem se mostrado como estratégia segura nesses pacientes, mas o uso de ventrículo artificial e a possibilidade de combinação das terapias devem ainda ser analisados em ensaios clínicos adequados.

É fundamental que esperemos os resultados de estudos distintos testando diferentes intervenções e terapias específicas, 
para que possamos definir as melhores opções e combinações de tratamento para essa doença, tendo em mente que: 1) não conhecemos completamente todos os detalhes da sua fisiopatologia; 2) não temos compreensão e experiência ampla de como as medicações funcionam nessa doença; 3) ainda não temos uma avaliação acurada, detalhada e de longo prazo dos riscos e benefícios dos diferentes tratamentos; 4) e também não conhecemos a relação entre dose e resposta das diferentes medicações para esse cenário clínico.

Dessa forma, julgamos que são ações relevantes e fundamentais a serem implantadas:
1) Criação de novos centros de referência/excelência em AC.

2) Capacitação de profissionais para o reconhecimento precoce e encaminhamento para centros especializados.

3) Estímulo para elaboração de um Registro Nacional de Amiloidose Cardíaca.

4) Organização e debate dos desafios para uma "Jornada do Paciente com Amiloidose" com segurança e qualidade.

5) Discussão de novos modelos de remuneração e de atenção na $A C$.

6) Incentivo à pesquisa clínica da AC em nosso país.

\section{Errata}

Edição de Setembro de 2021, vol. 117 (3), págs. 561-598

No "Posicionamento sobre Diagnóstico e Tratamento da Amiloidose Cardíaca - 2021", com número de DOI: https://doi. org/10.36660/abc.20210718, publicado no periódico Arquivos Brasileiros de Cardiologia, 117(3):561-598, na página 561, foi incluído o autor Flávio Henrique Valicelli, instituição de número 1, após o autor Carlos Eduardo Rochitte. Na página 564, foi inserido o conflito de interesse: "Nada a ser declarado", abaixo do nome Fernando Bacal.

\section{Referências}

1. Sipe JD, Cohen AS. Review: history of the amyloid fibril. J Struct Biol. 2000;130(23):88-98

2. Benson MD, Buxbaum JN, Eisenberg DS, Merlini G, Saraiva MJM, Sekijima Y, et al. Amyloid nomenclature 2018: recommendations by the International Society of Amyloidosis (ISA) nomenclature committee. Amyloid. 2018;25(4):215-9.

3. Falk RH, Alexander KM, Liao R, Dorbala S. AL (Light-Chain) CardiacAmyloidosis: A Review of Diagnosis and Therapy. J Am Coll Cardiol. 2016;68(12):1323-41.

4. Ruberg FL, Berk JL. Transthyretin (TTR) cardiac amyloidosis. Circulation. 2012;126(10):1286-300.

5. Zhao L, Buxbaum JN, Reixach N. Age-related oxidative modifications of transthyretin modulate its amyloidogenicity. Biochemistry. 2013;52(11):191326.

6. Buxbaum JN, Tagoe C, Gallo G, Walker JR, Kurian S, Salomon DR. Why are some amyloidoses systemic? Does hepatic "chaperoning at a distance" prevent cardiac deposition in a transgenic model of human senile systemic (transthyretin) amyloidosis? FASEB J. 2012;26(6):2283-93.

7. Gertz MA, Dispenzieri A, Sher T. Pathophysiology and treatment of cardiac amyloidosis. Nat Rev Cardiol. 2015;12(2):91-102.

8. Koike H, Katsuno M. Ultrastructure in Transthyretin Amyloidosis: From Pathophysiology to Therapeutic Insights. Biomedicines. 2019;7(1):11.

9. Ruberg FL, Grogan M, Hanna M, Kelly JW, Maurer MS. Transthyretin Amyloid Cardiomyopathy: JACC State-of-the-Art Review. J Am Coll Cardiol. 2019;73(22):2872-91.

10. Mankad AK, Sesayl, Shah KB. Light-chain cardiac amyloidosis. Curr Probl Cancer. 2017;41(2):144-56

11. Wechalekar AD, Gillmore JD, Hawkins PN. Systemic amyloidosis. Lancet. 2016;387(10038):2641-54.

12. Gertz MA, Dispenzieri A. Systemic Amyloidosis Recognition, Prognosis, and Therapy: A Systematic Review. JAMA. 2020;324(1):79-89.

13. Muchtar E, Dispenzieri A, Magen H, Grogan M, Mauermann M, McPhail ED, et al. Systemic amyloidosis from A (AA) to T (ATTR): a review. J Intern Med. 2021;289(3):268-92.

14. Milandri A, Farioli A, Gagliardi C, Longhi S, Salvi F, Curti S, et al. Carpal tunnel syndrome in cardiac amyloidosis: implications for early diagnosis and prognostic role across the spectrum of aetiologies. Eur J Heart Fail. 2020;22(3):507-15

15. Witteles RM, Bokhari S, Damy T, Elliott PM, Falk RH, Fine NM, etal. Screening for Transthyretin Amyloid Cardiomyopathy in Everyday Practice. JACC Heart Fail. 2019;7(8):709-16.

16. Jacobson D, Tagoe C, Schwartzbard A, Shah A, Koziol J, Buxbaum J. Relation of clinical, echocardiographic and electrocardiographic features of cardiac amyloidosis to the presence of the transthyretin V122I allele in older AfricanAmerican men. Am J Cardiol. 2011;108(3):440-4.

17. Parman Y, Adams D, Obici L, Galan L, Guergueltcheva V, SuhrOB, etal. Sixtyyears of transthyretin familial amyloid polyneuropathy (TTR-FAP) in Europe: where are we now? A European network approach to defining the epidemiology and management patterns for TTR-FAP. Curr Opin Neurol. 2016;29 Suppl 1:S3-S13.

18. Kyle RA, Linos A, Beard CM, Linke RP, Gertz MA, O'Fallon WM, et al. Incidence and natural history of primary systemic amyloidosis in Olmsted County, Minnesota, 1950 through 1989. Blood. 1992;79(7):1817-22.

19. Gillmore JD, Maurer MS, Falk RH, Merlini G, Damy T, Dispenzieri A, et al. Nonbiopsy Diagnosis of Cardiac Transthyretin Amyloidosis. Circulation. 2016;133(24):2404-12.

20. Lane T, Fontana M, Martinez-Naharro A, Quarta CC, Whelan CJ, Petrie A, et al. Natural History, Quality of Life, and Outcome in Cardiac Transthyretin Amyloidosis. Circulation. 2019;140(1):16-26.

21. Gonzalez-LopezE, Gallego-DelgadoM, Guzzo-MerelloG, de Haro-Del Moral FJ, Cobo-Marcos M, Robles C, etal. Wild-type transthyretin amyloidosis as a cause of heartfailure with preserved ejection fraction. Eur HeartJ. 2015;36(38):2585-94.

22. Cornwell GG, 3rd, Murdoch WL, Kyle RA, WestermarkP, Pitkanen P. Frequency and distribution of senile cardiovascular amyloid. A clinicopathologic correlation. Am J Med. 1983;75(4):618-23.

23. Tanskanen M, Peuralinna T, Polvikoski T, Notkola IL, Sulkava R, Hardy J, et al. Senile systemic amyloidosis affects $25 \%$ of the very aged and associates with genetic variation in alpha2-macroglobulin and tau: a population-based autopsy study. Ann Med. 2008;40(3):232-9

24. Cruz MW, Pinto MV, Pinto LF, Gervais R, Dias M, Perez C, et al. Baseline disease characteristics in Brazilian patients enrolled in Transthyretin Amyloidosis Outcome Survey (THAOS). Arq Neuropsiquiatr. 2019;77(2):96-100. 
25. Gilstrap LG, Dominici F, Wang Y, El-Sady MS, Singh A, Di Carli MF, et al. Epidemiology of Cardiac Amyloidosis-Associated Heart Failure Hospitalizations Among Fee-for-Service Medicare Beneficiaries in the United States. Circ Heart Fail. 2019;12(6):e005407.

26. Lousada I, Comenzo RL, Landau H, Guthrie S, Merlini G. Light Chain Amyloidosis: Patient Experience Survey from the Amyloidosis Research Consortium. Adv Ther. 2015;32(10):920-8.

27. Adams D, Polydefkis M, Gonzalez-Duarte A, Wixner J, Kristen AV, Schmidt $\mathrm{HH}$, et al. Long-term safety and efficacy of patisiran for hereditary transthyretin-mediated amyloidosis with polyneuropathy: 12-month results of an open-label extension study. Lancet Neurol. 2021;20(1):49-59.

28. Plante-Bordeneuve V, Said G. Familial amyloid polyneuropathy. Lancet Neurol. 2011;10(12):1086-97.

29. Sekijima Y. Transthyretin (ATTR) amyloidosis: clinical spectrum, molecular pathogenesis and disease-modifying treatments. J Neurol Neurosurg Psychiatry. 2015;86(9):1036-43.

30. Pinto MV, Pinto LF, Dias M, Rosa RS, Mundayat R, Pedrosa RC, et al. Late-onset hereditary ATTR V30M amyloidosis with polyneuropathy: Characterization of Brazilian subjects from the THAOS registry. J Neurol Sci. 2019;403:1-6.

31. Rapezzi C, Quarta CC, Riva L, Longhi S, Gallelli I, Lorenzini M, et al. Transthyretin-related amyloidoses and the heart: a clinical overview. Nat Rev Cardiol. 2010;7(7):398-408.

32. Kapoor M, Rossor AM, Laura M, Reilly MM. Clinical Presentation, Diagnosis and Treatment of TTR Amyloidosis. J Neuromuscul Dis. 2019;6(2):189-99.

33. Lahuerta-Pueyo CL, Tubar Arregui MA, Gracia- Gutierrez AG, Buena Juana E, Guillén SM. Estimating the prevalence of allelic variants in the transthyretin gene by analysing large-scale sequencing data. Eur J Hum Genet. 2019;27(5):783-91

34. Park GY, Jamerlan A, Shim KH, An SSA. Diagnostic and Treatment Approaches Involving Transthyretin in Amyloidogenic Diseases. Int J Mol Sci. 2019;20(12):2982.

35. Maurer MS, Bokhari S, Damy T, Dorbala S, Drachman BM, Fontana M, et al. Expert Consensus Recommendations for the Suspicion and Diagnosis of Transthyretin Cardiac Amyloidosis. Circ Heart Fail. 2019;12(9):e006075.

36. Obici L, Kuks JB, Buades J, Adams D, Suhr OB, Coelho T, et al. Recommendations for presymptomatic genetic testing and management of individuals at risk for hereditary transthyretin amyloidosis. Curr Opin Neurol. 2016;29 Suppl 1:S27-35.

37. Maurer MS, Elliott P, Comenzo R, Semigran M, Rapezzi C. Addressing Common Questions Encountered in the Diagnosis and Management of Cardiac Amyloidosis. Circulation. 2017;135(14):1357-77.

38. Castano A, Drachman BM, Judge D, Maurer MS. Natural history and therapy of TTR-cardiac amyloidosis: emerging disease-modifying therapies from organ transplantation to stabilizer and silencer drugs. Heart Fail Rev. 2015;20(2):163-78

39. Dungu JN, Anderson LJ, Whelan CJ, Hawkins PN. Cardiac transthyretin amyloidosis. Heart. 2012;98(21):1546-54.

40. Mohty D, Damy T, Cosnay P, Echahidi N, Casset-Senon D, Virot P, et al. Cardiac amyloidosis: updates in diagnosis and management. Arch Cardiovasc Dis. 2013;106(10):528-40.

41. Mohammed SF, Mirzoyev SA, Edwards WD, Dogan A, Grogan DR, Dunlay SM, et al. Left ventricular amyloid deposition in patients with heart failure and preserved ejection fraction. JACC Heart Fail. 2014;2(2):113-22.

42. Rapezzi C, Lorenzini M, Longhi S, Milandri A, Gagliardi C, Bartolomei I, et al. Cardiac amyloidosis: the great pretender. Heart Fail Rev. 2015;20(2):117-24 .

43. Yilmaz A, Bauersachs J, Bengel F, Buchel R, Kindermann I, Klingel K, et al. Diagnosis and treatment of cardiac amyloidosis: position statement of the German Cardiac Society (DGK). Clin Res Cardiol. 2021;110(4):479-506.
44. Nakagawa M, Sekijima Y, Yazaki M, Tojo K, Yoshinaga T, Doden T, etal. Carpa tunnel syndrome: a common initial symptom of systemic wild-type ATTR (ATTRwt) amyloidosis. Amyloid. 2016;23(1):58-63.

45. Geller HI, Singh A, Alexander KM, Mirto TM, Falk RH. Association Between Ruptured Distal Biceps Tendon and Wild-Type Transthyretin Cardiac Amyloidosis. JAMA. 2017;318(10):962-3.

46. Merlini G, Bellotti V. Molecular mechanisms of amyloidosis. N Engl J Med. 2003;349(6):583-96

47. Conceicao I, Gonzalez-Duarte A, Obici L, Schmidt HH, Simoneau D, Ong $\mathrm{ML}$, et al. "Red-flag" symptom clusters in transthyretin familial amyloid polyneuropathy. J Peripher Nerv Syst. 2016;21(1):5-9.

48. Sekijima Y, Ueda M, Koike H, Misawa S, Ishii T, Ando Y. Diagnosis and management of transthyretin familial amyloid polyneuropathy in Japan: red-flag symptom clusters and treatment algorithm. OrphanetJ Rare Dis. 2018;13(1):6.

49. Martinez-Naharro A, Treibel TA, Abdel-Gadir A, Bulluck H, Zumbo G, Knight DS, et al. Magnetic Resonance in Transthyretin Cardiac Amyloidosis. J Am Coll Cardiol. 2017;70(4):466-77.

50. Pibarot P, Lancellotti P, Narula J. Concomitant Cardiac Amyloidosis in Severe Aortic Stenosis: The Trojan Horse? J Am Coll Cardiol. 2021;77(2):140-3.

51. Cyrille NB, Goldsmith J, Alvarez J, Maurer MS. Prevalence and prognostic significance of low QRS voltage among the three main types of cardiac amyloidosis. Am J Cardiol. 2014;114(7):1089-93.

52. Quarta CC, Solomon SD, Uraizee I, Kruger J, Longhi S, Ferlito M, et al. Left ventricular structure and function in transthyretin-related versus light-chain cardiac amyloidosis. Circulation. 2014;129(18):1840-9.

53. Carroll JD, Gaasch WH, McAdam KP. Amyloid cardiomyopathy: characterization by a distinctive voltage/mass relation. Am J Cardiol. 1982;49(1):9-13.

54. Kittleson MM, Maurer MS, Ambardekar AV, Bullock-Palmer RP, Chang PP Eisen HJ, et al. Cardiac Amyloidosis: Evolving Diagnosis and Management: A Scientific Statement From the American Heart Association. Circulation. 2020;142(1):e7-e22.

55. Mitchell C, Rahko PS, Blauwet LA, Canaday B, Finstuen JA, Foste $M C$, et al. Guidelines for Performing a Comprehensive Transthoracic Echocardiographic Examination in Adults: Recommendations from the American Society of Echocardiography. J Am Soc Echocardiogr. 2019;32(1):1-64.

56. Kolias TJ, Aaronson KD, Armstrong WF. Doppler-derived dP/dt and $-\mathrm{dP} / \mathrm{dt}$ predict survival in congestive heart failure. J Am Coll Cardiol. 2000;36(5):1594-9.

57. Voigt JU, Pedrizzetti G, Lysyansky P, Marwick TH, Houle H, Baumann R, et al. Definitions for a common standard for 2D speckle tracking echocardiography: consensus document of the EACVI/ASE/Industry Task Force to standardize deformation imaging. J Am Soc Echocardiogr. 2015;28(2):183-93.

58. Collier P, Phelan D, Klein A. A Test in Context: Myocardial Strain Measured by Speckle-Tracking Echocardiography. J Am Coll Cardiol. 2017;69(8):1043-56

59. Pagourelias ED, Vassilikos VP, Voigt JU. Left Ventricular Pressure StrainDerived Myocardial Work at Rest and during Exercise in Patients with Cardiac Amyloidosis. J Am Soc Echocardiogr. 2020;33(10):1295-6.

60. Di Bella G, Pizzino F. Myocardial Deformation Analysis and Late-Gadolinium Enhancement: Important Markers of Cardiac Amyloidosis Involvement That Can Masquerade as a False-Negative Diagnosis. Circ J. 2018;82(10):2687.

61. Bravo PE, Fujikura K, Kijewski MF, Jerosch-Herold M, Jacob S, El-Sady MS, et al. Relative Apical Sparing of Myocardial Longitudinal Strain Is Explained by Regional Differences in Total Amyloid Mass Rather Than the Proportion of Amyloid Deposits. JACC Cardiovasc Imaging. 2019;12(7 Pt 1):1165-73.

62. Rapezzi C, Fontana M. Relative Left Ventricular Apical Sparing of Longitudinal Strain in Cardiac Amyloidosis: Is it Just Amyloid Infiltration? JACC Cardiovasc Imaging. 2019;12(7 Pt 1):1174-6. 
63. Monivas Palomero V, Durante-Lopez A, Sanabria MT, Cubero JS, GonzalezMirelis J, Lopez-Ibor JV, et al. Role of Right Ventricular Strain Measured by Two-Dimensional Echocardiography in the Diagnosis of Cardiac Amyloidosis. J Am Soc Echocardiogr. 2019;32(7):845-53 e1.

64. Brand A, Frumkin D, Hubscher A, Dreger H, Stangl K, Baldenhofer G, et al. Phasic left atrial strain analysis to discriminate cardiac amyloidosis in patients with unclear thick heart pathology. Eur Heart J Cardiovasc Imaging. 2020 Apr 3;jeaa043. Doi 10.1093/ehjci/jeaa043

65. Syed IS, Glockner JF, Feng D, Araoz PA, Martinez MW, Edwards WD, et al. Role of cardiac magnetic resonance imaging in the detection of cardiac amyloidosis. JACC Cardiovascular imaging. 2010;3(2):155-64.

66. Kwong RY, Falk RH. Cardiovascular magnetic resonance in cardiac amyloidosis. Circulation. 2005;111(2):122-4.

67. Maceira AM, Joshi J, Prasad SK, Moon JC, Perugini E, Harding I, et al. Cardiovascular magnetic resonance in cardiac amyloidosis. Circulation. 2005; 111(2):186-93.

68. Kotecha T, Martinez-Naharro A, Treibel TA, Francis R, Nordin S, Abdel-Gadir A, et al. Myocardial Edema and Prognosis in Amyloidosis. Journal of the American College of Cardiology. 2018;71(25):2919-31.

69. Fontana M, Corovic A, Scully P, Moon JC. Myocardial Amyloidosis: The Exemplar Interstitial Disease. JACC Cardiovascular imaging. 2019;12(11 Pt 2):2345-56.

70. Mongeon FP, Jerosch-Herold M, Coelho-Filho OR, Blankstein R, Falk RH Kwong RY. Quantification of extracellular matrix expansion by CMR in infiltrative heart disease. JACC Cardiovascular imaging. 2012;5(9):897-907.

71. Banypersad SM, Sado DM, Flett AS, Gibbs SD, Pinney JH, Maestrini V, et al. Quantification of myocardial extracellular volume fraction in systemic AL amyloidosis: an equilibrium contrast cardiovascular magnetic resonance study. Circulation Cardiovascular imaging. 2013;6(1):34-9.

72. Martinez-Naharro A, Kotecha T, Norrington K, Boldrini M, Rezk T, Quarta C, et al. Native T1 and Extracellular Volume in Transthyretin Amyloidosis. JACC Cardiovascular imaging. 2019;12(5):810-9.

73. Fontana M, Banypersad SM, Treibel TA, Maestrini V, Sado DM, White SK, et al. Native T1 mapping in transthyretin amyloidosis. JACC Cardiovascular imaging. 2014;7(2):157-65.

74. Fontana M, Chung R, Hawkins PN, Moon JC. Cardiovascular magnetic resonance for amyloidosis. Heart Fail Rev. 2015;20(2):133-44.

75. Baggiano A, Boldrini M, Martinez-Naharro A, Kotecha T, Petrie A, Rezk $\mathrm{T}$, et al. Noncontrast Magnetic Resonance for the Diagnosis of Cardiac Amyloidosis. JACC Cardiovasc Imaging. 2020;13(1 Pt 1):69-80.

76. Pozo E, Kanwar A, Deochand R, Castellano JM, Naib T, Pazos-Lopez P, et al. Cardiac magnetic resonance evaluation of left ventricular remodelling distribution in cardiac amyloidosis. Heart. 2014;100(21):1688-95.

77. Jurcut R, Onciul S, Adam R, Stan C, Coriu D, Rapezzi C, et al. Multimodality imaging in cardiac amyloidosis: a primer for cardiologists. European heart journal cardiovascular Imaging. 2020;21(8):833-44.

78. Dorbala S, Ando Y, Bokhari S, Dispenzieri A, Falk RH, Ferrari VA, et al. ASNC/AHA/ASE/EANM/HFSA/ISA/SCMR/SNMMI Expert Consensus Recommendations for Multimodality Imaging in Cardiac Amyloidosis: Part 1 of 2-Evidence Base and Standardized Methods of Imaging. J Card Fail.2019;25(11):e 1-e39.

79. Zhao L, Tian Z, Fang Q. Diagnostic accuracy of cardiovascular magnetic resonance for patients with suspected cardiac amyloidosis: a systematic review and meta-analysis. BMC Cardiovasc Dis. 2016;16:129.

80. Fontana M, Pica S, Reant P, Abdel-Gadir A, Treibel TA, Banypersad SM, etal. Prognostic Value of Late Gadolinium Enhancement Cardiovascular Magnetic Resonance in Cardiac Amyloidosis. Circulation. 2015;132(16):1570-9.

81. Boynton SJ, Geske JB, Dispenzieri A, Syed IS, Hanson TJ, Grogan M, et al. LGE Provides Incremental Prognostic Information Over Serum Biomarkers in AL Cardiac Amyloidosis. JACC Cardiovascular imaging. 2016;9(6):680-6.
82. Lin L, Li X, Feng J, Shen KN, Tian Z, Sun J, et al. The prognostic value of T1 mapping and late gadolinium enhancement cardiovascular magnetic resonance imaging in patients with light chain amyloidosis. Journal of cardiovascular magnetic resonance. J Cardiovasc Magn Reson. 2018;20(1):2.

83. Fontana M, White SK, Banypersad SM, Sado DM, Maestrini V, Flett AS, et al. Comparison of T1 mapping techniques for ECV quantification. Histological validation and reproducibility of ShMOLLI versus multibreath-hold T1 quantification equilibrium contrast CMR. Journal of cardiovascular magnetic resonance : J Cardiovasc Magn Reson. 2012;14:88.

84. White JA, Kim HW, Shah D, Fine N, Kim KY, Wendell DC, et al. CMR imaging with rapid visual T1 assessment predicts mortality in patients suspected of cardiac amyloidosis. JACC Cardiovasc Imaging. 2014;7(2):143-56.

85. Dorbala S, Cuddy S, Falk RH. How to Image Cardiac Amyloidosis: A Practical Approach. JACC Cardiovascular imaging. 2020;13(6):1299-310.

86. Pan JA, Kerwin MJ, Salerno M. Native T1 Mapping, Extracellular Volume Mapping, and Late Gadolinium Enhancement in Cardiac Amyloidosis: A Meta-Analysis. JACC Cardiovascular imaging. 2020;13(6):1299-310.

87. Singh V, Falk R, Di Carli MF, Kijewski M, Rapezzi C, Dorbala S. State-of-theart radionuclide imaging in cardiac transthyretin amyloidosis. J Nucl Cardiol. 2019;26(1):158-73.

88. Stats MA, Stone JR. Varying levels of small microcalcifications and macrophages in ATTR and AL cardiac amyloidosis: implications for utilizing nuclear medicine studies to subtype amyloidosis. Cardiovasc Pathol. 2016;25(5):413-7.

89. Perugini E, Guidalotti PL, Salvi F, Cooke RM, Pettinato C, Riva L, et al. Noninvasive etiologic diagnosis of cardiac amyloidosis using 99mTc-3,3diphosphono-1,2-propanodicarboxylic acid scintigraphy. J Am Coll Cardiol. 2005;46(6):1076-84.

90. Dorbala S, Ando Y, Bokhari S, Dispenzieri A, Falk RH, Ferrari VA, et al. ASNC/AHA/ASE/EANM/HFSA/ISA/SCMR/SNMMI expert consensus recommendations for multimodality imaging in cardiac amyloidosis: Part 1 of 2-evidence base and standardized methods of imaging. J Nucl Cardiol. 2019;26(6):2065-123

91. Hanna M, Ruberg FL, Maurer MS, Dispenzieri A, Dorbala S, Falk RH, et al. Cardiac Scintigraphy With Technetium-99m-Labeled Bone-Seeking Tracers for Suspected Amyloidosis: JACC Review Topic of the Week. J Am Coll Cardiol. 2020;75(22):2851-62.

92. Hutt DF, Quigley AM, Page J, Hall ML, Burniston M, Gopaul D, et al. Utility and limitations of 3,3-diphosphono-1,2-propanodicarboxylic acid scintigraphy in systemic amyloidosis. Eur Heart J Cardiovasc Imaging. 2014;15(11):1289-98.

93. Pepys MB, Dyck RF, de Beer FC, Skinner M, Cohen AS. Binding of serum amyloid P-component (SAP) by amyloid fibrils. Clin Exp Immunol. 1979;38(2):284-93.

94. Castano A, Haq M, Narotsky DL, Goldsmith J, Weinberg RL, Morgenstern R, et al. Multicenter Study of Planar Technetium 99m Pyrophosphate Cardiac Imaging: Predicting Survival for Patients With ATTR Cardiac Amyloidosis. JAMA Cardiol. 2016;1(8):880-9.

95. Vranian MN, Sperry BW, Hanna M, Hachamovitch R, Ikram A, Brunken $\mathrm{RC}$, et al. Technetium pyrophosphate uptake in transthyretin cardiac amyloidosis: Associations with echocardiographic disease severity and outcomes. J Nucl Cardiol. 2018;25(4):1247-56.

96. Kyriakou P, Mouselimis D, Tsarouchas A, Rigopoulos A, Bakogiannis C, Noutsias $M$, et al. Diagnosis of cardiac amyloidosis: a systematic review on the role of imaging and biomarkers. BMC Cardiovasc Disord. 2018;18(1):221.

97. Kristen AV, Maurer MS, Rapezzi C, Mundayat R, Suhr OB, Damy T, et al. Impact of genotype and phenotype on cardiac biomarkers in patients with transthyretin amyloidosis - Report from the Transthyretin Amyloidosis Outcome Survey (THAOS). PLoS One. 2017;12(4):e0173086.

98. Perfetto F, Bergesio F, Grifoni E, Fabbri A, Ciuti G, Frusconi S, et al. Different NT-proBNP circulating levels for different types of cardiac amyloidosis. J Cardiovasc Med (Hagerstown). 2016;17(11):810-7. 
99. Hahn VS, Yanek LR, Vaishnav J, Ying W, Vaidya D, Lee YZJ, et al. Endomyocardial Biopsy Characterization of Heart Failure With Preserved Ejection Fraction and Prevalence of Cardiac Amyloidosis. JACC Heart Fail. 2020;8(9):712-24

100. Kociol RD, Pang PS, Gheorghiade M, Fonarow GC, O'Connor CM, Felker GM. Troponin elevation in heart failure prevalence, mechanisms, and clinical implications. J Am Coll Cardiol. 2010;56(14):1071-8.

101. Takashio S, Yamamuro M, Izumiya Y, Hirakawa K, Marume K, Yamamoto M, et al. Diagnostic utility of cardiac troponin T level in patients with cardiac amyloidosis. ESC Heart Fail. 2018;5(1):27-35

102. Hafeez AS, Bavry AA. Diagnosis of Transthyretin Amyloid Cardiomyopathy. Cardiol Ther. 2020;9(1):85-95

103. Rajkumar SV. Multiple myeloma: 2011 update on diagnosis, riskstratification, and management. Am J Hematol. 2011;86(1):57-65.

104. Comenzo RL, Reece D, Palladini G, Seldin D, Sanchorawala V, Landau H, et al. Consensus guidelines for the conduct and reporting of clinical trials in systemic light-chain amyloidosis. Leukemia. 2012;26(11):2317-25.

105. Duston MA, Skinner M, Meenan RF, Cohen AS. Sensitivity, specificity, and predictive value of abdominal fat aspiration for the diagnosis of amyloidosis. Arthritis Rheum. 1989;32(1):82-5.

106. van G, II, Hazenberg BP, Bijzet J, van Rijswijk MH. Diagnostic accuracy of subcutaneous abdominal fat tissue aspiration for detecting systemic amyloidosis and its utility in clinical practice. Arthritis Rheum. 2006;54(6):2015-21.

107. Andrews TR, Colon-Otero G, Calamia KT, Menke DM, Boylan KB, Kyle RA. Utility of subcutaneous fat aspiration for diagnosing amyloidosis in patients with isolated peripheral neuropathy. Mayo Clin Proc. 2002;77(12):1287-90.

108. Fine NM, Arruda-Olson AM, Dispenzieri A, Zeldenrust SR, Gertz MA, Kyle RA, et al. Yield of noncardiac biopsy for the diagnosis of transthyretin cardiac amyloidosis. Am J Cardiol. 2014;113(10):1723-7.

109. Phull P, Sanchorawala V, Connors LH, Doros G, Ruberg FL, Berk JL, et al. Monoclonal gammopathy of undetermined significance in systemic transthyretin amyloidosis (ATTR). Amyloid. 2018;25(1):62-7.

110.Vrana JA, Gamez JD, Madden BJ, Theis JD, Bergen HR, 3rd, Dogan A. Classification of amyloidosis by laser microdissection and mass spectrometry-based proteomic analysis in clinical biopsy specimens. Blood. 2009;114(24):4957-9.

111. Musumeci MB, Cappelli F, Russo D, Tini G, Canepa M, Milandri A, et al. Low Sensitivity of Bone Scintigraphy in Detecting Phe64Leu MutationRelated Transthyretin Cardiac Amyloidosis. JACC Cardiovasc Imaging. 2020;13(6):1314-21.

112. Binder C, Duca F, Stelzer PD, Nitsche C, Rettl R, Aschauer S, et al. Mechanisms of heart failure in transthyretin vs. light chain amyloidosis. Eur Heart J Cardiovasc Imaging. 2019;20(5):512-24.

113. Podduturi V, Armstrong DR, Hitchcock MA, Roberts WC, Guileyardo JM. Isolated atrial amyloidosis and the importance of molecular classification. Proc (Bayl Univ Med Cent). 2013;26(4):387-9.

114. Gertz MA. Immunoglobulin light chain amyloidosis: 2018 Update on diagnosis, prognosis, and treatment. Am J Hematol. 2018;93(9):1169-80.

115. Kumar S, Dispenzieri A, Lacy MQ, Hayman SR, Buadi FK, Colby C, et al. Revised prognostic staging system for light chain amyloidosis incorporating cardiac biomarkers and serum free light chain measurements. J Clin Oncol. 2012;30(9):989-95

116. Koyama J, Falk RH. Prognostic significance of strain Doppler imaging in light-chain amyloidosis. JACC Cardiovasc Imaging. 2010;3(4):333-42.

117. Pislaru C, lonescu F, Alashry M, Petrescu I, Pellikka PA, Grogan M, et al. Myocardial Stiffness by Intrinsic Cardiac Elastography in Patients with Amyloidosis: Comparison with Chamber Stiffness and Global Longitudinal Strain. J Am Soc Echocardiogr. 2019;32(8):958-68 e4.
118. Kuruvilla S, Adenaw N, Katwal AB, Lipinski MJ, Kramer CM, Salerno M. Late gadolinium enhancement on cardiac magnetic resonance predicts adverse cardiovascular outcomes in nonischemic cardiomyopathy: a systematic review and meta-analysis. Circ Cardiovasc Imaging. 2014;7(2):250-8.

119. Raina S, Lensing SY, Nairooz RS, Pothineni NV, Hakeem A, Bhatti S, et al. Prognostic Value of Late Gadolinium Enhancement CMR in Systemic Amyloidosis. JACC Cardiovasc Imaging. 2016;9(11):1267-77.

120. Banypersad SM, Fontana M, Maestrini V, Sado DM, Captur G, Petrie A, et al. T1 mapping and survival in systemic light-chain amyloidosis. Eur Heart J. 2015;36(4):244-51.

121. Rapezzi C, Merlini G, Quarta CC, Riva L, Longhi S, Leone O, et al. Systemic cardiac amyloidoses: disease profiles and clinical courses of the 3 main types. Circulation. 2009;120(13):1203-12.

122. Chacko L, Martone R, Bandera F, Lane T, Martinez-Naharro A, Boldrini M, et al. Echocardiographic phenotype and prognosis in transthyretin cardiac amyloidosis. Eur Heart J. 2020;41(14):1439-47.

123. Siddiqi OK, Ruberg FL. Cardiac amyloidosis: An update on pathophysiology, diagnosis, and treatment. Trends Cardiovasc Med. 2018;28(1):10-21.

124. Sugiura A, Kitahara H, Iwahana T, Suzuki N, Okada S, Miyauchi H, et al. Association of heart failure duration with clinical prognosis in advanced heart failure. Clin Res Cardiol. 2020;109(3):350-7.

125. Kristen AV, Perz JB, Schonland SO, Hegenbart U, Schnabel PA, Kristen JH, et al. Non-invasive predictors of survival in cardiac amyloidosis. Eur J Heart Fail. 2007;9(6-7):617-24.

126. Pinney JH, Whelan CJ, Petrie A, Dungu J, Banypersad SM, Sattianayagam $P$, et al. Senile systemic amyloidosis: clinical features at presentation and outcome. J Am Heart Assoc. 2013;2(2):e000098.

127. Maurer MS, Hanna M, Grogan M, Dispenzieri A, Witteles R, Drachman B, et al. Genotype and Phenotype of Transthyretin Cardiac Amyloidosis: THAOS (Transthyretin Amyloid Outcome Survey). J Am Coll Cardiol. 2016;68(2):161-72.

128. Grogan M, Scott CG, Kyle RA, Zeldenrust SR, Gertz MA, Lin G, et al Natural History of Wild-Type Transthyretin Cardiac Amyloidosis and Risk Stratification Using a Novel Staging System. J Am Coll Cardiol. 2016;68(10):1014-20.

129. Hanson JLS, Arvanitis M, Koch CM, Berk JL, Ruberg FL, Prokaeva T, etal. Use of Serum Transthyretin as a Prognostic Indicator and Predictor of Outcome in Cardiac Amyloid Disease Associated With Wild-Type Transthyretin. Circ Heart Fail. 2018;11(2):e004000

130. Gillmore JD, Damy T, Fontana M, Hutchinson M, Lachmann HJ, MartinezNaharro A, et al. A new staging system for cardiac transthyretin amyloidosis. Eur Heart J. 2018;39(30):2799-806.

131. Cappelli F, Martone R, Gabriele M, Taborchi G, Morini S, Vignini E, et al. Biomarkers and Prediction of Prognosis in Transthyretin-Related Cardiac Amyloidosis: Direct Comparison of Two Staging Systems. Can J Cardiol. 2020;36(3):424-31.

132. Rubin J, Steidley DE, Carlsson M, Ong ML, Maurer MS. Myocardial Contraction Fraction by M-Mode Echocardiography Is Superior to Ejection Fraction in Predicting Mortality in Transthyretin Amyloidosis. J Card Fail. 2018;24(8):504-11.

133. Senapati A, Sperry BW, Grodin JL, Kusunose K, Thavendiranathan P, Jaber $\mathrm{W}$, et al. Prognostic implication of relative regional strain ratio in cardiac amyloidosis. Heart. 2016;102(10):748-54.

134. Knight DS, Zumbo G, Barcella W, Steeden JA, Muthurangu V, MartinezNaharro A, et al. Cardiac Structural and Functional Consequences of Amyloid Deposition by Cardiac Magnetic Resonance and Echocardiography and Their Prognostic Roles. JACC Cardiovasc Imaging. 2019;12(5):823-33.

135. Palladini G, Milani P, Merlini G. Management of AL amyloidosis in 2020 Blood. 2020:136(23):2620-7. 
136. Palladini G, Dispenzieri A, Gertz MA, Kumar S, Wechalekar A, Hawkins PN, et al. New criteria for response to treatment in immunoglobulin light chain amyloidosis based on free light chain measurement and cardiac biomarkers: impact on survival outcomes. J Clin Oncol. 2012;30(36):4541-9.

137. Mahmood S, Palladini G, Sanchorawala V, Wechalekar A. Update on treatment of light chain amyloidosis. Haematologica. 2014;99(2):209-21.

138. Palladini G, Hegenbart U, Milani P, Kimmich C, Foli A, Ho AD, et al. A staging system for renal outcome and early markers of renal response to chemotherapy in AL amyloidosis. Blood. 2014;124(15):2325-32.

139. Palladini G, Kastritis E, Maurer MS, Zonder J, Minnema MC, Wechalekar $A D$, et al. Daratumumab plus CyBorD for patients with newly diagnosed AL amyloidosis: safety run-in results of ANDROMEDA. Blood. 2020;136(1):71-80.

140. Cornell RF, Zhong X, Arce-Lara C, Atallah E, Blust L, Drobyski WR, et al. Bortezomib-based induction for transplant ineligible AL amyloidosis and feasibility of later transplantation. Bone Marrow Transplant. 2015;50(7):914-7.

141. Jaccard A, Moreau P, Leblond V, Leleu X, Benboubker L, Hermine O, et al. High-dose melphalan versus melphalan plus dexamethasone for $\mathrm{AL}$ amyloidosis. N Engl J Med. 2007;357(11):1083-93.

142. Moreau P, Leblond V, Bourquelot P, Facon T, Huynh A, Caillot D, et al. Prognostic factors for survival and response after high-dose therapy and autologous stem cell transplantation in systemic AL amyloidosis: a report on 21 patients. Br J Haematol. 1998;101(4):766-9.

143. Comenzo RL, Vosburgh E, Falk RH, Sanchorawala V, Reisinger J, Dubrey S, et al. Dose-intensive melphalan with blood stem-cell support for the treatment of $\mathrm{AL}$ (amyloid light-chain) amyloidosis: survival and responses in 25 patients. Blood. 1998;91(10):3662-70.

144. Cordes S, Dispenzieri A, Lacy MQ, Hayman SR, Buadi FK, Dingli D, et al. Tenyear survival after autologous stem cell transplantation for immunoglobulin light chain amyloidosis. Cancer. 2012;118(24):6105-9.

145. Landau H, Smith M, Landry C, Chou JF, Devlin SM, Hassoun H, et al. Longterm event-free and overall survival after risk-adapted melphalan and SCT for systemic light chain amyloidosis. Leukemia. 2017;31(1):136-42.

146. Sanchorawala V, Sun F, Quillen K, Sloan JM, Berk JL, Seldin DC. Longterm outcome of patients with AL amyloidosis treated with high-dose melphalan and stem cell transplantation: 20-year experience. Blood. 2015;126(20):2345-7.

147. Sidiqi MH, Aljama MA, Buadi FK, Warsame RM, Lacy MQ, Dispenzieri A, et al. Stem Cell Transplantation for Light Chain Amyloidosis: Decreased Early Mortality Over Time. J Clin Oncol. 2018;36(13):1323-9.

148. Gertz MA, Lacy MQ, Dispenzieri A, Kumar SK, Dingli D, Leung N, et al. Refinement in patient selection to reduce treatment-related mortality from autologous stem cell transplantation in amyloidosis. Bone Marrow Transplant. 2013;48(4):557-61.

149. Gertz MA, Lacy MQ, Dispenzieri A, Hayman SR, Kumar SK, Leung N, et al. Effect of hematologic response on outcome of patients undergoing transplantation for primary amyloidosis: importance of achieving a complete response. Haematologica. 2007;92(10):1415-8.

150. Kourelis TV, Kumar SK, Gertz MA, Lacy MQ, Buadi FK, Hayman SR, et al. Coexistent multiple myeloma or increased bone marrow plasma cells define equally high-risk populations in patients with immunoglobulin light chain amyloidosis. J Clin Oncol. 2013;31(34):4319-24.

151. Venner CP, Lane T, Foard D, Rannigan L, Gibbs SD, Pinney JH, et al. Cyclophosphamide, bortezomib, and dexamethasone therapy in $\mathrm{AL}$ amyloidosis is associated with high clonal response rates and prolonged progression-free survival. Blood. 2012;119(19):4387-90.

152. Mikhael JR, Schuster SR, Jimenez-Zepeda VH, Bello N, Spong J, Reeder CB, et al. Cyclophosphamide-bortezomib-dexamethasone (CyBorD) produces rapid and complete hematologic response in patients with AL amyloidosis. Blood. 2012;119(19):4391-4.

153. Palladini G, Sachchithanantham S, Milani P, Gillmore J, Foli A, Lachmann $\mathrm{H}$, et al. A European collaborative study of cyclophosphamide, bortezomib, and dexamethasone in upfront treatment of systemic AL amyloidosis. Blood. 2015;126(5):612-5

154. Jaccard A, Comenzo RL, Hari P, Hawkins PN, Roussel M, Morel P, et al. Efficacy of bortezomib, cyclophosphamide and dexamethasone in treatment-naive patients with high-risk cardiac AL amyloidosis (Mayo Clinic stage III). Haematologica. 2014;99(9):1479-85.

155. Kastritis E, Roussou M, Gavriatopoulou M, Migkou M, Kalapanida D, Pamboucas C, etal. Long-term outcomes of primary systemic light chain (AL) amyloidosis in patients treated upfront with bortezomib or lenalidomide and the importance of risk adapted strategies. Am J Hematol. 2015;90(4):E60-5.

156. Kastritis E, Leleu X, Arnulf B, Zamagni E, Cibeira MT, Kwok F, et al. Bortezomib, Melphalan, and Dexamethasone for Light-Chain Amyloidosis. J Clin Oncol. 2020;38(28):3252-60.

157. Holmgren G, Steen L, Ekstedt J, Groth CG, Ericzon BG, Eriksson S, et al. Biochemical effect of liver transplantation in two Swedish patients with familial amyloidotic polyneuropathy (FAP-met30). Clin Genet. 1991;40(3):242-6.

158. Liepnieks JJ, Zhang LQ, Benson MD. Progression of transthyretin amyloid neuropathy after liver transplantation. Neurology. 2010;75(4):324-7.

159. Okamoto S, Zhao Y, Lindqvist P, Backman C, Ericzon BG, Wijayatunga $\mathrm{P}$, et al. Development of cardiomyopathy after liver transplantation in Swedish hereditary transthyretin amyloidosis (ATTR) patients. Amyloid. 2011;18(4):200-5.

160. Sack FU, Kristen A, Goldschmidt H, Schnabel PA, Dengler T, Koch A, et al. Treatment options for severe cardiac amyloidosis: heart transplantation combined with chemotherapy and stem cell transplantation for patients with AL-amyloidosis and heart and liver transplantation for patients with ATTR-amyloidosis. Eur J Cardiothorac Surg. 2008;33(2):257-62.

161. Bulawa CE, Connelly S, Devit M, Wang L, Weigel C, Fleming JA, et al. Tafamidis, a potent and selective transthyretin kinetic stabilizer that inhibits the amyloid cascade. Proc Natl Acad Sci U S A. 2012;109(24):9629-34.

162. Coelho T, Maia LF, Martins da Silva A, Waddington Cruz M, PlanteBordeneuve $\mathrm{V}$, Lozeron $\mathrm{P}$, et al. Tafamidis for transthyretin familial amyloid polyneuropathy: a randomized, controlled trial. Neurology. 2012;79(8):785-92.

163. Maurer MS, SchwartzJH, Gundapaneni B, Elliott PM, Merlini G, WaddingtonCruz M, et al. Tafamidis Treatment for Patients with Transthyretin Amyloid Cardiomyopathy. N Engl J Med. 2018;379(11):1007-16.

164. Damy T, Garcia-Pavia P, Hanna M, Judge DP, Merlini G, Gundapaneni B, et al. Efficacy and safety of tafamidis doses in the Tafamidis in Transthyretin Cardiomyopathy Clinical Trial (ATTR-ACT) and long-term extension study. Eur J Heart Fail. 2020.

165. Hammarstrom P, Jiang X, Hurshman AR, Powers ET, Kelly JW. Sequencedependent denaturation energetics: A major determinant in amyloid disease diversity. Proc Natl Acad Sci U S A. 2002;99 Suppl 4:16427-32.

166. Judge DP, Heitner SB, Falk RH, Maurer MS, Shah SJ, Witteles RM, et al. Transthyretin Stabilization by AG10 in Symptomatic Transthyretin Amyloid Cardiomyopathy. J Am Coll Cardiol. 2019;74(3):285-95.

167. Adams D, Gonzalez-Duarte A, O'Riordan WD, Yang CC, Ueda M, Kristen AV, et al. Patisiran, an RNAi Therapeutic, for Hereditary Transthyretin Amyloidosis. N Engl J Med. 2018;379(1):11-21.

168. Benson MD, Waddington-Cruz M, Berk JL, Polydefkis M, Dyck PJ, Wang AK, et al. Inotersen Treatment for Patients with Hereditary Transthyretin Amyloidosis. N Engl J Med. 2018;379(1):22-31.

169. Emdin M, Aimo A, Rapezzi C, Fontana M, Perfetto F, Seferovic PM, et al. Treatment of cardiac transthyretin amyloidosis: an update. Eur Heart J. 2019;40(45):3699-706.

170. Cardoso I, Saraiva MJ. Doxycycline disrupts transthyretin amyloid: evidence from studies in a FAP transgenic mice model. FASEB J. 2006;20(2):234-9.

171. Cardoso I, Martins D, Ribeiro T, Merlini G, Saraiva MJ. Synergy of combined doxycycline/TUDCA treatment in lowering Transthyretin deposition 
and associated biomarkers: studies in FAP mouse models. J Transl Med. 2010;8:74.

172. Ritts AJ, Cornell RF, Swiger K, Singh J, Goodman S, Lenihan DJ. Current concepts of cardiac amyloidosis: diagnosis, clinical management, and the need for collaboration. Heart Failure Clinics. 2017;13(2):409-16.

173. Pollak A, Falk RH. Left ventricular systolic dysfunction precipitated by verapamil in cardiac amyloidosis. Chest. 1993;104(2):618-20.

174. Sanchis K, Cariou E, Colombat M, Ribes D, Huart A, Cintas P, et al. Atrial fibrillation and subtype of atrial fibrillation in cardiac amyloidosis: clinical and echocardiographic features, impact on mortality. Amyloid. 2019;26(3):128-38

175. Longhi S, Quarta CC, Milandri A, Lorenzini M, Gagliardi C, Manuzzi L, et al. Atrial fibrillation in amyloidotic cardiomyopathy: prevalence, incidence, risk factors and prognostic role. Amyloid. 2015;22(3):147-55.

176. Mints YY, Doros G, Berk JL, Connors LH, Ruberg FL. Features of atrial fibrillation in wild-type transthyretin cardiac amyloidosis: a systematic review and clinical experience. ESC heart failure. 2018;5(5):772-9.

177. Donnellan E, Wazni O, Kanj M, Elshazly MB, Hussein A, Baranowski B, et al. Atrial fibrillation ablation in patients with transthyretin cardiac amyloidosis. EP Europace. 2020;22(2):259-64.

178. Roberts WC, Waller BF. Cardiac amyloidosis causing cardiac dysfunction: analysis of 54 necropsy patients. The American journal of cardiology. 1983;52(1):137-46.

179. Feng D, Edwards WD, Oh JK, Chandrasekaran K, Grogan M, Martinez $\mathrm{MW}$, et al. Intracardiac thrombosis and embolism in patients with cardiac amyloidosis. Circulation. 2007;116(21):2420-6.

180. Feng D, Syed IS, Martinez M, Oh JK, Jaffe AS, Grogan M, et al. Intracardiac thrombosis and anticoagulation therapy in cardiac amyloidosis. Circulation. 2009; 119(18):2490.

181. Donnellan E, Elshazly MB, Vakamudi S, Wazni OM, Cohen JA, Kanj M, et al. No association between CHADS-VASc score and left atrial appendage thrombus in patients with transthyretin amyloidosis. JACC: Clinical Electrophysiology. 2019;5(12):1473-4.

182. El-Am EA, Dispenzieri A, Melduni RM, Ammash NM, White RD, Hodge DO, et al. Direct current cardioversion of atrial arrhythmias in adults with cardiac amyloidosis. Journal of the American College of Cardiology. 2019;73(5):589-97.

183. Goldsmith YB, Liu J, Chou J, Hoffman J, Comenzo RL, Steingart RM. Frequencies and types of arrhythmias in patients with systemic lightchain amyloidosis with cardiac involvement undergoing stem cell transplantation on telemetry monitoring. The American journal of cardiology. 2009;104(7):990-4.

184. Palladini G, Malamani G, Co F, Pistorio A, Recusani F, Anesi E, et al. Holter monitoring in AL amyloidosis: prognostic implications. Pacing and Clinical Electrophysiology. 2001;24(8):1228-33.

185. Towbin JA, McKenna WJ, Abrams DJ, Ackerman MJ, Calkins H, Darrieux FC, et al. 2019 HRS expert consensus statement on evaluation, risk stratification, and management of arrhythmogenic cardiomyopathy. Heart rhythm. 2019;16(11):e301-e72.

186. Members ATF, Priori SG, Blomström-Lundqvist C, Mazzanti A, Blom N, Borggrefe M, et al. 2015 ESC Guidelines for the management of patients with ventricular arrhythmias and the prevention of sudden cardiac death: The Task Force for the Management of Patients with Ventricular Arrhythmias and the Prevention of Sudden Cardiac Death of the European Society of Cardiology (ESC) Endorsed by: Association for European Paediatric and Congenital Cardiology (AEPC). Ep Europace. 2015;17(11):1601-87.

187. Cappelli F, Perfetto F, Martone R, Di Mario C. Cardiac Amyloidosis in Patients Undergoing TAVR: Why We Need to Think About It. Cardiovascular Revascularization Medicine. 2021;22:109-14.

188. Sayed RH, Rogers D, Khan F, Wechalekar AD, Lachmann HJ, Fontana M, et al. A study of implanted cardiac rhythm recorders in advanced cardiac AL amyloidosis. European heart journal. 2015;36(18):1098-105.
189. Giancaterino S, Urey MA, Darden D, Hsu JC. Management of arrhythmias in cardiac amyloidosis. Clinical Electrophysiology. 2020;6(4):351-61.

190. Ridolfi RL, Bulkley BH, Hutchins GM. The conduction system in cardiac amyloidosis: clinical and pathologic features of 23 patients. The American journal of medicine. 1977;62(5):677-86.

191. DePasquale EC, Nasir K, Jacoby DL. Outcomes of adults with restrictive cardiomyopathy after heart transplantation. The Journal of heart and lung transplantation. 2012;31(12):1269-75

192. Givens RC, Russo C, Green P, Maurer MS. Comparison of cardiac amyloidosis due to wild-type and $\mathrm{V} 122 \mathrm{I}$ transthyretin in older adults referred to an academic medical center. Aging health. 2013;9(2):229-35.

193. Topilsky Y, Pereira NL, Shah DK, Boilson B, Schirger JA, Kushwaha SS, et al. Left ventricular assist device therapy in patients with restrictive and hypertrophic cardiomyopathy. Circulation: Heart Failure. 2011;4(3):266-75.

194. Grupper A, Park SJ, Pereira NL, Schettle SD, Gerber Y, Topilsky Y, et al. Role of ventricular assist therapy for patients with heart failure and restrictive physiology: improving outcomes for a lethal disease. The Journal of Heart and Lung Transplantation. 2015;34(8):1042-9.

195. Kristen AV, Kreusser MM, Blum P, Schönland SO, Frankenstein L, Dösch $\mathrm{AO}$, et al. Improved outcomes after heart transplantation for cardiac amyloidosis in the modern era. The journal of heart and lung transplantation. 2018;37(5):611-8.

196. Trachtenberg BH, Kamble RT, Rice L, Araujo-Gutierrez R, Bhimaraj A, Guha A, et al. Delayed autologous stem cell transplantation following cardiac transplantation experience in patients with cardiac amyloidosis. American Journal of Transplantation. 2019;19(10):2900-9.

197.Biglia LV, Mendes SJ, Lima TM, Aguiar PM. Incorporações de medicamentos para doenças raras no Brasil: é possível acesso integral a estes pacientes? Cien Saúde Colet. 2020(julho/2020 - Está disponível em: http://www.cienciaesaudecoletiva.com.br/artigos/incorporacoesde-medicamentos-para-doencas-raras-no-brasil-e-possivel-acessointegral-a-estes-pacientes/17706?id=17706\&id=17706).

198. Silva EN, Sousa TR. Economic evaluation in the context of rare diseases: is it possible? Cad Saude Publica. 2015;31(3):496-506

199. Brasil. Ministério da Saúde. Política Nacional de Atenção Integral às Pessoas com Doenças Raras. Portaria GM no 199, de 30 de janeiro de 2014. Disponível em: http://bvsmssaudegovbr/bvs/saudelegis/gm/2014/ prt0199_30_01_2014html.

200. INTERFARMA. Doenças Raras: A urgência do acesso à saúde. Fevereiro de 2018. Disponivel em: https://www.interfarma.org.br/public/files/biblioteca/ doencas-raras--a-urgencia-do-acesso-a-saude-interfarma.pdf. Acesso em: 14 abr. 2019.

201. Novaes HMD, Soárez PC. Doenças raras, drogas órfãs e as políticas para avaliação e incorporação de tecnologias nos sistemas de saúde. Sociologias. 2019;21(5):332-64

202. Nicod E, Annemans L, Bucsics A, LeeA, Upadhyaya S, Facey K. HTA programme response to the challenges of dealing with orphan medicinal products: Process evaluation in selected European countries. Health Policy. 2019;123(2):140-51.

203. Kircher M, Ihne S, Brumberg J, Morbach C, Knop S, Kortum KM, et al Detection of cardiac amyloidosis with (18)F-Florbetaben-PET/CT in comparison to echocardiography, cardiac MRI and DPD-scintigraphy. Eur J Nucl Med Mol Imaging. 2019;46(7):1407-16.

204. Morgenstern R, Yeh R, Castano A, Maurer MS, Bokhari S. (18)Fluorine sodium fluoride positron emission tomography, a potential biomarker of transthyretin cardiac amyloidosis. J Nucl Cardiol. 2018;25(5):1559-67.

205. Kufova Z, Sevcikova T, Growkova K, Vojta P, Filipova J, Adam Z, et al. Biomarkers in Immunoglobulin Light Chain Amyloidosis. Klin Onkol.30(Suppl 2):60-7.

206. Paiva B, Martinez-Lopez J, Corchete LA, Sanchez-Vega B, Rapado I, Puig N, et al. Phenotypic, transcriptomic, and genomic features of clonal plasma cells in light-chain amyloidosis. Blood. 2016;127(24):3035-9. 